\title{
The Molecular Biology of Phosphodiesterase 4 Enzymes as Pharmacological Targets: An Interplay of Isoforms, Conformational States, and Inhibitors
}

Citation for published version (APA):

Paes, D., Schepers, M., Rombaut, B., van den Hove, D., Vanmierlo, T., \& Prickaerts, J. (2021). The Molecular Biology of Phosphodiesterase 4 Enzymes as Pharmacological Targets: An Interplay of Isoforms, Conformational States, and Inhibitors. Pharmacological Reviews, 73(3), 1016-1049. https://doi.org/10.1124/pharmrev.120.000273

Document status and date:

Published: 01/01/2021

DOI:

10.1124/pharmrev.120.000273

Document Version:

Publisher's PDF, also known as Version of record

Document license:

Taverne

Please check the document version of this publication:

- A submitted manuscript is the version of the article upon submission and before peer-review. There can be important differences between the submitted version and the official published version of record.

People interested in the research are advised to contact the author for the final version of the publication, or visit the DOI to the publisher's website.

- The final author version and the galley proof are versions of the publication after peer review.

- The final published version features the final layout of the paper including the volume, issue and page numbers.

Link to publication

\footnotetext{
General rights rights.

- You may freely distribute the URL identifying the publication in the public portal. please follow below link for the End User Agreement:

www.umlib.nl/taverne-license

Take down policy

If you believe that this document breaches copyright please contact us at:

repository@maastrichtuniversity.nl

providing details and we will investigate your claim.
}

Copyright and moral rights for the publications made accessible in the public portal are retained by the authors and/or other copyright owners and it is a condition of accessing publications that users recognise and abide by the legal requirements associated with these

- Users may download and print one copy of any publication from the public portal for the purpose of private study or research.

- You may not further distribute the material or use it for any profit-making activity or commercial gain

If the publication is distributed under the terms of Article $25 \mathrm{fa}$ of the Dutch Copyright Act, indicated by the "Taverne" license above, 


\section{The Molecular Biology of Phosphodiesterase 4 Enzymes as Pharmacological Targets: An Interplay of Isoforms, Conformational States, and Inhibitors ${ }^{[\mathrm{S}}$}

Dean Paes, Melissa Schepers, Ben Rombaut, Daniel van den Hove, Tim Vanmierlo, and Jos Prickaerts

Department of Psychiatry \& Neuropsychology, School for Mental Health and Neuroscience, EURON, Maastricht University, Maastricht,

The Netherlands (D.P, M.S., B.R., D.v.d.H., T.V., J.P.); Department of Neuroscience, Neuro-Immune Connect and Repair laboratory,

Biomedical Research Institute, Hasselt University, Hasselt, Belgium (D.P., M.S., B.R., T.V.); and Department of Psychiatry, Psychosomatics and Psychotherapy, University of Würzburg, Würzburg, Germany (D.v.d.H.)

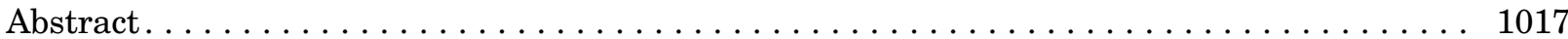

Significance statement $\ldots \ldots \ldots \ldots \ldots \ldots \ldots \ldots \ldots \ldots \ldots \ldots \ldots \ldots \ldots \ldots \ldots \ldots \ldots \ldots$

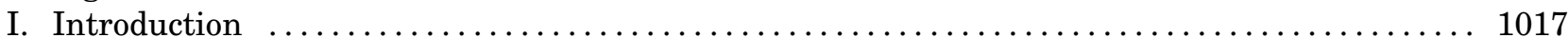

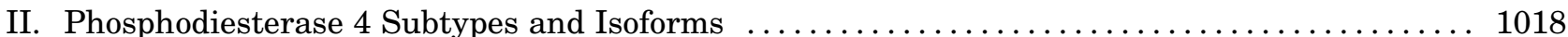

III. Phosphodiesterase 4 Modifications and Interactions $\ldots \ldots \ldots \ldots \ldots \ldots \ldots \ldots \ldots \ldots \ldots \ldots . \ldots 1023$

A. Upstream Conserved Region 1-Upstream Conserved Region 2 Module, Dimerization, and

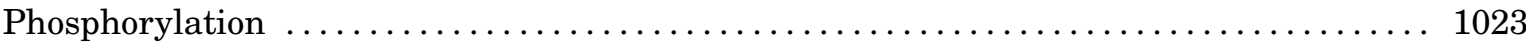

B. Phosphorylation at Sites Other than Upstream Conserved Region $1 \ldots \ldots \ldots \ldots \ldots \ldots 1023$

C. Indirect Regulation of Phosphodiesterase 4 Activity and Interactions . . ............ 1026

D. Conformational States Impacting upon Phosphodiesterase 4 Activity and Inhibitor

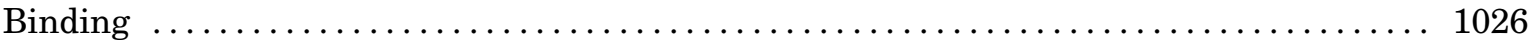

E. Intracellular Phosphodiesterase 4 Localization and Anchoring . . . . . . . . . . . . 1028

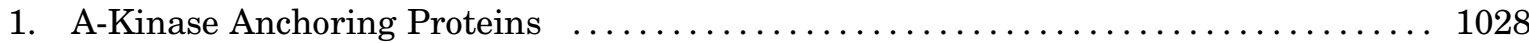

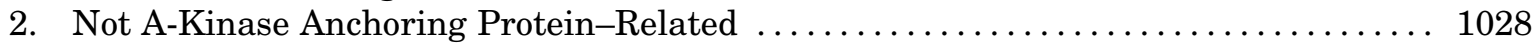

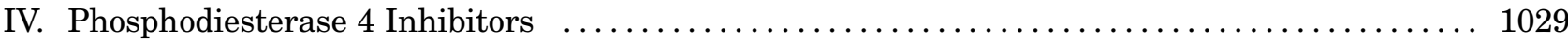

A. Phosphodiesterase 4 Inhibitors and High-Affinity and Low-Affinity Rolipram Binding

Sites .................................................... 1029

B. Determining Phosphodiesterase 4 Inhibitor Subtype and Isoform Selectivity in Assays . 1029

1. The Influence of Phosphodiesterase 4 Construct and Assay Type on Phosphodiesterase

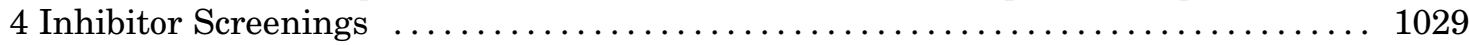

2. Optimizing Phosphodiesterase 4 Inhibitor Screenings $\ldots \ldots \ldots \ldots \ldots \ldots \ldots \ldots \ldots \ldots$

C. Mechanisms for Phosphodiesterase 4 Subtype Selectivity: Interactions with Regulatory

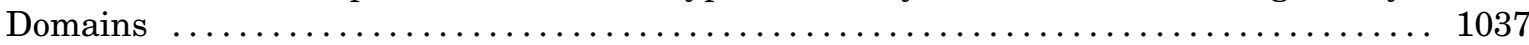

1. Interactions with the Upstream Conserved Region $2 \ldots \ldots \ldots \ldots \ldots \ldots \ldots \ldots \ldots \ldots$

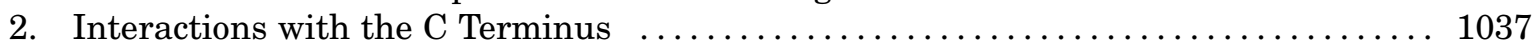

D. Stereoisomerism and Metabolites of Phosphodiesterase 4 Inhibitors $\ldots \ldots \ldots \ldots \ldots \ldots . \ldots 37$

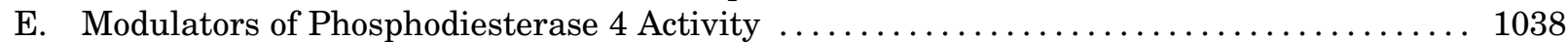

V. Adverse Effects of Phosphodiesterase 4 Inhibition $\ldots \ldots \ldots \ldots \ldots \ldots \ldots \ldots \ldots \ldots \ldots \ldots \ldots \ldots \ldots \ldots$

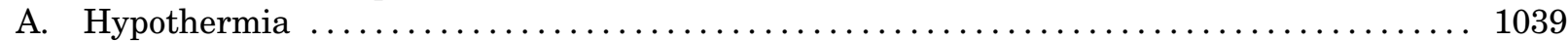

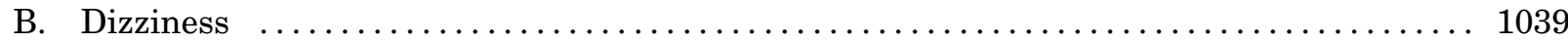

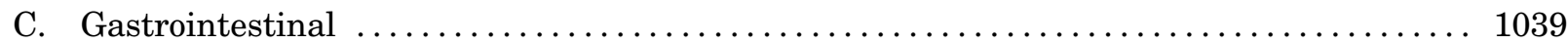

1. Diarrhea .................................................... 1039

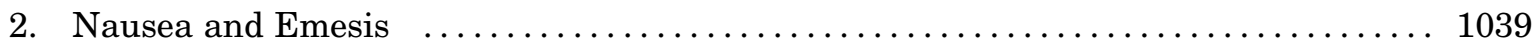

D. Strategies to Minimize Phosphodiesterase 4-Mediated Adverse Side Effects .......... 1042

Address correspondence to: Dr. J. Prickaerts, Maastricht University, PO Box 616, 6200 MD Maastricht, The Netherlands, E-mail: jos.prickaerts@maastrichtuniversity.nl

This work was supported by Internationale Stichting Alzheimer Onderzoek/Alzheimer Nederland [Grant WE.03-2016-07].

Tim Vanmierlo and Jos Prickaerts have a proprietary interest in selective PDE4D inhibitors for the treatment of neurodegenerative disorders. The other authors declare that they have no competing interests.

[S This article has supplemental material available at pharmrev.aspetjournals.org.

https://doi.org/10.1124/pharmrev.120.000273 


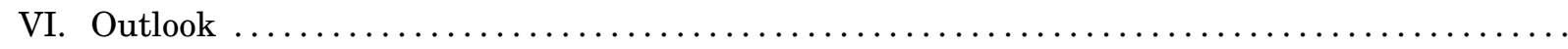

Abstract — The phosphodiesterase 4 (PDE4) enzyme family plays a pivotal role in regulating levels of the second messenger cAMP. Consequently, PDE4 inhibitors have been investigated as a therapeutic strategy to enhance cAMP signaling in a broad range of diseases, including several types of cancers, as well as in various neurologic, dermatological, and inflammatory diseases. Despite their widespread therapeutic potential, the progression of PDE4 inhibitors into the clinic has been hampered because of their related relatively small therapeutic window, which increases the chance of producing adverse side effects. Interestingly, the PDE4 enzyme family consists of several subtypes and isoforms that can be modified post-translationally or can engage in specific protein-protein interactions to yield a variety of conformational states. Inhibition of specific PDE4 subtypes, isoforms, or conformational states may lead to more precise effects and hence improve the safety profile of PDE4 inhibition. In this review, we provide an overview of the variety of PDE4 isoforms and how their activity and inhibition is influenced by post-translational modifications and interactions with partner proteins. Furthermore, we describe the importance of screening potential PDE4 inhibitors in view of different PDE4 subtypes, isoforms, and conformational states rather than testing compounds directed toward a specific PDE4 catalytic domain. Lastly, potential mechanisms underlying PDE4-mediated adverse effects are outlined. In this review, we illustrate that PDE4 inhibitors retain their therapeutic potential in myriad diseases, but target identification should be more precise to establish selective inhibition of disease-affected PDE4 isoforms while avoiding isoforms involved in adverse effects.

Significance statement__Although the PDE4 enzyme family is a therapeutic target in an extensive range of disorders, clinical use of PDE4 inhibitors has been hindered because of the adverse side effects. This review elaborately shows that safer and more effective PDE4 targeting is possible by characterizing 1) which PDE4 subtypes and isoforms exist, 2) how PDE4 isoforms can adopt specific conformations upon posttranslational modifications and protein-protein interactions, and 3) which PDE4 inhibitors can selecti vely bind specific PDE4 subtypes, isoforms, and/or conformations.

\section{Introduction}

Since the discovery of cAMP as a second messenger by Sutherland and Rall in 1958, its role in a wide variety of cellular processes, bodily functions, and pathologies has been thoroughly studied (Rall and Sutherland, 1958; Sutherland and Rall, 1958). Upon diverse extraand intracellular cues, the second messenger cAMP is synthesized by adenylyl cyclases to relay signaling to adaptive changes in the cell. This notion indicates that cAMP is used as a single generic signaling molecule to convey and amplify information from different sources, a notion supported by the principle that evolution promotes utilizing the same machinery for different functions (Purvis and Lahav, 2013). Through precise regulation of the localization, abundance, and dynamics of cAMP, different signaling modes can be generated using the same generic molecule. Consequently, slight disturbances in cAMP regulation could promote pathoph ysiology in different cell types. Levels of cAMP are predominantly controlled through exclusive breakdown by the $3^{\prime}, 5^{\prime}$-cyclic nucleotide phosphodiesterase (PDE) enzyme family. This PDE enzyme family comprises 11 gene families (PDE1-11), which display different selectivity toward their substrates cAMP and cGMP. PDE4, PDE7, and PDE8 are cAMP-selective, and PDE5, PDE6, and PDE9 selectively degrade cGMP. The other gene families, PDE1, 2, 3, 10, and 11, can hydrolyze both cAMP and cGMP (Beavo, 1995; Bender and Beavo, 2006). PDE4 enzymes make up a majority of cAMP-selective PDEs in different organs and cell types (Lakics et al., 2010; Baillie et al., 2019). Hence, PDE4 enzymes are interesting pharmacological targets to specifically modulate cAMP signaling. Hence, inhibition of PDE4 has been and is clinically investigated as a therapeutic strategy in a multitude of disease areas, as also recently reviewed (Peng et al., 2020), including cognitive and affective disorders [e.g., Alzheimer disease (NCT03817684), fragile X syndrome (NCT03569631), schizophrenia (NCT02539550), depression (Hebenstreit et al., 1989), and substance dependence (NCT03489850)], autoimmune disorders [e.g., multiple sclerosis (NCT01982942) (Schepers et al., 2019), rheumatoid arthritis, atopic dermatitis, and Behçet syndrome (NCT02307513)], respiratory system diseases [e.g., chronic obstructive pulmonary disease and asthma (Lipworth, 2005)], dermatological conditions [e.g., psoriasis (NCT03022617)], and cancer [e.g., glioblastoma (NCT03782415)].

ABBREVIATIONS: AKAP, A-kinase anchoring protein; AP, area postrema; CaMKII, calcium/calmodulin-dependent kinase II; CDK5, cyclin-dependent kinase 5; CFTR, cystic fibrosis transmembrane conductance regulator; circPDE4D, circular PDE4D; DISC1, disrupted in schizophrenia 1; ERK, extracellular signal-regulated kinase; Fyn, proto-oncogene tyrosine-protein kinase Fyn; HARBS, high-affinity rolipram binding site; 5HT4, 5-hydroxytryptamine 4; JNK, c-Jun N-terminal kinase; LARBS, low-affinity rolipram binding site; LR2, linker region 2; Lyn, Lck/Yes novel tyrosine kinase; MK2, MAPK-activated protein kinase 2; NCBI, National Center for Biotechnology Information; NTS, nucleus tractus solitaries; PDE, phosphodiesterase; PHD2, prolyl hydroxylase domain-containing protein 2; PKA, protein kinase A; p75NTR, p75 neurotrophin receptor; QKI, quaking; qPCR, quantitative polymerase chain reaction; RACK1, receptor of activated protein C kinase 1; Rheb, RAS homolog enriched in brain; Shank2, SH3 and multiple ankyrin repeat domains protein 2; SIK1, salt-inducible kinase 1; Src, proto-oncogene tyrosine-protein kinase; UCR1, upstream conserved region 1; UCR2, upstream conserved region 2; $3^{\prime} \mathrm{UTR}$, $3^{\prime}$ untranslated region; $5^{\prime} \mathrm{UTR}, 5^{\prime}$ untranslated region; XAP, HBV X-associated protein 2. 
Although inhibition of PDE4 shows widespread therapeutic potential in preclinical research, the progression of PDE4 inhibitors into the clinic has been held back by severe adverse effects, including headaches, diarrhea, dizziness, nausea, and vomiting (Spina, 2008). In fact, only three PDE4 inhibitors made it to the market because of their limited or reduced adverse effects: roflumilast (Daliresp, Daxas), apremilast (Otezla), and crisaborole (Eucrisa) for chronic obstructive pulmonary disease, psoriasis, and moderate atopic dermatitis, respectively (Baillie et al., 2019). Interestingly, the PDE4 gene family consists of four paralogous genes, which, correspondingly, encode PDE4 subtypes (i.e., PDE4A-D). Each of these genes generates a variety of transcript variants that translate into different protein isoforms (e.g., PDE4D1-9). As these PDE4 subtypes and isoforms show tissue- and cell type-specific expression and intracellular compartmentalization patterns (Houslay, 2010) [reviewed in Baillie et al. (2019)], more selective inhibition could reduce the abovementioned adverse effects while maintaining treatment efficacy. An additional layer of complexity is added by the fact that PDE4 enzymes can adopt different conformational states as a result of various posttranslational modifications and interactions with partner proteins. Consequently, this allows for more selective targeting, as PDE4 inhibitors will likely display different affinities toward different PDE4 subtypes, isoforms, and conformational states.

This review aims to provide an overview of the variety of PDE4 subtypes and isoforms and the mechanisms by which their cellular activity and inhibitor affinity is regulated through post-translational modifications and protein-protein interactions. Moreover, current advancements and strategies toward the development of PDE4 subtype- and/or conformationspecific compounds are discussed. Lastly, several mechanisms that potentially contribute to adverse side effect profiles of PDE4 inhibition are outlined to support the development of new, more specific, and safer PDE4-directed therapeutics.

\section{Phosphodiesterase 4 Subtypes and Isoforms}

Before the identification of the responsible enzymes in 1987, rolipram was shown to inhibit cAMP-specific PDE activity (Reeves et al., 1987). As this activity was distinct from three other types of PDE activity already known at the time, it was coined PDE IV. In retrospect, earlier studies had already identified rolipram-sensitive PDE activity to be present in rat brain material and to be involved in gastric secretion (Schwabe et al., 1976; Puurunen et al., 1978). A rat ortholog of the Drosophila cAMP-PDE enzyme, encoded by the dunce gene, was found to produce an enzyme that can be inhibited by rolipram (Davis et al., 1989; Swinnen et al., 1989a,b).
In mammals, four PDE4 genes can be distinguished, all of which show similar and evolutionarily conserved exon compositions, encoding the abovementioned PDE4 subtypes PDE4A, B, C, and D (Bolger et al., 1993, 1994; Milatovich et al., 1994; Johnson et al., 2010). Across species and among genes, there is particular sequence similarity in specific exons that encode the enzyme's catalytic domain and two regulatory domains, upstream conserved region 1 (UCR1) and upstream conserved region 2 (UCR2). Next to their sensitivity to rolipram, PDE4 enzymes can be distinguished from other PDEs by the presence of these UCR1 and UCR2 domains. Apart from the UCR1, UCR2, and catalytic domains, the amino acid sequences of human PDE4 subtypes differ notably in the linker region 1 (between UCR1 and UCR2), linker region 2 (LR2) (between UCR2 and catalytic domain), and the $\mathrm{C}$ termini. These differences allow for subtype-specific modulation while maintaining core PDE4 regulation and functionality as discussed in section III. Phosphodiesterase 4 Modifications and Interactions.

Additional diversity is achieved at the gene level as each of the PDE4 genes contains alternative promoters that can generate distinct transcript variants by incorporating unique exons and through recursive splicing mechanisms (Sibley et al., 2015). Different promoters may contain distinct transcription response elements that allow for transcriptional regulation associated with a diversity of signaling pathways. For example, specific promoters of the PDE $4 D$ gene have been identified to contain regulatory elements for the transcription factors cAMP-response element binding protein (Vicini and Conti, 1997; D'Sa et al., 2002; Le Jeune et al., 2002), melanocyte inducing transcription factor (Khaled et al., 2010), or activating transcription factor 4 (Soda et al., 2013). These transcriptional control mechanisms allow for intricate transcriptional feedback loops that upregulate PDE4 expression to terminate cAMP signaling associated with particular cascades. The activity of certain promoters is thus regulated by the presence of the various transcription factors, and the accessibility of the promoter may also be subject to epigenetic regulation. Indeed, epigenetic alterations at the level of DNA (hydroxy)methylation and histone modifications of the PDE $4 D$ gene have been associated with changes in expression on specific transcript variants (Tilley and Maurice, 2005; Paes et al., 2021a). Although the exact responsiveness of the different PDE4 promoters remains to be explored further, prior findings already suggest that PDE4 transcription can be regulated in an intricately regulated manner that enables organ- and cell-specific expression patterns.

Depending on the location of the promoter, PDE4 mRNA transcripts will include the exons encoding 
both UCR1 and UCR2, only UCR2, a truncated UCR2, or only exons that encode a part of the catalytic domain (Nemoz et al., 1996; Johnston et al., 2004). Based on the presence of these UCRs, the protein products of these transcripts can be categorized as long, short, and supershort isoforms, respectively. Transcripts encoding catalytically inactive isoforms are called dead-short (Houslay, 2001). Based on deletion mutant studies, the UCR domains were found to regulate catalytic activity, showing differential enzymatic kinetics for the different isoform categories (Jacobitz et al., 1996; Saldou et al., 1998). Via alternative promoters and alternative splicing mechanisms, more than 20 human PDE4 transcript variants have been identified, allowing for tissue- and cell-specific expression regulation.

Figure 1 highlights the exon composition per human PDE4 transcript. As described below, certain PDE4 transcripts have been identified or characterized in humans or rodents only; Supplemental Table 1 provides an overview of which PDE4 transcript has been described per species. Human PDE4A encodes four long isoforms [PDE4A8 (Mackenzie et al., 2008); PDE4A4, which is named PDE4A5 in rodents (Bolger et al., 1993; Naro et al., 1996); PDE4A11 (Wallace et al., 2005); and PDE4A10 (Rena et al., 2001)]; one supershort isoform [PDE4A1 (Sullivan et al., 1998)]; and a dead-short, catalytically inactive isoform [PDE4A7 (Johnston et al., 2004)] (Supplemental Table 1).

For human PDE4B, two long [PDE4B1 (Bolger et al., 1993) and PDE4B3 (Huston et al., 1997)], one short [PDE4B2 (McLaughlin et al., 1993)], and one supershort isoform [PDE4B5 (Cheung et al., 2007)] have been identified. In rodents, in addition, a long PDE4B4 isoform has been characterized that was suggested to have no functional equivalent in humans as a result of in-frame stop codons (Shepherd et al., 2003). However, PDE4B antibodies can clearly detect an $85-\mathrm{kDa}$ PDE4B species in human brain tissue corresponding to rodent PDE4B4, but the exact sequence remains to be determined (Fatemi et al., 2008) (Supplemental Table 1).

The least well characterized PDE4 subtype is PDE4C, which comprises three long isoforms [PDE4C1 (Engels et al., 1995), PDE4C2 (Owens et al., 1997b), and PDE4C3 (Obernolte et al., 1997)], but likely generates additional variants through complex alternative splicing (Obernolte et al., 1997). Interestingly, despite relatively little insight into its function, several studies found that the DNA methylation signature of the $P D E 4 C$ gene correlated with aging (Marquez-Ruiz et al., 2020).

Lastly, the human PDE4D gene produces the highest number of isoforms, i.e., six long isoforms [PDE4D3, PDE4D4, PDE4D5 (Bolger et al., 1997), PDE4D7, PDE4D8 (Wang et al., 2003), PDE4D9 (Gretarsdottir et al., 2003)], one short isoform [PDE4D1
(Bolger et al., 1997)], and two supershort isoforms [PDE4D2 (Bolger et al., 1997) and PDE4D6 (Wang et al., 2003)] (Supplemental Table 1).

Moreover, alternatively spliced transcripts have been described for PDE4D3, D4, and D5 that do not translate the catalytic domain because of in-frame stop codons caused by exon deletions or insertions (Fig. 1) (Miro et al., 2000). These variations of the "conventional" PDE4D3, D4, and D5 isoforms have been respectively coined PDE4DN1, PDE4DN2, and PDE4DN3 and can be categorized as dead-short forms based on the absence of the catalytic domain. For PDE4DN1, all exons encoding UCR1 are skipped, creating a transcript that encodes the unique $\mathrm{N}$-terminal of PDE4D3 followed by 31 frame-shifted codons of the UCR2 (Fig. 1). Based on this sequence, PDE4DN1 may engage in similar protein-protein interactions as PDE4D3 would using its N-terminal residues, but the exact functional role of PDE4DN1 remains undetermined (see also section III. Phosphodiesterase 4 Modifications and Interactions and Fig. 2). In contrast to PDE4DN1, PDE4DN2 and PDE4DN3 do incorporate the UCR1-encoding exons in their transcripts (Fig. 1). Similar to PDE4DN1, the unique N termini, as also present in PDE4D4 and PDE4D5, may allow PDE4DN2 and PDE4DN3 to bind specific protein partners or putatively cause competitive binding for these binding sites with full-length PDE4D4 and PDE4D5, respectively. This competitive binding may subsequently induce altered distribution of full-length PDE4 forms causing distinct cellular cAMP dynamics. Intriguingly, the presence of UCR 1 in these truncated forms may have functional consequences on fulllength PDE4 forms. It has been demonstrated that a peptide fragment of the UCR 1 can bind and activate full-length long PDE4 forms (Wang et al., 2015). PDE4DN2 and PDE4DN3, containing the same sequence as this peptide fragment, may exert similar actions and could biologically be relevant by providing an additional mechanism to elevate cellular PDE4 activity. The existence of these truncated forms at the protein level and their putative activating effects on full-length long PDE4D forms, however, remain to be validated.

Importantly, the existence of these truncated PDE4DN1-3 forms has a practical consequence for quantitative polymerase chain reaction (qPCR) measurements. Isoform-specific PDE4D expression can be measured using qPCR primers that amplify part of the sequence of the isoform-unique exon (and the first UCR1 exon), but in the case of PDE4D4 and PDE4D5, the respective expression of PDE4DN2 and PDE4DN3 will also be detected by qPCR. Hence, PCR and gel electrophoresis should be performed in parallel using appropriate primers to determine whether expression changes are found for both the full-length 


\section{PDE4 exon composition per transcript variant}

\begin{tabular}{|c|c|}
\hline $\begin{array}{l}\text { PDE4A8 } \\
(864 \text { aa) }\end{array}$ & long \\
\hline $\begin{array}{l}\text { PDE4A4 } \\
(886 \mathrm{aa})\end{array}$ & long \\
\hline $\begin{array}{l}\text { PDE4A11 } \\
(860 \mathrm{aa})\end{array}$ & long \\
\hline $\begin{array}{l}\text { PDE4A10 } \\
(825 \mathrm{aa})\end{array}$ & long \\
\hline $\begin{array}{l}\text { PDE4A1 } \\
(647 \mathrm{aa})\end{array}$ & supershort \\
\hline $\begin{array}{l}\text { PDE4A7 } \\
(323 \mathrm{aa})\end{array}$ & dead-short \\
\hline
\end{tabular}

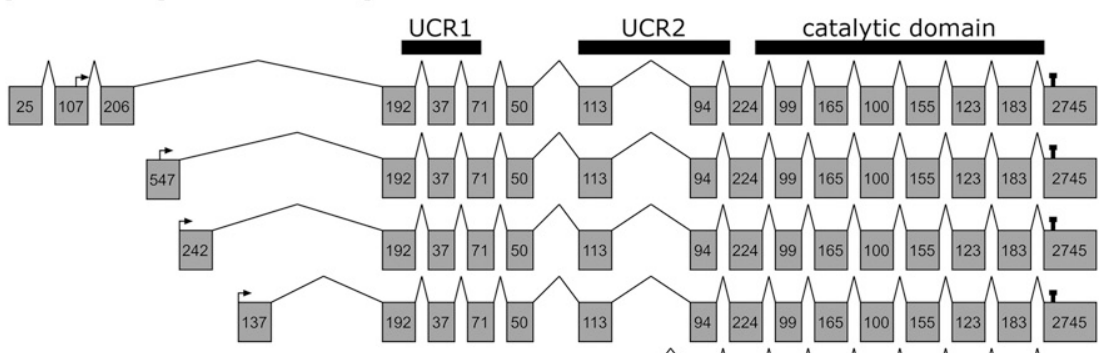

$\begin{array}{lll}\mathscr{N} & \text { PDE4B1 } & \text { long } \\ \text { (736 aa) } & \\ \text { PDE4B3 } & \text { long } \\ (721 \mathrm{aa}) & \\ \text { PDE4B2 } & \text { short } \\ (564 \mathrm{aa}) & \\ \text { PDE4B5 } & \text { supershort } \\ (503 \mathrm{aa}) & \end{array}$

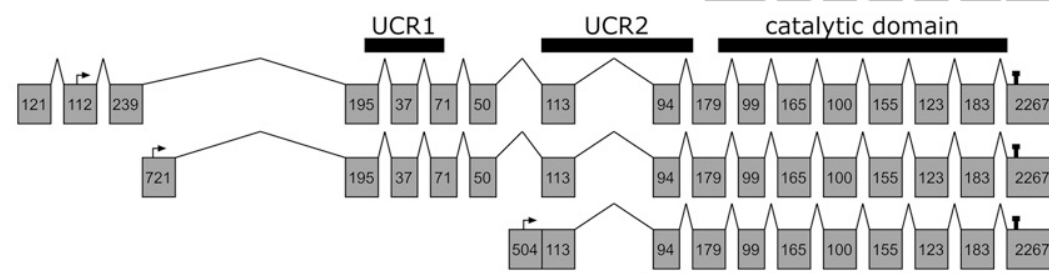

\begin{tabular}{|c|}
\hline $\begin{array}{l}\text { PDE4C1 } \\
(712 \mathrm{aa})\end{array}$ \\
\hline $\begin{array}{l}\text { PDE4C2 } \\
\text { (606 aa) }\end{array}$ \\
\hline $\begin{array}{l}\text { PDE4C3 } \\
\text { (680 aa) }\end{array}$ \\
\hline
\end{tabular}

PDE4D7 long
(748 aa)
PDE4D4 long
PE9
(809)
PDE4D5 long
(745 aa)
PDE4D3 long
(673 aa)
PDE4D8 long
(687 aa)
PDE4D9 long
(679 aa)
PDE4D1 short
(585 aa)
PDE4D2 supershort
(507 aa)
PDE4D6 supershort
(518 aa)
PDE4DN2 dead-short*
(274 aa*)
PDE4DN3 dead-short*
(215 aa*)
PDE4DN1 dead-short*
(47 aa*)
circPDE4D non-conding
(circRNA)

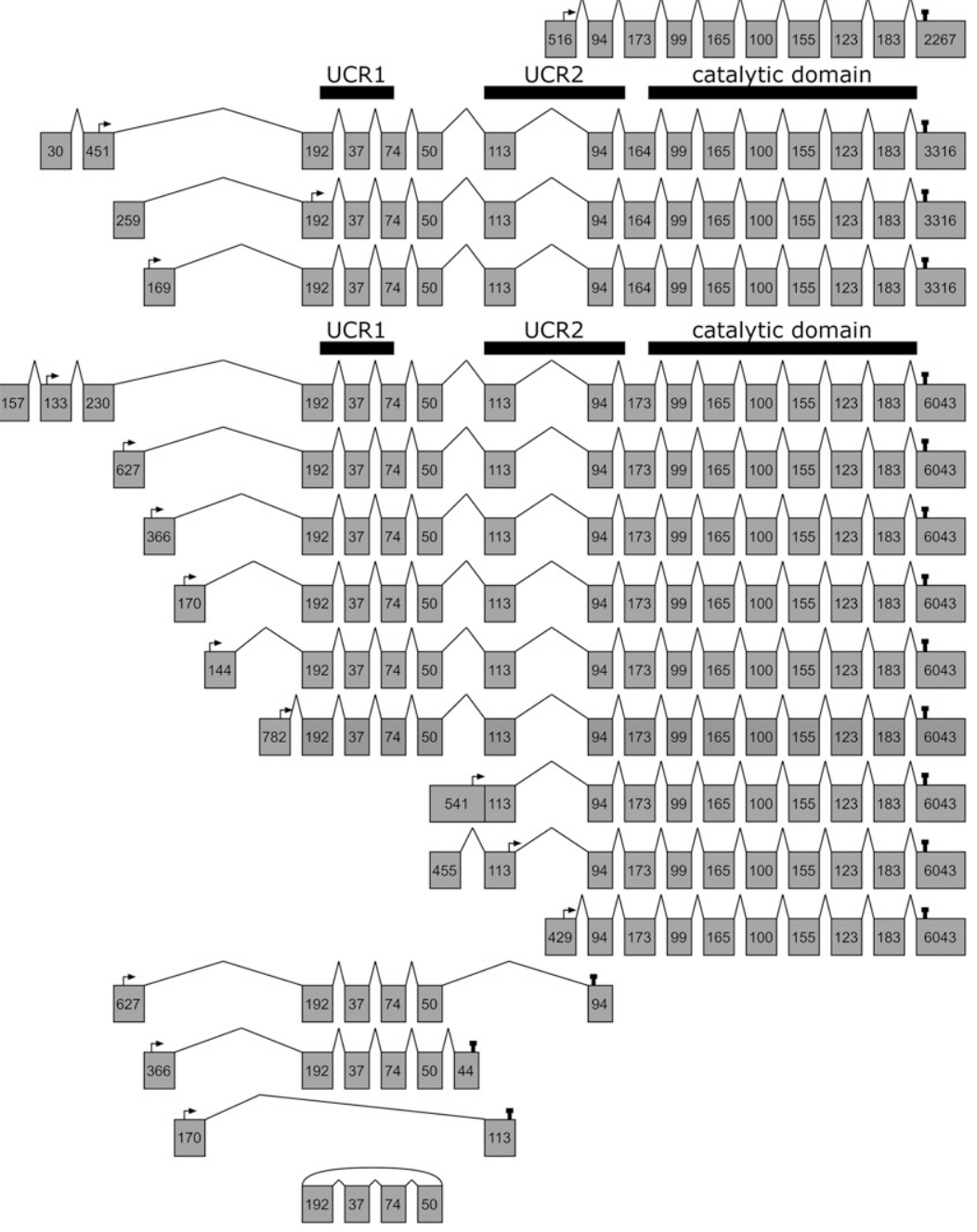

Fig 1. Exon composition per human PDE4 transcript variant. For each of the PDE4 genes (PDE4A-D), the exon composition is shown per transcript variant. Gray boxes depict exons and their nucleotide length. The protein isoform names and associated amino acid (aa) number per transcript are shown on the left. Start and stop codons are indicated by arrows and pins, respectively. The regions translating into UCR1, UCR2, and the catalytic domain are visualized by thick horizontal bars. *As the transcripts PDE4DN1-3 have only been identified on the mRNA level, amino acid lengths are isoform categories that are predictions based on inframe stop codons. This figure was established through analysis and crossreferencing of online databases (NCBI: https://www.ncbi.nlm.nih.gov/gene and Ensembl: $\mathrm{http} / / / \mathrm{www} . e n s e m b l . o r g / i n d e x . h t m l$ ) and original cloning studies (see references to studies per transcript variant in section II. Phosphodiesterase 4 Subtypes and Isoforms). An overview indicating which transcripts have counterparts in rodents or are only found in rodents is provided in the Supplemental Material. 


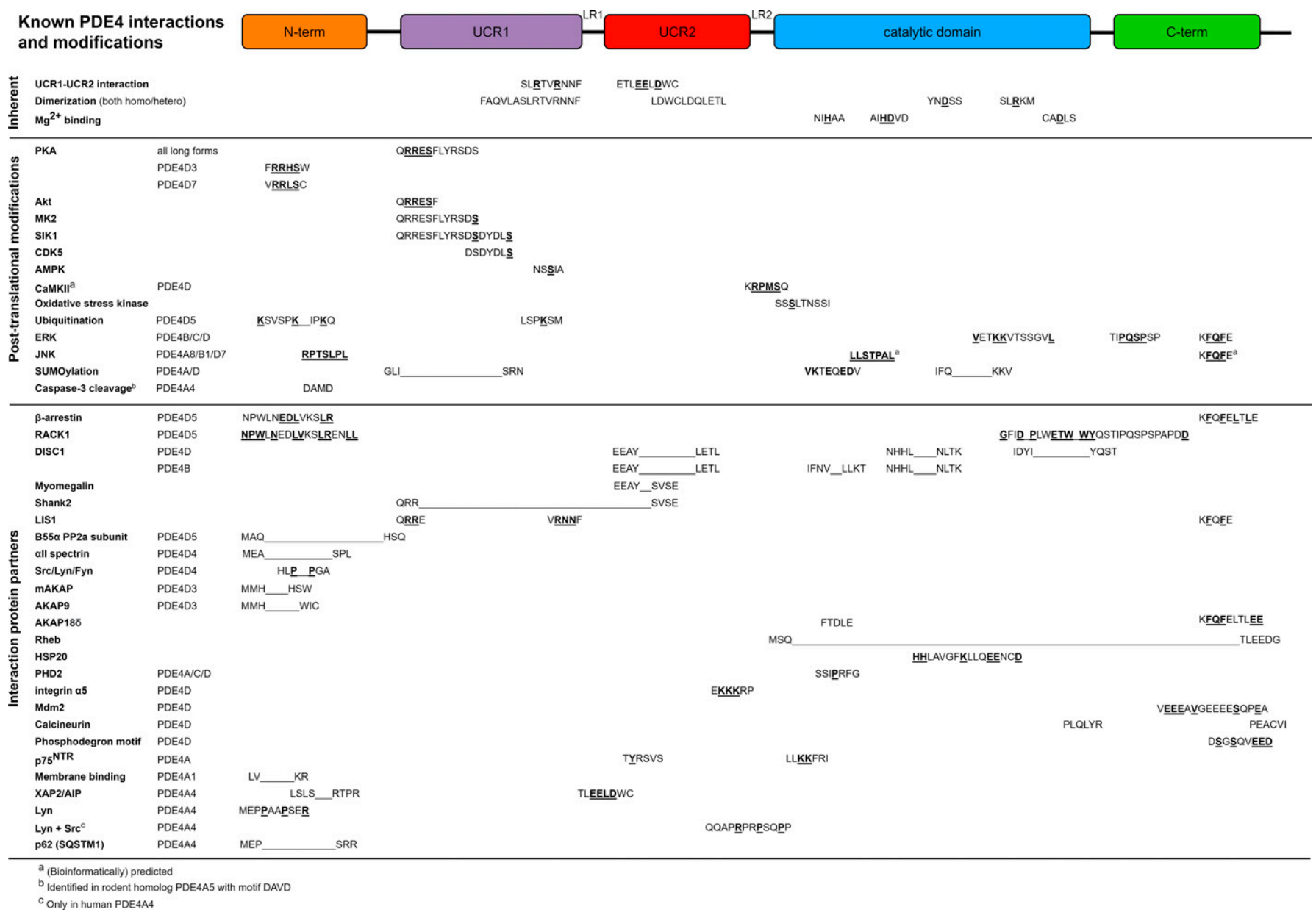

Fig 2. Graphical representation of regulatory protein domains of PDE4 proteins and PDE4 amino acids or domains involved in inherent features of PDE4 enzymes, post-translational modifications and interactions with protein partners. Colored rectangles indicate regulatory domains. Inherent features of PDE4 enzymes and associated amino acids are also visualized in Supplemental Video. Those post-translational modifications and protein-protein interactions for which the involved PDE4 domains or specific amino acid residues have been identified are listed in this figure. If specific amino acids in involved regions have been identified to mediate the modification or interaction, these amino acids are indicated in bold and underlined. In case the specific amino acids are unidentified, the involved region is indicated by the region's first and last amino acids connected by a line. Of note, for simplicity, PDE4D amino acids are shown for nonconserved amino acids involved in modifications or interactions that can occur in multiple PDE4 subtypes. Importantly, not all proteins or mechanisms in Figure 2 are listed in Table 1, and vice versa, as one of both aspects (i.e., either involved amino acids or effect of activity) may not have been revealed yet. The determination of amino acids involved in each of the modifications or interactions was based on the references as listed below: AKAP9 (Terrenoire et al., 2009); AKAP18 $\delta$ (Stefan et al., 2007); Akt (Fang et al., 2015); AMPK, AMP-activated protein kinase (Sheppard et al., 2014); $\beta$-arrestin (Bolger et al., 2006; Baillie et al., 2007; Smith et al., 2007; Bolger, 2016); aII spectrin (Creighton et al., 2008); B55 $\alpha$ PP2a subunit (Yun et al., 2019b); calcineurin (Zhu et al., 2010); CaMKII (Mika et al., 2015); caspase-3 (Huston et al., 2000); CDK5 (Plattner et al., 2015); C-term, C terminus; dimerization (Lee et al., 2002; Richter and Conti, 2002; 2004; Xie et al., 2014; Bolger et al., 2015; Cedervall et al., 2015); DISC1 (Millar et al., 2005; Cheung et al., 2007; Murdoch et al., 2007; Soda et al., 2013); ERK ( Hoffmann et al., 1999; Baillie et al., 2000; MacKenzie et al., 2000); HSP20 (Sin et al., 2011); integrin $\alpha 5$ (Yun et al., 2016, 2019b); JNK (Sharrocks et al., 2000; Bogoyevitch and Kobe, 2006; Zeke et al., 2015); LIS1 (Murdoch et al., 2011); LR1, linker region 1; Lyn (Beard et al., 2002); Lyn + Src (McPhee et al., 1999); mAKAP (Dodge et al., 2001; Carlisle Michel et al., 2004); Mdm2, mouse double minute 2 homolog (Li et al., 2009); membrane binding (Baillie et al., 2002); $\mathrm{Mg}^{2+}$ binding (Alvarez et al., 1995; Saldou et al., 1998; Laliberte et al., 2000; Liu et al., 2001); MK2 (MacKenzie et al., 2011; Bolger, 2016; Houslay et al., 2017; Houslay et al., 2019); myomegalin (Verde et al., 2001); N-term, N terminus; oxidative stress kinase (Hill et al., 2006; Bolger, 2016); p62 (SQSTM1, sequestosome 1) (Christian et al., 2010); PHD2 (Huo et al., 2012); phosphodegron motif (Zhu et al., 2010); PKA (Alvarez et al., 1995; Sette and Conti, 1996; Hoffmann et al., 1998; Beard et al., 2000; MacKenzie et al., 2002; Byrne et al., 2015; Bolger, 2016); p75 ${ }^{\mathrm{NTR}}$ (Sachs et al., 2007; Houslay et al., 2019); RACK1 (Yarwood et al., 1999; Bolger et al., 2002; Bolger et al., 2006; Smith et al., 2007; Bird et al., 2010); Rheb (Kim et al., 2010; Meng et al., 2017); Shank2 (Lee et al., 2007); SIK1 (Kim et al., 2015); Src/Lyn/Fyn (O’Connell et al., 1996; Beard et al., 1999); SUMOylation (Li et al., 2010); ubiquitination (Li et al., 2009); UCR1UCR2 interaction (Beard et al., 2000); XAP/aryl hydrocarbon receptor-interacting protein (AIP) (Bolger et al., 2003).

and truncated transcript or for only one of these transcripts.

Recently, it has been described that PDE $4 D$ also encodes a highly stable, mainly cytoplasmic, circular RNA, circPDE4D, which is formed through circularization of exons $2-5$ of the PDE4D gene (Fig. 1) (Wu et al., 2021). The expression of circPDE4D and linear PDE4D mRNA was found not to be correlated, indicating that distinct mechanisms produce these transcript types. Wu et al. (2021) identified regulatory regions in the flanking introns (i.e., upstream of exon 2 and downstream of exon 5) that are crucial for circPDE4D circularization. Through specific CRISPR-Cas9 editing, the authors were able to decrease circPDE4D expression and 
determine that QKI response elements are involved in circularization of the PDE4D pre-mRNA. QKI response elements bind the RNA-binding protein quaking (QKI), which has previously been shown to regulate the circularization of many pre-mRNAs (Conn et al., 2015). The functional role of circPDE4D remains largely to be determined, but $\mathrm{Wu}$ et al. (2021) identified that circPDE4D can bind specific microRNAs and thereby indirectly modulates the translation of mRNAs that otherwise would be degraded by the now-scavenged microRNA. In the same study, circPDE4D was found to be downregulated in osteoarthritic cartilage tissue, and intra-articular injection of circPDE4D could mitigate impairments in a mouse model of osteoarthritis.

As circPDE4D contains four exons that are also present in linear long-form PDE4D mRNA, it can be speculated that circPDE4D scavenges microRNAs that bind linear long-form PDE4D mRNA, and circPDE4D may therefore indirectly modulate PDE4D protein expression. Moreover, circRNAs can also directly regulate protein function, protein scaffolding, and protein localization, but these potential roles still remain to be determined for circPDE4D (Kristensen et al., 2019). These recent findings underline the complex transcriptional control of the PDE4D gene and warrant further investigation into non-protein-coding transcripts of the PDE4 gene family.

For murine Pde4d, the additional long PDE4D11 and supershort PDE4D10 isoforms have been described (Chandrasekaran et al., 2008; Lynex et al., 2008) (Supplemental Table 1). Furthermore, additional murine PDE4D transcripts have been identified that all encode supershort PDE4D2 but are generated through diverse exon incorporation, resulting in diverse $5^{\prime}$ UTR sequences and lengths (Chandrasekaran et al., 2008) (Supplemental Table 1). Regarding $5^{\prime} \mathrm{UTR}$ and $3^{\prime} \mathrm{UTR}$ lengths, discrepancies exist regarding the reported transcript lengths when comparing NCBI Gene and Ensembl databases. 5'UTR lengths can differ depending on where the transcriptional machinery binds the DNA and initiates transcription, as exemplified for mouse PDE4D1 (McLaughlin et al., 1993). Similarly, the PDE4 transcript's $3^{\prime}$ UTR may differ in length, as it contains multiple polyadenylation sites (Sullivan et al., 1998; Wang et al., 2003). According to this variability at the $5^{\prime} \mathrm{UTR}$ and $3^{\prime} \mathrm{UTR}$, certain gene data banks may show other lengths for the first unique and last common exons compared with those displayed in Fig. 1. As $5^{\prime}$ UTR and $3^{\prime}$ UTR sequences have been found to function as "zip codes" for specific intracellular transcript transport, it can be speculated that variation in these PDE4 transcript sequences may contribute to specific intracellular localization patterns for the different PDE4 isoforms (Andreassi and Riccio, 2009; Chin and Lecuyer, 2017). Wang et al. (2003) identified 10 putative consensus polyadenylation signals in the 3 UTR of PDE4D mRNA, which indicates that multiple transcripts that differ in their $3^{\prime}$ UTR length can be generated depending on which polyadenylation site is used. Subsequently, differences in $3^{\prime}$ UTR length may give rise to mRNA transcripts that exhibit different recognition motifs for several RNA-binding proteins (Di Liegro et al., 2014). For example, self-complementary sequences in mRNA can form secondary-structure hairpin loops that can be recognized and bound by RNA-binding proteins to regulate mRNA stability and transportation (Di Liegro et al., 2014). Depending on PDE4 $3^{\prime}$ UTR length, different secondary structures may be formed and bound by different transport proteins, which localize the transcript to distinct intracellular compartments. There, the specific PDE4 mRNA may be locally translated, after which the PDE4 protein isoform can be anchored to other proteins or membranes through its (isoform-specific) amino acids (see section III. Phosphodiesterase 4 Modifications and Interactions). Although the role of $5^{\prime} \mathrm{UTR}$ and $3^{\prime} \mathrm{UTR}$ sequence differences in mRNA transportation has not yet been explicitly demonstrated for PDE4 transcripts, these sequence differences could provide another mechanism through which PDE4 subtypes and isoforms can display a distinct cell type-specific and tissue type-specific intracellular distribution.

The intracellular localization of PDE4 isoforms is particularly regulated via isoform-specific $\mathrm{N}$ termini at the protein level, encoded by typical unique exon incorporation. These different $\mathrm{N}$ termini permit PDE4 isoforms to interact with protein partners or membranes in specific intracellular compartments (Houslay et al., 1995). In Aplysia, apPDE4 was found to require N-terminal residues for membrane binding, which indicates a conserved role for isoform-specific $\mathrm{N}$ termini in PDE4 localization (Jang et al., 2010). Likewise, different mammalian PDE4 subtypes (e.g., PDE4B and PDE4D) locate to different intracellular compartments (Blackman et al., 2011).

In addition to the scaffolding function, interactions with partner proteins can, as mentioned above, act upon the enzyme's conformational state and hence affect its catalytic activity and inhibitor affinity. Similarly, PDE4 subtypes and isoforms are subject to posttranslational modifications that differentially alter the conformation and activity of the enzyme.

To develop more efficacious and safer PDE4 inhibitors for different diseases, it is crucial to identify which PDE4 subtypes and isoforms should be targeted in disease-relevant tissues and cell types. Similarly, insight into which PDE4 subtypes and isoforms mediate adverse effects will determine which specific targets to avoid to improve the treatment's safety profile. Additionally, understanding the conformational state of the isoform(s) involved in the compartmentalized signaling 
important to treat the disease at hand determines which compounds would be most potent. In the following section, an overview is provided on the different manners by which PDE4 activity and inhibitor affinity are influenced by post-translational modifications and interactions with partner proteins.

\section{Phosphodiesterase 4 Modifications and Interactions}

As mentioned before, catalytically active PDE4 isoforms can be categorized as long, short, or supershort based on the presence of UCR1 and UCR2 domains. Depending on the PDE4 subtype, isoform category, and unique N-terminal features, different post-translational modifiers and interaction partners can influence the conformation of the enzyme. These mechanisms allow for the dynamic regulation of the amount, localization, and activity of PDE4 enzymes to shape and respond to spatiotemporal cAMP signaling [as also recently reviewed for all PDE gene families (Baillie et al., 2019)]. The seminal work by Houslay and collaborators has provided a detailed understanding of which PDE4 amino acid residues are crucial for several modifications and interactions (Klussmann, 2016). Those post-translational modifications and protein-protein interactions for which involved PDE4 domains or specific amino acid residues have been identified are graphically represented in Fig. 2. These and other modifications and interactions, for which involved regions have not been determined, are discussed below in more detail. Furthermore, the known functional consequences of several modifications and interactions on PDE4 activity and inhibitor binding are elaborated upon in the following subsections and are summarized in Table 1.

\section{A. Upstream Conserved Region 1-Upstream Conserved Region 2 Module, Dimerization, and Phosphorylation}

PDE4 activity is profoundly regulated by its own UCR domains as, in long isoforms, the C-terminal of UCR1 forms a module with the N-terminal of UCR2, which autoinhibits its activity through the capping of the UCR2 $\alpha$-helix NQVSE[F/Y]ISXTFLD across the catalytic domain (Kovala et al., 1997; Lim et al., 1999; Beard et al., 2000; Houslay and Adams, 2010) (Fig. 3; Table 1; Supplemental Video). Furthermore, the UCR1 and UCR2 domains enable long isoforms to homo- and heterodimerize, whereas short and supershort isoforms (lacking UCR1) exist as monomers (Xie et al., 2014). The UCR1-UCR2 module is disrupted upon serine phosphorylation in the conserved protein kinase A (PKA) consensus motif RRES in UCR1 of all long PDE4 isoforms. The liberation of this UCR1UCR2 module attenuates the autoinhibitory effect causing enzyme activation (Hoffmann et al., 1998; Beard et al., 2000). As PKA is a direct downstream effector protein of cAMP, this modification serves as a negative feedback loop restoring cAMP levels through enhanced PDE4 activity. Although PKA phosphorylation can activate all long isoforms, the amplitude of PKA activation can differ among these isoforms as reported for long PDE4D isoforms (Richter et al., 2005). This indicates that additional regulatory mechanisms influence enzymatic activity. For example, the presence of additional PKA phosphorylation sites in PDE4D3 and PDE4D7, upon combined PKA phosphorylation, leads to differential effects in terms of catalytic activity (Sette and Conti, 1996; Collins et al., 2008; Byrne et al., 2015). Indeed, unique phosphorylation in the N-terminal PDE4D7, but not at the unique site in PDE4D3, induces an inhibitory effect on activity as opposed to PKA phosphorylation at the conserved UCR1 site (Byrne et al., 2015). Although PKA phosphorylation provides a negative feedback loop to restore cAMP levels, this regulation can be influenced by other protein interactors as well. For example, when PDE4D is bound by the protein coiled-coil and C2 domain-containing protein 1A (CC2D1), phosphorylation by PKA is prevented (Al-Tawashi et al., 2012; Al-Tawashi and Gehring, 2013). In addition to PKA, it was found that the same serine residue in UCR1 can be phosphorylated by Akt (Fang et al., 2015). Other conserved serine residues in the UCR1 also serve as phosphorylation sites for other kinases such as MK2, SIK1, CDK5, and AMP-activated protein kinase, which may modulate PDE4 activity by similarly affecting UCR1-UCR2 module formation/stabilization (MacKenzie et al., 2011; Sheppard et al., 2014; Kim et al., 2015; Plattner et al., 2015; Bolger, 2016; Houslay et al., 2019). Next to phosphorylation events, binding of phosphatidic acid or phosphatidylserine to the UCR1-UCR2 module increases PDE4 activity (Nemoz et al., 1997). The regulatory role of the UCR1-UCR2 module is further supported by the observation that several PDE4D mutations associated with the rare genetic disorder acrodysostosis localize to these regions, causing either increased or decreased PDE4D activity (Kaname et al., 2014; Gurney et al., 2015; Briet et al., 2017).

\section{B. Phosphorylation at Sites Other than Upstream Conserved Region 1}

Through the use of multiple phosphorylation sites, PDE4 functionality can be modulated in a conditional manner, requiring multiphosphorylation, as has been reported for the role of PDE4D9 in mitosis (Sheppard et al., 2014). Next to the UCR1, the $\mathrm{N}$ terminus of the catalytic domain comprises phosphorylation sites for CaMKII and an "oxidative stress" or "switch" kinase. CaMKII phosphorylation is PDE4D-specific and induces enzyme activation in a manner distinct from PKA activation (Mika et al., 2015). In response to oxidative stress, an as of yet unidentified oxidative stress or switch kinase can increase PDE4 enzyme activity by 
TABLE 1

Overview of modifications and interactions that influence PDE4 activity and the affinity of PDE4 inhibitors

\begin{tabular}{|c|c|c|c|c|}
\hline $\begin{array}{l}\text { Effect on PDE } 4 \\
\text { Activity }\end{array}$ & Interaction/Modification & Effect on Inhibitor affinity & Comments & References \\
\hline \multirow[t]{17}{*}{ Increase } & Akt & - & & Fang et al., 2015 \\
\hline & B55 $\alpha$ PP2a subunit & - & $\begin{array}{l}\text { Dephosphorylation at } \\
\text { ERK site on PDE4D5 }\end{array}$ & Yun et al., 2019a \\
\hline & Calcineurin & - & $\begin{array}{c}\text { Protects against } \\
\text { degradation }\end{array}$ & Zhu et al., 2010 \\
\hline & CaMKII & - & & Mika et al., 2015 \\
\hline & Caspase-3 cleavage & - & & Huston et al., 2000 \\
\hline & CDK5 & - & $\begin{array}{c}\text { Possible synergistic } \\
\text { activation by PKA }\end{array}$ & Plattner et al., 2015 \\
\hline & ERK & - & $\begin{array}{l}\text { Short isoforms of PDE4B, } \\
4 \mathrm{C} \text {, and } 4 \mathrm{D} \text { only }\end{array}$ & $\begin{array}{l}\text { Baillie et al., 2000; } \\
\text { MacKenzie et al., 2000 }\end{array}$ \\
\hline & mAKAP/AKAP6 & - & Presumably through & Carlisle Michel et al., \\
\hline & Metal binding $(\mathrm{Mg} 2+)$ & $\begin{array}{l}\text { Increase ( } R \text {-rolipram, } \\
S \text {-rolipram, CDP-840, } \\
\text { cilomilast, roflumilast, } \\
\text { piclamilast, PMNPQ) }\end{array}$ & & $\begin{array}{l}\text { Huang et al., 2007; } \\
\text { Laliberte et al., 2000; } \\
\text { Liu et al., 2001; Saldou } \\
\text { et al., } 1998\end{array}$ \\
\hline & $\begin{array}{l}\text { Oxidative stress switch } \\
\text { kinase }\end{array}$ & No effect (rolipram) & $\begin{array}{c}\text { Switches ERK inhibition } \\
\text { to activation, } \\
\text { phosphomimetic } \\
\text { mutation prevents } \\
\text { dimerization }\end{array}$ & $\begin{array}{c}\text { Bolger, 2016; Hill et al., } \\
2006\end{array}$ \\
\hline & Phosphatidic acid & - & $\begin{array}{l}\text { Dimerization necessary } \\
\quad \text { for activation }\end{array}$ & $\begin{array}{c}\text { Grange et al., 2000; } \\
\text { Nemoz et al., 1997; } \\
\text { Richter and Conti, 2004 }\end{array}$ \\
\hline & Phosphatidylserine & - & & Nemoz et al., 1997 \\
\hline & $\mathrm{PI} 3 \mathrm{~K} \gamma$ & - & & $\begin{array}{l}\text { D'Andrea et al., 2015; } \\
\text { Ghigo et al., } 2012\end{array}$ \\
\hline & PKA & $\begin{array}{c}\text { Increase (rolipram, } \\
\text { BPN14770, RS-25344, } \\
\text { RS-33793) }\end{array}$ & & $\begin{array}{l}\text { Alvarez et al., 1995; } \\
\text { Bolger, 2016; Hoffmann } \\
\text { et al., 1998; MacKenzie } \\
\text { et al., 2002; Sette and } \\
\text { Conti, 1996; } \\
\text { Zhang et al., 2018 }\end{array}$ \\
\hline & RACK1 & Increase (rolipram) & Ablates dimerization & $\begin{array}{c}\text { Bird et al., 2010; Bolger } \\
\text { et al., 2006; Bolger } \\
\text { et al., 2002; Yarwood et } \\
\text { al., } 1999\end{array}$ \\
\hline & Rheb & - & $\begin{array}{l}\text { Stabilizes PDE4D protein } \\
\text { expression }\end{array}$ & $\begin{array}{l}\text { Kim et al., 2010; Meng } \\
\text { et al., } 2017\end{array}$ \\
\hline & SIK1 & - & & $\begin{array}{l}\text { Kim et al., 2015; Liu } \\
\text { et al., } 2020\end{array}$ \\
\hline \multirow[t]{8}{*}{ Decrease } & CC2D1A & - & $\begin{array}{c}\text { Prevents activation by } \\
\text { PKA }\end{array}$ & $\begin{array}{l}\text { Al-Tawashi and } \\
\text { Gehring, } 2013\end{array}$ \\
\hline & DISC1 & - & $\begin{array}{l}\text { PKA phosphorylation } \\
\text { releases DISC1 }\end{array}$ & $\begin{array}{l}\text { Cheung et al., 2007; } \\
\text { Millar et al., 2005; } \\
\text { Murdoch et al., 2007 }\end{array}$ \\
\hline & ERK & - & $\begin{array}{l}\text { Long and supershort } \\
\text { isoforms of PDE4B, } 4 \mathrm{C}, \\
\text { and 4D only }\end{array}$ & $\begin{array}{l}\text { Baillie et al., 2000; } \\
\text { MacKenzie et al., } 2000\end{array}$ \\
\hline & PHD2 & - & $\begin{array}{l}\text { Presumably induces } \\
\text { PDE4 protein } \\
\text { degradation }\end{array}$ & Huo et al., 2012 \\
\hline & PKA (PDE4D7-specific) & - & & Byrne et al., 2015 \\
\hline & Smurf2 & - & $\begin{array}{l}\text { Ubiquitination and } \\
\text { degradation of PDE4B }\end{array}$ & Cai et al., 2018 \\
\hline & SUMO E3 ligase PIASy & 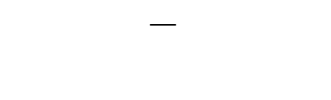 & $\begin{array}{l}\text { Augments PKA } \\
\text { phosphorylation, reduces } \\
\text { ERK inhibition }\end{array}$ & Li et al., 2010 \\
\hline & UCR1-UCR2 interaction & $\begin{array}{l}\text { No effect (IBMX, } \\
\text { rolipram, piclamilast, } \\
\text { RS-25344) }\end{array}$ & & $\begin{array}{l}\text { Beard et al., 2000; } \\
\text { Saldou et al., } 1998\end{array}$ \\
\hline \multirow[t]{3}{*}{ None } & $\begin{array}{l}\text { XAP2/AIP } \\
\text { Dimerization }\end{array}$ & $\begin{array}{c}\text { Increase (rolipram) } \\
\text { Increase }(R \text {-rolipram), no } \\
\text { effect (piclamilast)/no } \\
\text { effect (rolipram)/ } \\
\text { increased (rolipram) }\end{array}$ & $\begin{array}{l}\text { Dimerization enables } \\
\text { UCR2 to bind rolipram }\end{array}$ & $\begin{array}{c}\text { Bolger et al., 2003 } \\
\text { Bolger et al., 2015; } \\
\text { Cedervall et al., 2015; } \\
\text { Richter and Conti, } 2004\end{array}$ \\
\hline & Lyn, Src & Increase for rolipram & & $\begin{array}{l}\text { Beard et al., 2002; Beard } \\
\text { et al., 1999; McPhee } \\
\text { et al., 1999; O'Connell } \\
\text { et al., } 1996\end{array}$ \\
\hline & MK2 phosphorylation & - & $\begin{array}{c}\text { Phosphomimetic } \\
\text { mutation prevents } \\
\text { dimerization; attenuation }\end{array}$ & $\begin{array}{l}\text { Bolger, 2016; Houslay } \\
\text { et al., 2019; MacKenzie } \\
\text { et al., } 2011\end{array}$ \\
\hline
\end{tabular}


TABLE 1-Continued

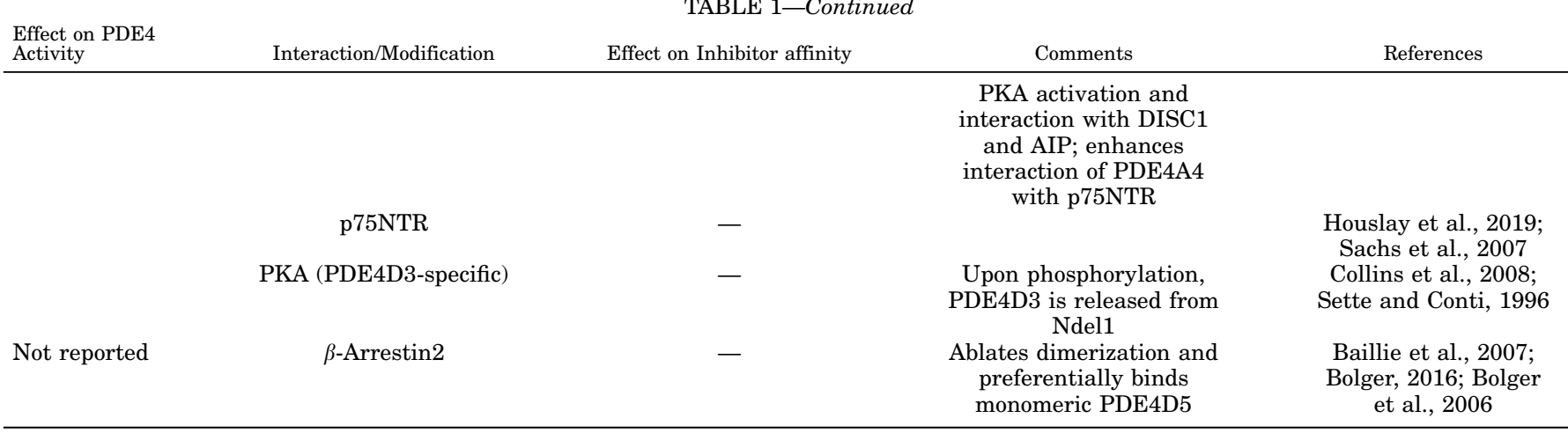

AIP, aryl hydrocarbon receptor-interacting protein; CC2D1A, coiled-coil and C2 domain-containing protein 1A; PIASy, protein inhibitor of activated STAT protein gamma; PI3Ky, phosphoinositide 3-kinase gamma.

switching the inhibitory effect of phosphorylation by extracellular signal-regulated kinase (ERK) to an activating effect (Hill et al., 2006; Bolger, 2016). Similarly, inhibition of PDE4D by ERK is diminished upon SUMOylation mediated by protein inhibitor of activated STAT protein gamma (PIASy), and this SUMOylation augments PKA activation of PDE4A and PDE4D (Fig. 2; Table 1) (Li et al., 2010).

Phosphorylation by ERK is established through the docking of ERK at the KIM and FQF motifs, which

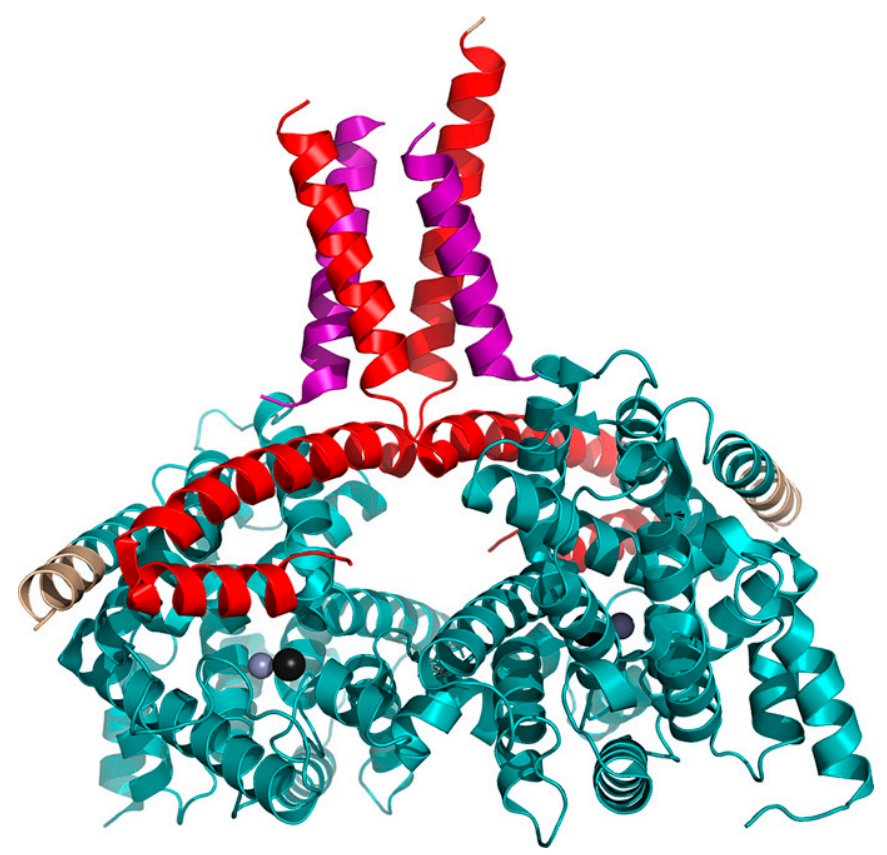

Fig 3. Tertiary structure of dimerized PDE4B demonstrating capping of UCR2 across the catalytic domain and helices 10 and 11 . Crystal structure was derived from Protein Data Bank [PDB: 4WZI, (Cedervall et al., 2015)]. UCR1 and UCR2 regions of both monomers are indicated in purple and red, respectively. Catalytic domains are colored cyan and have the catalytic metals (i.e., $\mathrm{Mg}^{2+}$ and $\mathrm{Zn}^{2+}$ ) embedded as shown by the spheres. Wheat-colored helices form part of the linking region between catalytic domains and, nonmodeled, C termini. A three-dimensional representation of the image is provided in Supplemental Video. are located in catalytic domains and the $\mathrm{C}$ terminus, respectively (Fig. 2) (Houslay and Baillie, 2003). Upon docking of ERK, the consensus motif PXSP can be phosphorylated, which is present at the end of the catalytic domain in PDE4B, 4C, and 4D. Although PDE4A phosphorylation at this motif has been detected, this is unlikely induced by ERK, given the absence of the consensus motif, or it does not result in changed PDE4A activity (Baillie et al., 2000; Lario et al., 2001). Phosphorylation by ERK reduces the catalytic activity of long and supershort PDE4B, 4C, and $4 \mathrm{D}$ isoforms, presumably by intramolecular stabilization of the UCR2-capped configuration (Baillie et al., 2000; Houslay and Baillie, 2003). Conversely, short isoforms are activated upon ERK phosphorylation. However, removal of the UCR2 region in the short PDE4B2 form prevents an effect by phosphorylation by ERK, which supports the notion that UCR2 capping is required for ERK-mediated effects (Rocque et al., 1997b). Moreover, when ERK phosphorylation is paired with additional PKA or switch kinase phosphorylation, enzyme activity will increase in long isoforms as well (Hoffmann et al., 1999; Hill et al., 2006). Apart from these direct effects on PDE4 activity, phosphorylation by ERK may make PDE4 less prone to proteolysis (Lenhard et al., 1996). The PDE4D5 isoform may be minimally subjected to phosphorylation by ERK, as its unique $\mathrm{N}$ terminus binds the protein phosphatase B55 $\alpha$ subunit, which dephosphorylates at the ERK site, reversing its inhibition (Yun et al., 2019). Furthermore, PDE4D5 specifically interacts with the proteins $\beta$-arrestin and RACK1, which can block the docking and phosphorylation by ERK, respectively (Table 1) (Bolger et al., 2006). Consequently, PDE4 activity can be increased upon these interactions, as reported for RACK1 (Yarwood et al., 1999; Bolger et al., 2002, 2006; Bird et al., 2010). Of note, binding of $\beta$-arrestin and RACK 1 ablates dimerization, but they bind mutually exclusively as a result 
of overlapping binding residues in the PDE4D5 $\mathrm{N}$ terminus (Bolger, 2016). Additional mouse double minute 2 homolog-mediated ubiquitination putatively primes PDE4D5 to interact with $\beta$-arrestin rather than RACK1 (Li et al., 2009). Although $\beta$-arrestin preferentially binds PDE4D5, when bound to the RXFP1 rector, it prioritizes binding PDE4D3 (Halls and Cooper, 2010). These findings indicate that, because of the differential and combined interactions with partner partners, phosphorylation and binding events may be stimulated, prevented, or countered in an isoform-specific manner.

The ERK-associated KIM docking motif can also be used by c-Jun N-terminal kinase (JNK) (Sharrocks et al., 2000; Houslay and Adams, 2003). Intriguingly, the specific isoforms PDE4A8, PDE4B1, and PDE4D7 all contain an additional, evolutionary conserved docking site for JNK in their unique $\mathrm{N}$ terminus (Fig. 2). Previously, it has been demonstrated that PDE4B1 can indeed bind JNK, but it remains to be verified whether JNK effectively phosphorylates PDE4 and whether this changes PDE4 enzymatic activity (Zeke et al., 2015). A putative JNK phosphorylation site can be found in the accessible LLSTPAL motif in the catalytic domain, which corresponds with the heptapeptidic consensus sequence surrounding the JNK phosphorylation site (Bogoyevitch and Kobe, 2006).

\section{Indirect Regulation of Phosphodiesterase 4 Activity and Interactions}

Next to the aforementioned mechanisms, cellular PDE4 activity can be regulated through mechanisms distinct from phosphorylation. These regulatory mechanisms may be therapeutically relevant for the disease of interest, as exemplified by the disrupted in schizophrenia 1 (DISC1) protein. DISC1 is a PDE4 interaction partner and has been found to be a risk factor for the development of psychiatric diseases when mutated (Millar et al., 2005; Cheung et al., 2007; Soda et al., 2013). DISC1 can bind and inhibit both PDE4B and PDE4D through homologous amino acids, causing occlusion of the catalytic domain, and additional subtype-specific binding sites allow for a stronger interaction with PDE4B than with PDE4D (Fig. 2) (Murdoch et al., 2007). Consequently, upon cAMP elevation, DISC1 dissociates from PDE4D while retaining its interaction with $\mathrm{PDE} 4 \mathrm{~B}$, resulting in functionally distinct roles for these PDE4 subtypes (Murdoch et al., 2007). Hence, mutations in either DISC1 or PDE4, or both, can impair or enhance this inhibitory action of DISC1, leading to aberrant PDE4 activity.

Through regulation of PDE4 mRNA and protein stability, cellular PDE4 activity can also be influenced. For example, cold-inducible RNA-binding protein, which acts as a cellular stress regulator, can stabilize PDE4B and PDE4D mRNA expression (Xie et al., 2020). Moreover, PDE4B mRNA was found to be stabilized by the common RNA modification $N^{6}$ methyladenosine, providing another mechanism to regulate PDE4 translation and subsequent activity (Huang et al., 2020). At the protein level, PDE4 expression and activity were found to be decreased upon overexpression of the oxygen-sensing protein prolyl hydroxylase domain-containing protein 2 (PHD2) through hydroxylation of a specific site in the catalytic domain (Fig. 2) (Huo et al., 2012). PDE4D contains a phosphodegron motif in its $\mathrm{C}$ terminus, which upon dual phosphorylation by casein kinase I and glycogen synthase kinase $3 \beta$, induces PDE4D degradation (Fig. 2). However, through binding of the serine/threonine protein phosphatase calcineurin, PDE4D can be protected against phosphodegron-mediated degradation, which would stabilize PDE4 activity (Zhu et al., 2010). Notably, both calcineurin inhibitors and PDE4 inhibitors are used in the treatment of atopic dermatitis (Papier and Strowd, 2018). Based on the calcineurin-PDE4 interaction, these calcineurin inhibitors may, at least in part, be effective through stimulation of PDE4 degradation. Likewise, the small GTPase Rhebstabilizes PDE4D protein expression and dissociates upon cAMP elevation to activate the mTOR pathway (Kim et al., 2010; Meng et al., 2017). Lastly, PDE4B ubiquitination can be induced upon interaction with the E3 ubiquitin ligase SMAD ubiquitination regulatory factor 2 (Smurf2) (Cai et al., 2018). Thus, PDE4 activity is indirectly regulated through control of its degradation. Conversely, when these regulatory mechanisms are affected in a disease state (e.g., in case of DISC1 mutations), PDE4 activity can consequently become dysregulated.

\section{Conformational States Impacting upon Phosphodiesterase 4 Activity and Inhibitor Binding}

Upon modifications and interactions, PDE4 can exist in different conformational states. Historically, this has been recognized by PDE4 activity that could be distinguished based on different binding affinities for rolipram, a high-affinity rolipram binding site (HARBS) and low-affinity rolipram binding site (LARBS); see also section IV. Phosphodiesterase 4 Inhibitors below (Jacobitz et al., 1996; Rocque et al., 1997a,b; Souness and Rao, 1997). Multiple studies have demonstrated several factors that contribute to the existence of distinct conformers. For example, binding $\mathrm{Mg}^{2+}$ in the catalytic domain dose-dependently increases enzymatic activity but also increases the affinity to bind rolipram and other inhibitors (Table 1) (Wilson et al., 1994; Alvarez et al., 1995; Laliberte et al., 2000). Similarly, phosphorylation by PKA and RACK1 binding both increase PDE4 activity and induce an increase in rolipram affinity (MacKenzie et al., 2002; Zhang et al., 2018). However, the effect of 
phosphorylation by PKA on rolipram affinity can be different per long isoform (MacKenzie et al., 2002). Interestingly, increases in enzyme activity upon phosphorylation by PKA may actually be a consequence of an increase in $\mathrm{Mg}^{2+}$ sensitivity, which subsequently would facilitate cAMP catalysis as well as binding of certain inhibitors through water-mediated interactions (Saldou et al., 1998; Laliberte et al., 2000). Indeed, as proposed by Houslay and Adams (2003), modifications at the $\mathrm{N}$ terminus may be relayed via conformational changes to the catalytic domain to eventually influence enzyme activity. For example, upon PKA phosphorylation and possibly also other PDE4-activating phosphorylation events in the UCR1 (Fig. 2), the UCR1-UCR2 module and/or UCR2-catalytic domain interactions may be disrupted (Beard et al., 2000; Houslay and Adams, 2003). Subsequently, this altered conformation could change the orientation of helices 10 and 11 in the catalytic domain that flank the catalytic metals, thereby impacting the way these metals are held in place. More specifically, helices 10 and 11 form a tweezer-like structure (Fig. 4, dark blue helices) and are connected by a loop (Fig. 4, orange), which may interact with UCR2 and/or LR2 residues (Fig. 4). As such, N-terminal modifications and interactions can, directly or through modulation of this UCR2/LR2 stretch, alter the conformation of

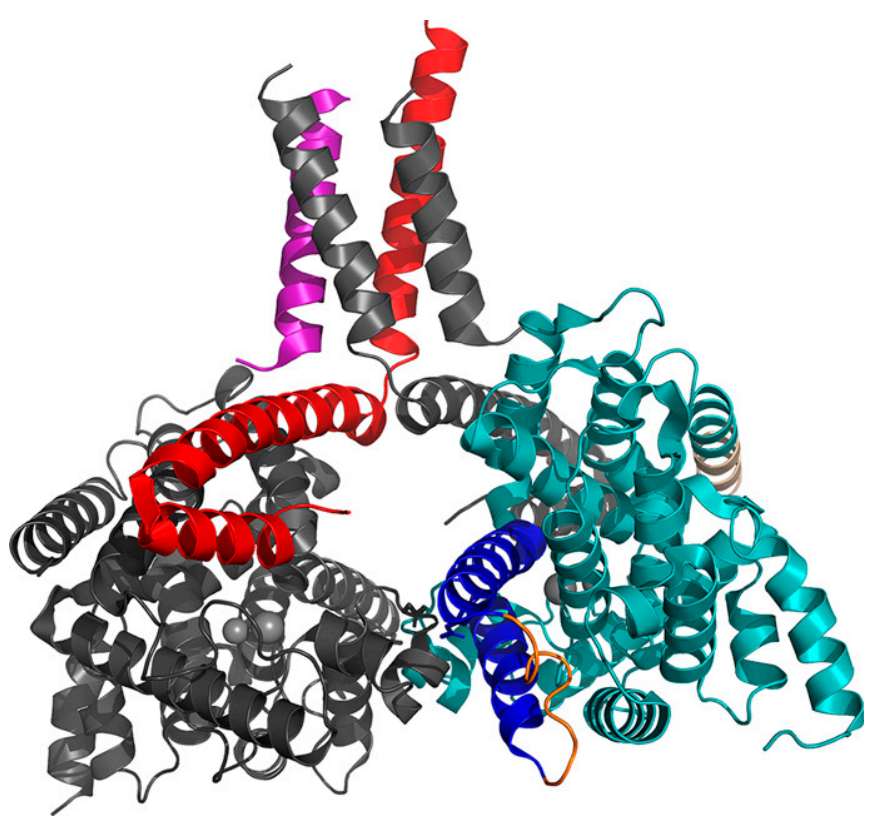

Fig 4. Tertiary structure of dimerized PDE4B demonstrating helices 10 and 11 and its connecting loop. One monomer is colored dark gray, and helices 10 and 11, flanking the catalytic metals, of the other monomer are now colored dark blue. The connecting loop between helices 10 and 11 is indicated in orange. The $\mathrm{C}$ terminus of UCR2 (red loose end in the middle) is connected to the $\mathrm{N}$ terminus of the catalytic domain (loose end in cyan in right-bottom corner) via LR2, which is not modeled but which would fold across the helix 10-11 connecting loop. Modifications and interactions in the $\mathrm{N}$ terminus are hypothesized to be relayed, via UCR2/LR2associated changes, to the connecting loop of helices 10 and 11 to change catalytic metal ion coordination, which subsequently impacts cAMP catalysis and affinity toward certain metal-interacting inhibitors. this connecting loop, thereby changing the way helices 10 and 11 stabilize catalytic metal binding. Consequently, catalytic activity and metal-mediated inhibitor binding will be influenced. Vice versa, inhibitor binding can impact the ability of PDE4 forms to engage in protein-protein interactions via inside-out signaling, which supports the notion that conformational changes are relayed between the catalytic domain and N-terminal regions. (Terry et al., 2003; Day et al., 2011). Interestingly, as the LR2 region is not conserved among PDE4 subtypes, its effect on metal coordination through interaction with the helix 10-11 connecting loop may be different per PDE4 subtype. Indeed, deletion of the UCR2 and LR2 regions significantly decreases the sensitivity of PDE4D, but not PDE4A or PDE4B, to bind $\mathrm{Mg}^{2+}$ (Saldou et al., 1998).

PDE4 enzymes exhibiting increased activity are not analogous to increased inhibitor affinity, as interactions that do not increase PDE4 activity also influence inhibitor binding. Binding of the proteins XAP2 and Lyn enhances the sensitivity to rolipram but has a negative or no effect on PDE4 activity, respectively (Table 1) (McPhee et al., 1999; Bolger et al., 2003). Furthermore, it has been postulated that the HARBS conformer is constituted of long isoforms since their dimerized state stabilizes HARBS (Richter and Conti, 2004). However, HARBS is not dependent on dimerization or the presence of UCR 1 but rather is formed by inhibitor-UCR2 interactions, indicating that (super)short isoforms can also exhibit HARBS (Jacobitz et al., 1996). Indeed, truncated proteins similar to supershort forms that do possess the inhibitory UCR2 helix exhibit both HARBS and LARBS, whereas further deletion of the entire UCR2 only displays LARBS (Rocque et al., 1997a,b). These findings correspond to the fact that UCR2/LR2 residues may bind the connecting loop between helices 10 and 11 to regulate catalytic metal ion coordination. Absence of these residues would ablate the ability to change metal coordination and the consequent change in enzyme activity and metal-engaging inhibitor binding. Thus, both HARBS and LARBS comprise different states that depend on dimerization, degree of metal binding, interaction with partner proteins, and phosphorylation but which display similar affinities to inhibitors. Selective inhibition of PDE4 forms in HARBS or LARBS conformation has been shown to yield distinct biologic effects, although the exact PDE4 isoforms and/or conformation mediators remain to be specified. For example, inhibition of HARBS in the brain was found to produce antidepressant-like effects in rats (Zhang et al., 2006). Moreover, using PDE4 inhibitors that selectively bind HARBS or LARBS, Boomkamp et al. (2014) identified that inhibition of HARBS, but not LARBS, mediates myelination and neurite outgrowth in vitro. 
The notion that inhibitors can display divergent affinities toward isoforms in different conformational states and that conformation-specific inhibition can exert different biologic effects has implications for drug discovery and development. Hence, it is crucial to understand which isoforms, in what conformational state, should be targeted in the disease of interest that determine the most potent inhibitor (see also section IV. Phosphodiesterase 4 Inhibitors).

\section{E. Intracellular Phosphodiesterase 4 Localization and Anchoring}

1. A-Kinase Anchoring Proteins. In addition to activity-altering interactions, $\mathrm{PDE} 4$ engages in proteinprotein interactions that contribute to specific intracellular localization patterns. Accurate localization of PDE4 enzymes is crucial for the directed breakdown of compartmentalized cAMP. Many studies have indicated an essential role for A-kinase anchoring proteins (AKAP) in tethering signaling molecules regulating cAMP signaling, including PDE4 subtypes and isoforms [reviewed in, e.g., McConnachie et al. (2006), Wild and Dell'Acqua (2018), and Omar and Scott (2020)]. Through specific binding domains, the extensive collection of AKAPs allows the assembly of signaling modules consisting of PKA and PDE4 that are anchored to specific organelles, receptors [e.g., to the 5HT4b receptor (Weninger et al., 2014)], or cytoskeletal proteins (McConnachie et al., 2006). Important to note is that phosphorylation of the PDE4D3specific PKA site facilitates its binding to mAKAP, which localizes to the ryanodine receptor (Carlisle Michel et al., 2004; Lehnart et al., 2005). Additionally, as PKA is bound to AKAPs as well, tethering PDE4D3 to mAKAP also promotes phosphorylation of the common PKA site, causing PDE4 activation near the ryanodine receptor (Dodge et al., 2001). Moreover, PDE4D3 can be brought into contact with $\mathrm{I}_{\mathrm{K}}$ calciumactivated potassium channels through selectively binding AKAP9 (Terrenoire et al., 2009; Terrin et al., 2012). Interestingly, the PDE4 residues involved in binding AKAP $18 \delta$ are present in all isoforms, but tissue-specific expression causes only PDE4D3 and PDE4D9 to be associated with AKAP18 $\delta$ (also known as AKAP7) in the kidney, highlighting the importance of studying cellular-, tissue-, or disease-relevant PDE4 expression (Stefan et al., 2007). Furthermore, PDE4 has been shown to associate with AKAP450 (also known as AKAP350, centrosome and Golgi localized PKN-associated protein (CG-NAP), Hyperion, or Yotiao) (Tasken et al., 2001; McCahill et al., 2005), AKAP95 (AKAP8) (Asirvatham et al., 2004; Clister et al., 2019), AKAP3 (does not bind PDE4D) (Bajpai et al., 2006), myeloid translocation gene on chromosome 16 (MTG16B) (Asirvatham et al., 2004), AKAP149 (Asirvatham et al., 2004), AKAP5 (also known as AKAP79) (Choi et al., 2011; Kocer et al., 2012), and
Gravin (also called AKAP12, AKAP250, or Src-suppressed C kinase substrate (SSeCKS), which binds PDE4D3 and PDE4D5) (Willoughby et al., 2006). Although direct effects of AKAP binding on PDE4 activity remain largely undetermined, it is known that myomegalin (PDE4DIP) utilizes the same PDE4 residues that mediate UCR1-UCR2 interaction and dimerization and hence could influence the conformational state and activity of the bound PDE4 (Verde et al., 2001; Uys et al., 2011). Moreover, interactions between specific PDE4 forms and specific AKAPs may only occur in specific cell types or organs, as more specifically described elsewhere (Baillie et al., 2019; Zaccolo et al., 2021).

2. Not A-Kinase Anchoring Protein-Related. Independently of AKAPs, certain PDE4 isoforms can bind to specific structures through subtype- or isoform-specific amino acids. For example, the PDE4D4 and PDE4A4 isoforms have been found to localize to specific organelles and the plasma membrane through interactions with SRC homology 3 domains of the tyrosine kinases Lyn, Src, and Fyn via their N-terminal proline residues that possibly affect inhibitor binding (Table 1) (O'Connell et al., 1996; Beard et al., 1999, 2002; McPhee et al., 1999; Huston et al., 2000). Additionally, PDE4D4 is anchored to the cytoskeleton via interaction with $\alpha$ II spectrin (Creighton et al., 2008). The PDE4D-specific LR2 sequence allows interaction with integrin $\alpha 5$, which brings PDE4D in vicinity to a phosphatase that rectifies ERK-induced phosphorylation (Fig. 2) (Yun et al., 2016; Yun et al., 2019). The supershort PDE4A1 is membranebound via specific residues in its $\mathrm{N}$ terminus (Shakur et al., 1993; Baillie et al., 2002), and similar observations have been made for the short PDE4B2 isoform (Lobban et al., 1994). Likewise, PDE4A4 is associated with the membrane, but upon cleavage by caspase- 3 , it is redistributed within the membrane (Huston et al., 2000). Hence, post-translational modifications can alter intracellular distribution and compartmentalization, which is also supported by the fact that phosphorylation events can translocate membrane-associated PDE4 to the cytosol (Liu and Maurice, 1999). Through interactions in UCR1 and UCR2, mainly long PDE4D forms have been found to interact with Shank2 (Lee et al., 2007). As Shank2 also binds cystic fibrosis transmembrane conductance regulator (CFTR), this may explain the association of PDE4 enzymes with CFTR (Lee et al., 2007; Blanchard et al., 2014). Lastly, PDE4 enzymes can be intracellularly recruited to the $\mathrm{p} 75^{\mathrm{NTR}}$ and neuropilin receptors, which are involved in neuronal growth (Sachs et al., 2007; Ge et al., 2015; Houslay et al., 2019). Vice versa, PDE4 enzymes can modulate cellular signaling cascades through scaffolding other molecules away from their usual binding partners. This is exemplified by the fact that PDE4 can recruit lissencephaly-1 (LIS1), causing it to disassociate from dynein. Subsequently, dynein function will be impaired, causing changes in 
microtubule transport and directed cell migration (Murdoch et al., 2011). As many interactions between PDE4 and partner proteins rely on isoform-specific amino acid stretches, these interactions can localize PDE4 isoforms to distinct subcellular compartments. Consequently, different PDE4 isoforms may regulate spatially distinct cAMP signaling cascades, and isoform-specific PDE4 inhibition would enable more precise modulation of these different cAMP cascades.

\section{Phosphodiesterase 4 Inhibitors}

As an important cellular regulator of cAMP levels and associated intracellular signal transduction, PDE4 has been investigated as a therapeutic target in a wide variety of disorders. Based on promising observations upon treatment with nonselective PDE inhibitors and the prototypical PDE4-selective inhibitor rolipram, PDE4 inhibitors have been developed with improved potency. Despite increased potency, clinical progression of PDE4 inhibitors has been hampered primarily because of the occurrence of severe adverse side effects (see also below in section V. Adverse Effects of Phosphodiesterase 4 Inhibition). Therefore, to improve treatment efficacy and safety, PDE4 inhibitor specificity next to potency may have to be considered. As discussed above, the diversity in PDE4 isoforms that display distinct enzymatic properties, the amino acid differences among subtypes, and isoform-specific $\mathrm{N}$ termini allow for complex activity regulation by post-translational modifications and interactions with partner proteins. Eventually, this regulatory control can influence the enzyme's activity through conformational changes. These specific interactions, nonconserved amino acids, and distinct conformational states can provide the opportunity to target PDE4 activity more specifically at the subtype and isoform level.

This section will outline several aspects that should be considered when determining PDE4 inhibitor specificity toward subtypes or isoforms by providing an extensive overview of inhibitor screening literature. Furthermore, this section will summarize which PDE4 inhibitors have been developed to show more specific targeting of subtypes, isoform, and/or conformations.

\section{A. Phosphodiesterase 4 Inhibitors and High-Affinity and Low-Affinity Rolipram Binding Sites}

As mentioned above, HARBS and LARBS represent different conformational states that exhibit different inhibitor affinities and can be influenced through several mechanisms (e.g., metal binding, phosphorylation, or binding of partner proteins). Based on the observation that preferential inhibition of HARBS was correlated with adverse effects, efforts were made to develop PDE4 inhibitors with reduced HARBS binding (Barnette et al., 1995; Duplantier et al., 1996). Selective inhibition of HARBS or LARBS can produce distinct cellular effects, which provides additional support for improved therapeutic potential of conformation-specific inhibitors (Zhang et al., 2006; Boomkamp et al., 2014). However, HARBS and LARBS conformations can occur in all PDE4 subtypes, and HARBS seems to require a part of the UCR2 domain, suggesting that both long and short PDE4 isoforms can exert HARBS (Souness and Rao, 1997). Thus, although HARBS and LARBS can be preferentially bound by certain inhibitors, selective binding of these conformations does not directly allow for PDE4 subtype or isoform selectivity. However, as described in subsection III.D., HARBS and LARBS conformations may, in part, be a consequence of differences in the orientation of two helices that flank the catalytic domain and that coordinate the catalytic metals (Houslay and Adams, 2003). The positioning of these helices is likely impacted by LR2 residues, which are nonconserved among PDE4 subtypes. Associated with these PDE4 subtype-specific LR2 residues, changes in metal orientation between HARBS and LARBS may be different among the PDE4 subtypes, which is supported by subtype-specific sensitivities to $\mathrm{Mg}^{2+}$ depending on whether LR2 is present or not (Saldou et al., 1998). Hence, although highly speculative, it may be possible to alter PDE4 activity subtype-selectively by means of allosteric modulation in the LR2 region, which subsequently modifies enzyme activity through changes in metal orientation. In support of this hypothesis, the kinases CaMKII and the oxidative stress kinase both phosphorylate residues in the LR2 region and have been shown to modulate PDE4 activity (Fig. 2; Table 1) (Hill et al., 2006; Mika et al., 2015).

As PDE4 subtypes and isoforms regulate distinct cellular and behavioral functions, PDE4 subtype-selective inhibition, rather than preferential binding of HARBS or LARBS, may show superior treatment efficacy compared with nonselective PDE4 inhibition (Blackman et al., 2011; Zhang et al., 2017).

\section{B. Determining Phosphodiesterase 4 Inhibitor Subtype and Isoform Selectivity in Assays}

1. The Influence of Phosphodiesterase 4 Construct and Assay Type on Phosphodiesterase 4 Inhibitor Screenings. Given the importance of subtype-, isoform-, or conformation-specific inhibition for treatment efficacy and safety, it is crucial to assess these properties of PDE4 inhibitors. Initial high-throughput screenings often used the catalytic domain of a single PDE4 subtype only to determine the ability of a compound to inhibit PDE4 activity. Since these catalytic domain constructs may not express UCR2 domains, these enzymes do not resemble cellular PDE4 activity, as UCR2-mediated autoinhibition or capping is not possible. Furthermore, the lack of the UCR2 alters the $\mathrm{Mg}^{2+}$ sensitivity of the enzyme and could therefore 
skew screening results, as both enzyme activity and $\mathrm{Mg}^{2+}$-mediated inhibitor binding may be impacted (Saldou et al., 1998). Hence, compound screening for PDE4 inhibitory activity using the catalytic domain of a single PDE4 subtype only will provide limited insight into the compound's potential subtype selectivity. Subtype selectivity should therefore be assessed by using constructs of these different PDE4 subtypes and constituting a full-length protein rather than the catalytic domain only. Linked to this, as catalytic domains show large similarity among PDE4 subtypes, selectivity can more likely be achieved through interactions with amino acid residues outside of the catalytic domain (Wang et al., 2007a). Thus, to determine potential subtype selectivity of PDE4 inhibitors, the use of full-length PDE4 constructs will provide a better understanding compared with using only PDE4 catalytic domains.

PDE4 inhibitors can be tested in both cellular assays and assays utilizing purified PDE4, but affinity values cannot be directly compared across studies, as they are dependent on the used assay. For example, affinity values derived from assays using purified PDE4 versus overexpressed PDE4 constructs in a cellular assay can show an 80-fold difference (Wunder et al., 2013). Moreover, other studies showed that inhibitor affinity to isolated PDE4 enzymes does not reflect its potency in intact tissue (Harris et al., 1989). Furthermore, differences exist regarding which cell lines and heterologous expression systems are used for cellular assays or purified protein assays, respectively, which prevents comparison across studies that use different methodologies. Although assays using purified protein can provide a detailed understanding on the affinity and potency of an inhibitor, these assays do not reflect dynamic changes in (subtype-specific) PDE4 conformational states and associated affinity changes that would occur in a cellular environment. Hence, when assessing potential subtype specificity of PDE4 inhibitors, affinity values can only be compared within studies, and the most accurate approximation of in vivo PDE4 inhibition can be assessed by using full-length enzymes that contain all regulatory elements.

Table 2 provides a comprehensive overview of studies in which affinities of PDE4 inhibitors toward different PDE4 subtypes were assessed. As mentioned, affinity values, indicated as nanomolar concentrations that cause half-maximum inhibition $\left(\mathrm{IC}_{50}\right)$, cannot be compared across studies, as different assays may have been used. For each subtype construct, it is indicated whether a particular isoform was used and whether the construct entailed the full-length protein or was truncated. From this overview, it becomes evident that several studies have assessed compound selectivity for PDE4 subtypes by using constructs of different isoform categories (i.e., long, short, or supershort) per subtype. Several studies indicate that inhibitors can exhibit different affinities toward PDE4 subtypes. For example, cilomilast seems to show slightly higher affinity toward PDE4D, irrespective of whether truncated supershort or long isoforms are used (Huang et al., 2007; Asaka et al., 2010). Interestingly, many compounds show notably lower affinity toward PDE4C, whereas other compounds (e.g., UFM24) preferentially bind PDE4C (Tsai et al., 2017). As PDE4C shows the least homology with the other subtypes, PDE4C-specific residues therefore may either promote or impede inhibitor binding, yielding PDE4C-specific or PDE4C-aversive binding, respectively.

Importantly, subtype selectivity may seemingly be a result of or biased by preferred binding to an isoform of particular length rather than specificity to the PDE4 subtype. Since isoforms of different lengths exhibit different properties as a result of the presence or absence of regulatory domains (e.g., long forms can dimerize via UCR1-UCR2 interactions), isoform categories of the same PDE4 subtype may be preferentially bound by certain inhibitors. To reveal potential isoform-specific binding, Table 3 presents an overview of compounds that were tested, in the same assay, for their affinity toward PDE4 constructs of different lengths of the same PDE4 subtype. Various compounds show increased affinity toward the long isoforms compared with its catalytic domain only, in which the regulatory UCR1, UCR2, and C-terminal domains are deleted (Wunder et al., 2013). As these regulatory domains convey effects of post-translational modifications and interactions with partner proteins, these modifications and interactions themselves may exert an effect on inhibitor affinity within the same PDE4 isoform, as explained earlier. Indeed, for example, PKA phosphorylation has been shown to profoundly impact inhibitor affinity (Hoffmann et al., 1998), which supports the notion that assays using purified, nonphosphorylated enzyme cannot be compared with cellular assays in which PDE4 activity is dynamically regulated (Wunder et al., 2013). As certain modifications or interactions can only occur in specific PDE4 subtypes or isoforms to induce conformational changes (Fig. 2), these conformations actually provide other means of achieving more specific PDE4 inhibition. Therefore, it is crucial to understand how different conformational states, caused by modifications or interactions, impact inhibitor affinity.

Several studies have investigated these effects of conformational state on PDE4 inhibitor affinity, and these findings are summarized in Table 4. By means of mutations that mimic phosphorylation by PKA and ablate phosphorylation by ERK, the effects of PKA phosphorylation per se on inhibitor affinity can be simulated (Hoffmann et al., 1998; Burgin et al., 
TABLE 2

PDE4 inhibitors tested for their selectivity against different PDE4 subtypes

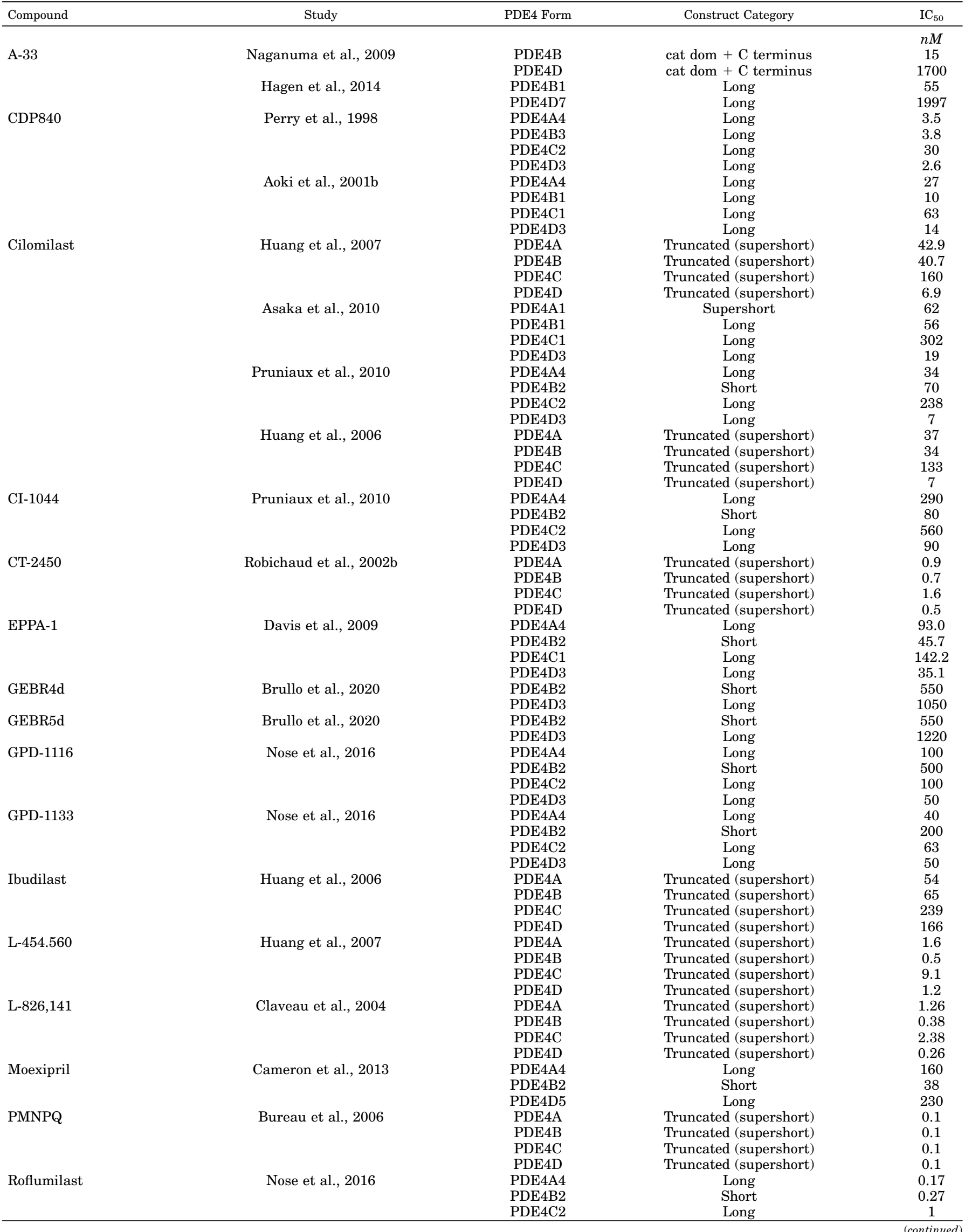


TABLE 2-Continued

\begin{tabular}{|c|c|c|c|c|}
\hline Compound & Study & PDE4 Form & Construct Category & $\mathrm{IC}_{50}$ \\
\hline & & PDE4D3 & Long & 0.15 \\
\hline & Claveau et al., 2004 & PDE4A & Truncated (supershort) & 0.16 \\
\hline & & PDE4B & Truncated (supershort) & 0.11 \\
\hline & & PDE4C & Truncated (supershort) & 0.61 \\
\hline & & PDE4D & Truncated (supershort) & 0.11 \\
\hline & Huang et al., 2007 & PDE4A & Truncated (supershort) & 0.16 \\
\hline & & PDE4B & Truncated (supershort) & 0.11 \\
\hline & & PDE4C & Truncated (supershort) & 0.61 \\
\hline & & PDE4D & Truncated (supershort) & 0.11 \\
\hline \multirow[t]{8}{*}{ Roflumilast N-oxide } & Claveau et al., 2004 & PDE4A & Truncated (supershort) & 0.58 \\
\hline & & PDE4B & Truncated (supershort) & 0.37 \\
\hline & & PDE4C & Truncated (supershort) & 3.2 \\
\hline & & PDE4D & Truncated (supershort) & 0.31 \\
\hline & Huang et al., 2007 & PDE4A & Truncated (supershort) & 0.58 \\
\hline & & PDE4B & Truncated (supershort) & 0.37 \\
\hline & & PDE4C & Truncated (supershort) & 3.2 \\
\hline & & PDE4D & Truncated (supershort) & 0.31 \\
\hline \multirow[t]{8}{*}{ Rolipram } & Aoki et al., 2001b & PDE4A4 & Long & 690 \\
\hline & & PDE4B1 & Long & 270 \\
\hline & & PDE4C1 & Long & 1900 \\
\hline & & PDE4D3 & Long & 260 \\
\hline & Asaka et al., 2010 & PDE4A1 & Supershort & 565 \\
\hline & & PDE4B1 & Long & 402 \\
\hline & & PDE4C1 & Long & 888 \\
\hline & & PDE4D3 & Long & 234 \\
\hline \multirow[t]{8}{*}{ R-rolipram } & Claveau et al., 2004 & PDE4A & Truncated (supershort) & 4.8 \\
\hline & & PDE4B & Truncated (supershort) & 5.4 \\
\hline & & PDE4C & Truncated (supershort) & 40.5 \\
\hline & & PDE4D & Truncated (supershort) & 3.9 \\
\hline & Perry et al., 1998 & PDE4A4 & Long & 84.4 \\
\hline & & PDE4B3 & Long & 69 \\
\hline & & $\mathrm{PDE} 4 \mathrm{C} 2$ & Long & 612 \\
\hline & & PDE4D3 & Long & 84.3 \\
\hline \multirow[t]{4}{*}{ RP73401 } & Aoki et al., 2001b & PDE4A4 & Long & 0.9 \\
\hline & & PDE4B1 & Long & 0.32 \\
\hline & & PDE4C1 & Long & 4.8 \\
\hline & & PDE4D3 & Long & 0.42 \\
\hline \multirow[t]{4}{*}{ TAS-203 } & Asaka et al., 2010 & PDE4A1 & Supershort & 47 \\
\hline & & PDE4B1 & Long & 35 \\
\hline & & PDE4C1 & Long & 227 \\
\hline & & PDE4D3 & Long & 43 \\
\hline \multirow[t]{4}{*}{ UFM24 } & Tsai et al., 2017 & PDE4A1 & Supershort & 7510 \\
\hline & & PDE4B2 & Short & 8580 \\
\hline & & PDE4C1 & Long & 1750 \\
\hline & & PDE4D2 & Supershort & 3530 \\
\hline \multirow[t]{4}{*}{ YM976 } & Aoki et al., 2001b & PDE4A4 & Long & 3.5 \\
\hline & & PDE4B1 & Long & 1 \\
\hline & & PDE4C1 & Long & 13 \\
\hline & & PDE4D3 & Long & 1.7 \\
\hline \multirow[t]{2}{*}{9} & Hagen et al., 2014 & PDE4B1 & Long & 770 \\
\hline & & PDE4D7 & Long & 5611 \\
\hline 29 & Hagen et al., 2014 & PDE4B1 & Long & 165 \\
\hline & & PDE4D7 & Long & 7 \\
\hline 5 & Skoumbourdis et al., 2009 & PDE4A1 & Supershort & 12.9 \\
\hline & & PDE4B1 & Long & 48.2 \\
\hline & & PDE4B2 & Short & 37.2 \\
\hline & & PDE4C1 & Long & 452 \\
\hline & & PDE4D2 & Supershort & 49.2 \\
\hline 10 & Skoumbourdis et al., 2009 & PDE4A1 & Supershort & 0.26 \\
\hline & & PDE4B1 & Long & 2.3 \\
\hline & & PDE4B2 & Short & 1.6 \\
\hline & & PDE4C1 & Long & 46 \\
\hline & & PDE4D2 & Supershort & 1.9 \\
\hline 18 & Skoumbourdis et al., 2009 & PDE4A1 & Supershort & 0.6 \\
\hline & & PDE4B1 & Long & 4.1 \\
\hline & & PDE4B2 & Short & 2.9 \\
\hline & & $\mathrm{PDE} 4 \mathrm{C} 1$ & Long & 106 \\
\hline & & PDE4D2 & Supershort & 2.1 \\
\hline $11 \mathrm{r}$ & Tang et al., 2019 & PDE4B1 & Long & 340 \\
\hline & & PDE4D7 & Long & 380 \\
\hline $16 \mathrm{a}$ & Huang et al., 2019 & PDE4B1 & Long & 293 \\
\hline & & PDE4D7 & Long & 312 \\
\hline 44 & Goto et al., 2014 & PDE4B2 & Short & 4.6 \\
\hline & & PDE4D2 & Supershort & 620 \\
\hline $5 a$ & Brullo et al., 2014 & PDE4B2 & Short & 1600 \\
\hline & & PDE4D3 & Long & 660 \\
\hline $10 \mathrm{~b}$ & Brullo et al., 2014 & PDE4B2 & Short & 18,000 \\
\hline
\end{tabular}




\begin{tabular}{|c|c|c|c|c|}
\hline Compound & Study & $\begin{array}{l}\text { ontinued } \\
\text { PDE4 Form }\end{array}$ & Construct Category & $\mathrm{IC}_{50}$ \\
\hline & & PDE4D4 & Long & 210 \\
\hline \multirow[t]{4}{*}{1} & Purushothaman et al., 2018 & PDE4A4 & Long & 45 \\
\hline & & PDE4B1 & Long & 31 \\
\hline & & PDE4C1 & Long & 77 \\
\hline & & PDE4D7 & Long & 220 \\
\hline \multirow[t]{4}{*}{2} & Purushothaman et al., 2018 & PDE4A4 & Long & 152 \\
\hline & & PDE4B1 & Long & 15 \\
\hline & & PDE4C1 & Long & 57 \\
\hline & & PDE4D7 & Long & 108 \\
\hline \multirow[t]{3}{*}{ A } & Manning et al., 1999 & PDE4A4 & Long & 6.46 \\
\hline & & PDE4B2 & Short & 14.13 \\
\hline & & PDE4D3 & Long & 39.81 \\
\hline \multirow[t]{3}{*}{ B } & Manning et al., 1999 & PDE4A4 & Long & 100.00 \\
\hline & & PDE4B2 & Short & 77.62 \\
\hline & & PDE4D3 & Long & 13.49 \\
\hline \multirow[t]{3}{*}{$\mathrm{C}$} & Manning et al., 1999 & PDE4A4 & Long & 33.11 \\
\hline & & PDE4B2 & Short & 30.20 \\
\hline & & PDE4D3 & Long & 295.12 \\
\hline \multirow[t]{3}{*}{$\mathrm{D}$} & Manning et al., 1999 & PDE4A4 & Long & 1318.26 \\
\hline & & PDE4B2 & Short & 316.23 \\
\hline & & PDE4D3 & Long & 257.04 \\
\hline \multirow[t]{3}{*}{$\mathrm{E}$} & Manning et al., 1999 & PDE4A4 & Long & 208.93 \\
\hline & & PDE4B2 & Short & 173.78 \\
\hline & & PDE4D3 & Long & 36.31 \\
\hline \multirow[t]{3}{*}{$\mathrm{F}$} & Manning et al., 1999 & PDE4A4 & Long & 63.10 \\
\hline & & PDE4B2 & Short & 57.54 \\
\hline & & PDE4D3 & Long & 11.75 \\
\hline \multirow[t]{3}{*}{ G } & Manning et al., 1999 & PDE4A4 & Long & 588.84 \\
\hline & & PDE4B2 & Short & 389.05 \\
\hline & & PDE4D3 & Long & 54.95 \\
\hline \multirow[t]{3}{*}{$\mathrm{H}$} & Manning et al., 1999 & PDE4A4 & Long & 1.23 \\
\hline & & PDE4B2 & Short & 1.51 \\
\hline & & PDE4D3 & Long & 10.96 \\
\hline \multirow[t]{3}{*}{ I } & Manning et al., 1999 & PDE4A4 & Long & 0.25 \\
\hline & & PDE4B2 & Short & 0.69 \\
\hline & & PDE4D3 & Long & 4.17 \\
\hline \multirow[t]{3}{*}{ J } & Manning et al., 1999 & PDE4A4 & Long & 0.27 \\
\hline & & PDE4B2 & Short & 1.35 \\
\hline & & PDE4D3 & Long & 3.98 \\
\hline
\end{tabular}

cat dom, catalytic domain.

2010). This phosphorylation-mimicking mutation profoundly increases the affinity of rolipram and BPN14770 to bind the long-form PDE4D7 (Zhang et al., 2018) (see Table 4), indicating that inhibitors can preferentially bind PKA-phosphorylated PDE4 states. Mechanistically, increased inhibitor affinity upon phosphorylation by PKA could be due to a more favorable positioning of UCR2, increased $\mathrm{Mg}^{2+}$ sensitivity to aid inhibitor binding, or a combination of both. Interestingly, although PDE4 phosphorylation by PKA also increases enzymatic activity as a biologic feedback loop, this feedback mechanism would actually facilitate or strengthen binding of these inhibitors. Since PKA-phosphorylated PDE4 displays higher enzymatic activity, preferential inhibition of this activated state may actually produce more potent effects on cAMP levels in an in vitro or in vivo setting. Conversely, as inhibitors may bind only the phosphorylated fraction of PDE4 forms, inhibition of nonphosphorylated PDE4 may be minimal, yielding only a partial inhibition of total PDE4 activity. Therefore, it is essential to consider the potency of
PDE4 inhibitors in addition to their affinity when determining which inhibitor, with its affinity profile against different PDE4 subtypes, isoforms, and conformations, shows the most therapeutic benefit in the disease of interest.

In addition to specific PDE4 phosphorylation, PDE4 isoforms can show different affinities toward inhibitors depending on whether these isoforms are located in the cytosol or have complexed with other cellular structures, as elaborately investigated by Houslay and collaborators (Bolger et al., 1997; Huston et al., 1996, 1997; Rena et al., 2001; Wallace et al., 2005). By subcellular fractionation, both cytosolic and particulate fractions of PDE4 forms can be separated, which can show differential affinities to inhibitors in an isoform-dependent manner (Table 4). Per cellular fraction, PDE4 isoforms may engage in different proteinprotein interactions, which subsequently can alter their conformation, leading to divergent effects on inhibitor affinity. Thus, based on its specific subcellular localization and local interactions or modifications, the same PDE4 isoform can adopt different 
TABLE 3

PDE4 inhibitors tested for their selectivity against different PDE4 isoforms or construct lengths of the same PDE4 subtype

\begin{tabular}{|c|c|c|c|c|c|}
\hline Compound & Study & Construct & Construct Category & Truncation/Modification & $\mathrm{IC}_{50}$ \\
\hline \multirow{5}{*}{ CDP840 } & \multirow{5}{*}{ Perry et al., 1998} & & & & $n M$ \\
\hline & & PDE4B2 & Short & & 1.9 \\
\hline & & PDE4B3 & Long & & 3.8 \\
\hline & & PDE4D2 & Supershort & & 2.9 \\
\hline & & PDE4D3 & Long & & 2.6 \\
\hline \multirow[t]{2}{*}{ Chlorbipram } & \multirow[t]{2}{*}{ Zhang et al., 2013} & PDE4B2 & Short & & 99,300 \\
\hline & & PDE4B5 & Supershort & & 8320 \\
\hline \multirow[t]{2}{*}{ Cilomilast } & \multirow[t]{2}{*}{ Wunder et al., 2013} & PDE4D3 & & cat dom & 20.5 \\
\hline & & PDE4D3 & Long & & 10.1 \\
\hline \multirow[t]{2}{*}{ Denbufylline } & \multirow[t]{2}{*}{ Owens et al., 1997a } & PDE4A4 & Long & & 295 \\
\hline & & PDE4A4 & cat dom & UCR1-UCR2 deleted & 550 \\
\hline D159153 & Wunder et al., 2013 & PDE4D3 & & cat dom & 20,500 \\
\hline & & PDE4D3 & Long & & 68.3 \\
\hline D159404 & Wunder et al., 2013 & PDE4D3 & & cat dom & 20,000 \\
\hline & & PDE4D3 & Long & & 380 \\
\hline Etazolate & Wunder et al., 2013 & PDE4D3 & & cat dom & 143 \\
\hline & & PDE4D3 & Long & & 240 \\
\hline GEBR-32a & Ricciarelli et al., 2017 & PDE4D1 & Short & & 4970 \\
\hline & & PDE4D2 & Supershort & & 2890 \\
\hline & & PDE4D3 & Long & & 2420 \\
\hline & & PDE4D5 & Long & & 3180 \\
\hline & & PDE4D7 & Long & & 1140 \\
\hline & Prosdocimi et al., 2018 & PDE4D & cat dom & cat dom, no C-term & 2300 \\
\hline & & PDE4D3 & Long & PKA-mimetic, ERK-ablative & 1000 \\
\hline$(S)-(+)-G E B R-32 a$ & Cavalloro et al., 2020 & PDE4D & cat dom & cat dom, no C-term & 19,500 \\
\hline & & PDE4D3 & Long & PKA-mimetic, ERK-ablative & 2100 \\
\hline$(R)-(-)-G E B R-32 \mathrm{a}$ & Cavalloro et al., 2020 & PDE4D & cat dom & cat dom, no C-term & 31,800 \\
\hline & & PDE4D3 & Long & PKA-mimetic, ERK-ablative & 15,500 \\
\hline GEBR-7b & Prosdocimi et al., 2018 & PDE4D & cat dom & cat dom, no C-term & 1600 \\
\hline & & PDE4D3 & Long & PKA-mimetic, ERK-ablative & 1100 \\
\hline GEBR-20b & Prosdocimi et al., 2018 & PDE4D & cat dom & cat dom, no C-term & 800 \\
\hline & & PDE4D3 & Long & PKA-mimetic, ERK-ablative & 600 \\
\hline GEBR-4a & Prosdocimi et al., 2018 & PDE4D & cat dom & cat dom, no C-term & 7000 \\
\hline & & PDE4D3 & Long & PKA-mimetic, ERK-ablative & 2100 \\
\hline GEBR-11b & Prosdocimi et al., 2018 & PDE4D & cat dom & cat dom, no C-term & 900 \\
\hline & & PDE4D3 & Long & PKA-mimetic, ERK-ablative & 400 \\
\hline GEBR-26g & Prosdocimi et al., 2018 & PDE4D & cat dom & cat dom, no C-term & 17,000 \\
\hline & & PDE4D3 & Long & PKA-mimetic, ERK-ablative & 3500 \\
\hline GEBR-54 & Prosdocimi et al., 2018 & PDE4D & cat dom & cat dom, no C-term & 20,000 \\
\hline & & PDE4D3 & Long & PKA-mimetic, ERK-ablative & 4600 \\
\hline GEBR-18b & Prosdocimi et al., 2018 & PDE4D & cat dom & cat dom, no C-term & 16,000 \\
\hline & & PDE4D3 & Long & PKA-mimetic, ERK-ablative & 4800 \\
\hline GEBR-18a & Prosdocimi et al., 2018 & PDE4D & cat dom & cat dom, no C-term & 23,000 \\
\hline & & PDE4D3 & Long & PKA-mimetic, ERK-ablative & 5000 \\
\hline Lirimilast & Wunder et al., 2013 & PDE4D3 & & cat dom & 3725 \\
\hline & & PDE4D3 & Long & & 54.3 \\
\hline Oglemilast & Wunder et al., 2013 & PDE4D3 & & cat dom & 0.5 \\
\hline & & PDE4D3 & Long & & 1.1 \\
\hline Piclamilast & Wunder et al., 2013 & PDE4D3 & & cat dom & 0.064 \\
\hline & & PDE4D3 & Long & & 0.12 \\
\hline PMNPQ & Wunder et al., 2013 & PDE4D3 & & cat dom & 115 \\
\hline & & PDE4D3 & Long & & 0.43 \\
\hline Roflumilast & Wunder et al., 2013 & PDE4D3 & & cat dom & 0.039 \\
\hline & & PDE4D3 & Long & & 0.076 \\
\hline Roflumilast $\mathrm{N}$-oxide & Wunder et al., 2013 & PDE4D3 & & cat dom & 0.079 \\
\hline & & PDE4D3 & Long & & 0.26 \\
\hline Rolipram & Bruno et al., 2009 & PDE4D1 & Short & & 910 \\
\hline & & PDE4D2 & Supershort & & 1170 \\
\hline & & PDE4D3 & Long & & 550 \\
\hline & Wunder et al., 2013 & PDE4D3 & & cat dom & 510 \\
\hline & & PDE4D3 & Long & & 72.8 \\
\hline & Zhang et al., 2013 & PDE4D4 & Long & & 470 \\
\hline & & PDE4D5 & Long & & 190 \\
\hline & Wang et al., 2003 & PDE4D6 & Supershort & & 57 \\
\hline & & PDE4D7 & Long & & 42 \\
\hline R-rolipram & Perry et al., 1998 & PDE4B2 & Short & & 60.5 \\
\hline & & PDE4B3 & Long & & 69 \\
\hline & & PDE4D2 & Supershort & & 26.9 \\
\hline & & PDE4D3 & Long & & 84.3 \\
\hline Ro20-1724 & Owens et al., 1997a & PDE4A4 & Long & & 1450 \\
\hline & & PDE4A4 & cat dom & UCR1-UCR2 deleted & 4154 \\
\hline YM976 & Wunder et al., 2013 & PDE4D3 & & cat dom & 0.34 \\
\hline & & PDE4D3 & Long & & 0.73 \\
\hline Zardaverine & Wunder et al., 2013 & PDE4D3 & & cat dom & 163 \\
\hline & & PDE4D3 & Long & & 65.3 \\
\hline
\end{tabular}




\begin{tabular}{|c|c|c|c|c|c|}
\hline \multirow[b]{2}{*}{ Compound } & \multirow[b]{2}{*}{ Study } & \multicolumn{2}{|c|}{ TABLE 3-Continued } & \multirow[b]{2}{*}{ Truncation/Modification } & \multirow[b]{2}{*}{$\mathrm{IC}_{50}$} \\
\hline & & Construct & Construct Category & & \\
\hline \multirow[t]{3}{*}{$4 \mathrm{a}$} & Bruno et al., 2009 & PDE4D1 & Short & & 7090 \\
\hline & & PDE4D2 & Supershort & & 9180 \\
\hline & & PDE4D3 & Long & & 2860 \\
\hline \multirow[t]{4}{*}{$4 \mathrm{e}$} & Liang et al., 2020 & PDE4B2 & Short & cat dom & 10 \\
\hline & & PDE4B1 & Long & & 8 \\
\hline & & PDE4D2 & Supershort & cat dom & 17 \\
\hline & & PDE4D7 & Long & & 9 \\
\hline
\end{tabular}

cat dom, catalytic domain; C-term, $\mathrm{C}$ terminus.

conformations that may be preferentially bound by certain inhibitors (e.g., the different affinities of rolipram toward particulate and cytosolic PDE4A4; Table 4). As such, these inhibitors can modulate PDE4 activity with different potency at the subcellular level.

2. Optimizing Phosphodiesterase 4 Inhibitor Screenings. The involvement of PDE4 in various cellular processes makes these enzymes attractive pharmacological targets, but it simultaneously makes nonspecific PDE4 inhibition prone to modulating unwanted biologic mechanisms. Hence, to optimize the efficacy and safety of PDE4 inhibitors, it is crucial to specify which PDE4 subtypes or isoforms are involved in the (disease-affected) cellular functions that are to be modified. In this subsection, we highlight how the choice of assay, target specification, and the use of "toolbox" compounds that apply distinct binding mechanisms can guide drug development toward safe and efficacious PDE4 subtype/isoform inhibition.

Firstly, considering that PDE4 enzymes can dynamically adopt several conformational states that can show different affinities to inhibitors, screening assays using purified PDE4 constructs are limited in predicting the inhibitory potential of a compound, as they assess affinities against a static, rather than a dynamic, enzyme. Hence, cell-based screening assays will more accurately indicate the PDE4 inhibitory potential of compounds when other influencing factors, including phosphorylation events, interactor proteins, and biologic feedback mechanisms, are present. When using cell-based assays, we argue it is essential to assess a PDE4-regulated phenotypical or physiologic readout that is relevant to a healthy or pathologic process of interest rather than an overall change in cAMP levels. Thus, the quality (i.e., cAMP elevation at the desired intracellular location) of PDE4 inhibition is more important than the quantity (i.e., profound cAMP elevation but not intracellularly confined) to achieve efficacious treatment while minimizing side effects. The use of cell-based assays that focus on a phenotypical or physiologic readout may also lead to discovery of efficacious PDE4 inhibitors with additional activity on other relevant targets, which would be undetectable in assays using solely purified PDE4 enzymes.

Using a cell-based, possibly disease-relevant, assay, experiments can be conducted to specify which PDE4 subtypes and isoforms regulate the chosen phenotypical or physiologic readout. By means of genetic knockout (e.g., using CRISPR-Cas9) or short-hairpin RNA-mediated knockdown, it can be specified which PDE4 subtypes or individual PDE4 isoforms regulate the biologic readout process. Conveniently, the typical PDE4 gene structures allow for targeting of isoforms selectively, as they each contain (parts of) a unique exon that can be targeted at the DNA level (e.g., using CRISPR-Cas9) or the transcript level (e.g., using short-hairpin RNA) (Fig. 1). Validation of the role of specific subtypes or isoforms in the chosen readout can be performed by overexpressing the subtype/isoform to assess whether it induces an opposite effect on the readout compared with subtype/isoform knockout. The involvement of specific isoforms in the process of interest can also be corroborated using a dominant-negative approach in which a catalytically inactive PDE4 form is being overexpressed. Subsequently, overexpressed inactive PDE4 isoforms will (partly) displace endogenous, active PDE4 isoforms, inducing local decreases in PDE4 activity. Functional roles of specific PDE4 isoforms have already been successfully identified using this approach (Perry et al., 2002; Campbell et al., 2017; Bolger et al., 2020). Although dominant-negative PDE4 forms can isoformspecifically displace endogenous forms, their overexpression may also cause excessive scaffolding of PDE4 interaction proteins that could alter cellular signaling. Hence, depending on the biologic mechanism of interest, validation of the role of specific PDE4 subtypes and isoforms may be best supported by a combination of the abovementioned strategies. Upon target specification and validation, drug design is suggested to be conducted in a structure-based manner. In case the functionally relevant PDE4 forms belong to a specific subtype, subtype-specific differences in PDE4 structure may be exploited to develop PDE4 subtypeselective inhibitors, as described in section C. Mechanisms for Phosphodiesterase 4 Subtype Selectivity: Interactions with Regulatory Domains.

Since there already exist PDE4 inhibitors that preferentially bind certain subtypes, isoforms, and/or conformations (Tables 2-4), these compounds can be used as toolbox compounds to determine which binding mechanism induces the most prominent effect on the assay readout. Parallel insights from the target validation approaches and use of toolbox compounds 
TABLE 4

PDE4 inhibitors tested for their selectivity against different PDE4 conformational states or PDE4 isoforms in different cellular fractions

\begin{tabular}{|c|c|c|c|c|c|}
\hline Compound & Study & Construct & Construct Category & Mutation/Modification/Cellular Fraction & $\mathrm{IC}_{50}$ \\
\hline & \multirow{5}{*}{ Fox et al., 2014} & & & & $n M$ \\
\hline \multirow[t]{4}{*}{ A-33 } & & PDE4B1 & Long & PKA-mimetic, ERK-ablative & 32 \\
\hline & & PDE4B1 & Long & L674Q, PKA-mimetic, ERK-ablative & 2035 \\
\hline & & PDE4D7 & Long & PKA-mimetic, ERK-ablative & 1569 \\
\hline & & PDE4D7 & Long & Q594L, PKA-mimetic, ERK-ablative & 21 \\
\hline \multirow[t]{5}{*}{ BPN14770 } & \multirow[t]{5}{*}{ Zhang et al., 2018} & PDE4D7 & Long & - & 1018 \\
\hline & & PDE4D7 & Long & PKA-mimetic, ERK-ablative & 7.8 \\
\hline & & PDE4D3 & Long & PKA-mimetic, ERK-ablative & 7.4 \\
\hline & & PDE4D2 & Supershort & ERK-ablative & 127 \\
\hline & & PDE4B1 & Long & PKA-mimetic, ERK-ablative & 2013 \\
\hline \multirow[t]{5}{*}{ Cilomilast } & \multirow[t]{5}{*}{ Wallace et al., 2005} & PDE4A11 & Long & Cytosolic & 34 \\
\hline & & PDE4A11 & Long & Particulate P2 & 34 \\
\hline & & PDE4A4 & Long & Cytosolic & 61 \\
\hline & & PDE4A4 & Long & Particulate P2 & 59 \\
\hline & & PDE4A10 & Long & Cytosolic & 130 \\
\hline \multirow[t]{5}{*}{ Denbufylline } & \multirow[t]{5}{*}{ Wallace et al., 2005} & PDE4A11 & Long & Cytosolic & 250 \\
\hline & & PDE4A11 & Long & Particulate P2 & 310 \\
\hline & & PDE4A4 & Long & Cytosolic & 560 \\
\hline & & PDE4A4 & Long & Particulate P2 & 460 \\
\hline & & PDE4A10 & Long & Cytosolic & 590 \\
\hline PMNPQ & Burgin et al., 2010 & PDE4D7 & Long & PKA-mimetic & 5 \\
\hline & & PDE4D7 & Long & PKA-mimetic, Phe196Ala & 170 \\
\hline & & PDE4D7 & Long & PKA-mimetic, Phe201Ala & 310 \\
\hline & & PDE4D7 & Long & PKA-mimetic, ERK-ablative & 0.52 \\
\hline & & PDE4D2 & Supershort & ERK-ablative & 0.66 \\
\hline & & PDE4B1 & Long & PKA-mimetic & 4.4 \\
\hline Roflumilast & Wallace et al., 2005 & PDE4A11 & Long & Cytosolic & 4.8 \\
\hline & & PDE4A11 & Long & Particulate P2 & 3.9 \\
\hline & & PDE4A4 & Long & Cytosolic & 9.0 \\
\hline & & PDE4A4 & Long & Particulate P2 & 2.5 \\
\hline & & PDE4A10 & Long & Cytosolic & 4.1 \\
\hline Rolipram & Zhang et al., 2018 & PDE4D7 & Long & - & 675 \\
\hline & & PDE4D7 & Long & PKA-mimetic, ERK-ablative & 32 \\
\hline & & PDE4D3 & Long & PKA-mimetic, ERK-ablative & 29 \\
\hline & & PDE4D2 & Supershort & ERK-ablative & 142 \\
\hline & & PDE4B1 & Long & PKA-mimetic, ERK-ablative & 175 \\
\hline & Huston et al., 1996 & PDE4A4 & Long & Particulate & 195 \\
\hline & & PDE4A4 & Long & Cytosolic & 1600 \\
\hline & Wallace et al., 2005 & PDE4A11 & Long & Cytosolic & 720 \\
\hline & & PDE4A11 & Long & Particulate P2 & 660 \\
\hline & & PDE4A4 & Long & Cytosolic & 1310 \\
\hline & & PDE4A4 & Long & Particulate P2 & 260 \\
\hline & & PDE4A10 & Long & Cytosolic & 64 \\
\hline & Rena et al., 2001 & PDE4A10 & Long & Particulate P1 & 54 \\
\hline & & PDE4A10 & Long & Particulate P2 & 52 \\
\hline & & PDE4A10 & Long & Cytosolic & 56 \\
\hline & Huston et al., 1997 & PDE4B1 & Long & Particulate P1 & 100 \\
\hline & & PDE4B1 & Long & Particulate P2 & 50 \\
\hline & & PDE4B1 & Long & Cytosolic & 80 \\
\hline & & PDE4B3 & Long & Particulate P1 & 140 \\
\hline & & PDE4B3 & Long & Particulate P2 & 100 \\
\hline & & PDE4B3 & Long & Cytosolic & 50 \\
\hline & & PDE4B2 & Short & Particulate P1 & 180 \\
\hline & & PDE4B2 & Short & Particulate P2 & 210 \\
\hline & & PDE4B2 & Short & Cytosolic & 20 \\
\hline & Bolger et al., 1997 & PDE4D1 & Short & Particulate P2 & $\mathrm{n} / \mathrm{a}$ \\
\hline & & PDE4D1 & Short & Cytosolic & 50 \\
\hline & & PDE4D2 & Supershort & Particulate P2 & $\mathrm{n} / \mathrm{a}$ \\
\hline & & PDE4D2 & Supershort & Cytosolic & 50 \\
\hline & & PDE4D3 & Long & Particulate P2 & 320 \\
\hline & & PDE4D3 & Long & Cytosolic & 140 \\
\hline & & PDE4D4 & Long & Particulate P2 & 50 \\
\hline & & PDE4D4 & Long & Cytosolic & 60 \\
\hline & & PDE4D5 & Long & Particulate P2 & 590 \\
\hline & & PDE4D5 & Long & Cytosolic & 80 \\
\hline Ro $20-1724$ & Wallace et al., 2005 & PDE4A11 & Long & Cytosolic & 990 \\
\hline & & PDE4A11 & Long & Particulate P2 & 910 \\
\hline & & PDE4A4 & Long & Cytosolic & 2930 \\
\hline & & PDE4A4 & Long & Particulate P2 & 2900 \\
\hline & & PDE4A10 & Long & Cytosolic & 1240 \\
\hline RS25344 & Burgin et al., 2010 & PDE4D7 & Long & PKA-mimetic & 19 \\
\hline & & PDE4D7 & Long & PKA-mimetic, Phe196Ala & 4.1 \\
\hline & & PDE4D7 & Long & PKA-mimetic, Phe201Ala & 6.2 \\
\hline & & PDE4D7 & Long & PKA-mimetic, ERK-ablative & 0.91 \\
\hline & & PDE4D2 & Supershort & ERK-ablative & 0.81 \\
\hline & & PDE4B1 & Long & PKA-mimetic & 9.4 \\
\hline
\end{tabular}




\begin{tabular}{|c|c|c|c|c|c|}
\hline Compound & Study & Construct & $\begin{array}{l}\text { E 4-Continued } \\
\text { Construct Category }\end{array}$ & Mutation/Modification/Cellular Fraction & $\mathrm{IC}_{50}$ \\
\hline \multirow{4}{*}{ RS33793 } & \multirow{2}{*}{ Alvarez et al., 1996} & PDE4D3 & Long & - & 3.16 \\
\hline & & PDE4D3 & Long & PKA-mimetic & 0.5 \\
\hline & \multirow{2}{*}{ Alvarez et al., 1996} & PDE4D3 & Long & - & 39.8 \\
\hline & & PDE4D3 & Long & PKA-mimetic & 0.2 \\
\hline
\end{tabular}

n/a, not applicable.

would eventually provide the insight and understanding to develop PDE4 inhibitors that apply a particular binding mode to selectively bind and inhibit the most relevant PDE4 forms to subsequently efficaciously attenuate a biologic dysfunction of interest.

\section{Mechanisms for Phosphodiesterase 4 Subtype Selectivity: Interactions with Regulatory Domains}

1. Interactions with the Upstream Conserved Region 2. Although the different subtypes possess highly similar catalytic domains, subtle amino acid differences exist in regulatory regions (i.e., UCR2 and C terminus) that can be positioned across the catalytic pocket. When the UCR2 is capped, certain residues can interact with inhibitors as their side chains extend into the catalytic domain (Fig. 3; Supplemental Video). UCR2 capping is postulated to occur via intermolecular actions in long, dimerized PDE4 isoforms in which the UCR2 of one monomer folds across the catalytic domain of the other monomer (Cedervall et al., 2015). As the UCR2 also is autoinhibitory in monomeric, short PDE4D1, intramolecular UCR2 capping may also occur (Kovala et al., 1997). Irrespective of whether UCR2 capping occurs in trans (intermolecularly) or in cis (intramolecularly), inhibitors can engage in interactions with UCR2 residues. Intriguingly, in primates, a polymorphism has occurred in PDE4D leading to the expression of a phenylalanine instead of tyrosine in the UCR2 region. This subtypespecific difference has been successfully exploited, and validated by mutation studies, to generate PDE4D-selective inhibitors (e.g., BPN14770) that interact with the PDE4D-specific phenylalanine in the UCR2 region (Table 4) (Burgin et al., 2010). Interestingly, Gurney et al. (2019) have shown that certain compounds that use UCR2 for binding, like BPN14770, behave as partial inhibitors. It is hypothesized that, in dimerized PDE4, through inhibitor-UCR2 interactions at one monomer, the other UCR2 cannot effectively trans-cap the other monomer. Since this UCR2-capping is involved in compound binding, inhibitor binding at this monomer will be reduced, resulting in overall partial inhibition. Conversely to binding the UCR2 phenylalanine, inhibitors can preferentially interact with the tyrosine residue in PDE4A-C, producing PDE4D-sparing actions, as reported for ABI-4 (PF-06266047) (Hedde et al., 2017). Notably, several classes of PDE4 inhibitors have been found to stabilize a UCR2-capped state, as elaborately indicated by Day et al. (2011). Although PDE4 modifications and protein-protein interactions can influence inhibitor affinity by influencing UCR2-capping, stabilization of UCR2 capping by certain inhibitors can, conversely, also alter the conformation of regulatory domains that affect PDE4 modifications and interactions (Terry et al., 2003). In the case of PDE4A4, stabilization of UCR2 capping by inhibitor binding causes its intracellular redistribution, demonstrating that inhibitor binding can induce additional cellular changes next to elevation of local cAMP levels (Day et al., 2011). This use of UCR2 by certain compounds makes their affinity also dependent on post-translational modifications and interactions with partner proteins as they can influence the UCR2 capping state, as explained before.

2. Interactions with the C Terminus. Similar to the use of UCR2 residues to achieve subtype selectivity, amino acid differences in the $\mathrm{C}$ terminus can be employed to achieve subtype-specific inhibitor binding. Through interactions with residues unique to the PDE4B C terminus, PDE4B selectivity has been achieved for the compounds A33 and a tetrahydrobenzothiophene inhibitor (see Table 4) (Kranz et al., 2009; Naganuma et al., 2009; Fox et al., 2014). The C terminus is capped across the catalytic domain in an intramolecular manner, as the linker region between the $\mathrm{C}$ terminus and the catalytic domain is too short to achieve capping the other monomer in a PDE4 dimer. Inhibitors that employ $\mathrm{C}$ terminus residues may therefore preferentially bind capped over uncapped states producing a degree of conformation-dependent binding. As both UCR2 and C terminus capping are dependent on multiple cellular events, including phosphorylation or interactions with partner proteins, conformation-dependent inhibitors may bind PDE4 in a selective spatial and/or temporal manner.

\section{Stereoisomerism and Metabolites of Phosphodiesterase 4 Inhibitors}

In 1983, it had already been described that the enantiomer $(R)$-rolipram and racemic rolipram are more potent in increasing cerebral cAMP levels than $(S)$-rolipram (Wachtel, 1983a,b; Schneider, 1984). Accordingly, several studies have indicated that $(R)$-rolipram shows higher PDE4 affinity than $(S)$-rolipram (Torphy et al., 1992; Barnette et al., 1996; Laliberte et al., 2000). This suggests that stereoisomerism of PDE4 inhibitors can influence the inhibitor's affinity depending on whether a racemic mixture or purified enantiomer is tested. Both $(R)$-rolipram and $(S)$ - 
rolipram seem to exhibit similar binding modes in PDE4D2 crystal structures, but increased affinity of $(R)$-rolipram may be conveyed via other isoforms and/ or conformational states than those captured by the reported crystal structures (Huai et al., 2003). Indeed, rolipram can adopt a slightly different conformation in crystals that include UCR2 domains (Cedervall et al., 2015). For another set of enantiomeric inhibitors (L-869298 and L-869299), stereochemistry does change the binding mode in a $\mathrm{Mg}^{2+}$-interacting manner, which is concurrent with differences in affinity (Huai et al., 2006). Next to the aforementioned enantiomeric inhibitors, also for the PDE4D-selective inhibitor GEBR32a, different affinities are reported for its enantiomers (Table 3) (Cavalloro et al., 2020). Hence, in the case of racemic inhibitors, it has to be considered that enantiomers can exhibit different binding modes and affinities for specific PDE4 conformations. Consequently, certain enantiomers may display favorable pharmacological properties superior to its racemic mixture. Enantiomer-specific effects can provide important insights into the molecular binding modes crucial for efficacy and can subsequently facilitate pharmacophore determination and inhibitor optimization.

Similar to the use of racemic PDE4 inhibitor mixtures, metabolism of administered PDE4 inhibitors can produce multiple metabolites that each show differences in their binding mode and affinity. For example, the PDE4 inhibitor roflumilast is metabolized into roflumilast $\mathrm{N}$-oxide, which shows distinct subtype selectivity compared with roflumilast itself (Tables 2 and 3) (Claveau et al., 2004; Huang et al., 2007; Wunder et al., 2013). The inhibitory potential of inhibitor metabolites on PDE4 activity should therefore be taken into account as combined actions of PDE4 inhibitors, and its metabolites may cause certain PDE4 subtypes, isoforms, or conformations to be more potently inhibited in vivo, resulting in a more favorable or unfavorable pharmacological profile.

\section{E. Modulators of Phosphodiesterase 4 Activity}

Next to PDE4 inhibitors, molecules have been described that influence PDE4 activity in a noninhibiting manner. For example, atropine, a muscarinic acetylcholine receptor antagonist, has been described to allosterically inhibit PDE4 while also potentiating rolipram binding (Perera et al., 2017). These effects correspond to those of modulation by several intracellular factors as discussed above in section III. Phosphodiesterase 4 Modifications and Interactions. In contrast to allosterically inhibiting molecules, PDE4 activity can also be stimulated through allosteric binding. For example, early studies by the Conti and coworkers showed that binding of antibodies targeting the UCR2 autoinhibitory domain increased PDE4 activity similar to phosphorylation by PKA (Conti et al., 1995; Lim et al., 1999).

More recently, also small molecules have been described that increase PDE4 activity through allosteric binding (Omar et al., 2019). More specifically, these compounds bind and activate long, dimerized PDE4 and thereby mimic the activating actions of PKA. This mechanistic similarity of activation is further supported by the inability of these small molecules to increase activity in PKA-mimicking PDE4 mutants. Hence, these small molecule allosteric activators have therapeutic utility in disorders in which cAMP signaling is aberrantly increased. For example, in autosomal dominant polycystic kidney disease, elevated cAMP levels promote the formation of cysts. Omar et al. (2019) have demonstrated that the use of allosteric activators can successfully diminish cyst formation in cell models of autosomal dominant polycystic kidney disease. It can be speculated that allosteric PDE4 activators also have therapeutic applicability in other disorders displaying elevated cAMP signaling, such as the genetic condition McCune-Albright syndrome, in which gain-of-function Gs $\alpha$ subunit mutations lead to exaggerated cAMP synthesis (Levine, 1999; Innamorati et al., 2018). Hence, PDE4 enzymes have therapeutic utility as pharmacological targets in both conditions displaying reduced and conditions displaying heightened levels of cAMP.

Lastly, PDE4 peptide fragments have been developed that can either stimulate PDE4 activity (Wang et al., 2015) or reduce activation by scavenging the PDE4-activating phosphorylation by Cdk5 (Plattner et al., 2015).

\section{Adverse Effects of Phosphodiesterase 4 Inhibition}

Although PDE4 inhibition shows therapeutic potential in a variety of disease areas, clinical exploitation of PDE4 inhibitors has often been held back by dose limitations caused by adverse side effects. Side effects upon PDE4 inhibitor administration are mainly gastrointestinal in nature (i.e., nausea, vomiting and diarrhea), but headaches and dizziness have also been reported (Compton et al., 2001). These side effects may be overcome by more precise targeting of PDE4 subtypes, isoforms, or conformational states. Accordingly, subtype-selective PDE4 inhibitors have been developed that exploit subtle sequence differences and distinct conformational states that may result from different PDE4 lengths and specific interactions and modifications (Burgin et al., 2010; Fox et al., 2014; Hedde et al., 2017). While this allows for more precise targeting, insight into which PDE4 subtypes or isoforms mediate unwanted effects is therefore crucial to understand which subtypes/conformations not to target. This section will discuss PDE4 expression 
and functionality in brain and bodily areas, and potential molecular mechanisms related to the different PDE4-mediated side effects. In addition, an overview is provided of those PDE4 inhibitors that have been tested for possible adverse side effects.

\section{A. Hypothermia}

Several preclinical studies using mice, rats, and guinea pigs have demonstrated that PDE4 inhibitors can induce hypothermia (Wachtel, 1983a,b,c; McDonough et al., 2020b). These effects seem to be regulated via PDE4-mediated dopamine signaling in the hypothalamus, which is supported by the fact that PDE4 inhibitors that enter the brain with difficulty have less profound effects on body temperature (McDonough et al., 2020b). Although not explicitly described as an adverse side effect in humans, hypothermia may contribute to uncomfortable feelings during treatment with PDE4 inhibitors.

\section{B. Dizziness}

PDE4 inhibition has also been reported to cause dizziness (Blokland et al., 2019). In cochlear and vestibular nuclei in the brainstem, PDE4D was found to be expressed higher than other PDE4 subtypes (Iwahashi et al., 1996; Perez-Torres et al., 2000). More specifically, PDE4D1, PDE4D2, and PDE4D3 mRNA was expressed in the rat dorsal cochlear and vestibular nuclei (Miro et al., 2002b). As the cochlear and vestibular nuclei relay signaling from the inner ear, altered cAMP modulation by PDE4 inhibition in these areas may provoke feelings of dizziness and, through subsequent signaling to other brains stem areas, promote nausea and emesis. Interestingly, in the vestibular apparatus in the inner ear itself, PDE4D is expressed, and rolipram induces endolymphatic hydrops in the mouse, which is associated with feelings of dizziness (Nakashima et al., 2016; Degerman et al., 2017).

\section{Gastrointestinal}

1. Diarrhea. Concerning effects of PDE4 inhibition on the gastrointestinal system, diarrhea has been reported as an adverse effect. Through PKA-dependent activation of the CFTR, PDE4 inhibition may cause diarrhea by elevating intestinal $\mathrm{Cl}^{-}$secretion (Chao et al., 1994). Specifically, PDE4D may mediate this effect upon PDE4 inhibition, as PDE4D has been found to be recruited to CFTR via binding the scaffolding protein Shank2 (Lee et al., 2007). Moreover, PDE4 inhibition can facilitate 5HT4 receptor-mediated acetylcholine release, causing contraction of large intestinal circular smooth muscle (Pauwelyn et al., 2018). Specifically, the PDE4D3 and PDE4D5 isoforms have been found to associate with 5HT4(b) receptors and may, therefore, be involved in gastrointestinal effects caused by PDE4(D) inhibition
(Weninger et al., 2014). Despite the fact that diarrhea has been reported as a PDE4-mediated adverse event, it is striking that roflumilast has actually been found to exhibit antidiarrheal effects in mice, which may be associated with antispasmodic actions of roflumilast in the jejunum (Rehman et al., 2020).

2. Nausea and Emesis. Regarding nausea and emesis, PDE4 actions within both the central nervous and gastrointestinal systems seem to be involved. In an early study, intravenous administration of rolipram and Ro20-1724 was found to increase gastric acid and pepsin secretion in anesthetized rats (Puurunen et al., 1978). Correspondingly, Lamontagne et al. (2001) suggested that, in the stomach, pepsinogen-releasing chief cells primarily express the PDE4D subtype, whereas acid-releasing parietal cells expressed PDE4A. Moreover, binding of specifically HARBS configurations in gastric glands showed strong correlation with the degree of gastric acid secretion (Barnette et al., 1995). Interestingly, gastric transit was found to be more strongly inhibited by roflumilast than by a selective PDE4B inhibitor, which may suggest PDE4B inhibition contributes relatively little to gastric side effects (Suzuki et al., 2013). Recently, it was shown that nonselective PDE4 inhibition induces gastroparesis (i.e., delayed gastric transit) in mice (McDonough et al., 2020a). More importantly, this study showed that genetic ablation of any of the four PDE4 subtypes does not affect gastroparesis or protect against inhibitor-induced gastroparesis, which suggests that two or more PDE4 subtypes contribute to PDE4-mediated gastroparesis. As gastroparesis is strongly associated with nausea and emesis in humans, this physiologic effect of PDE4 inhibition warrants further investigation as a possible predictive measure for the side effect profile of PDE4 inhibitors (Grover et al., 2019).

Although PDE4 inhibition causes profound local gastric effects, emesis is eventually effectuated through signaling in brainstem nuclei such as the nodose ganglion, area postrema (AP), and nucleus tractus solitarius (NTS) (Miller and Leslie, 1994; du Sert et al., 2012). In the nodose ganglion of the squirrel monkey, cell bodies of gastric vagal nerve fibers can be found in which predominantly PDE4D is present compared with lower expression levels of PDE4C or long PDE4A forms (Lamontagne et al., 2001). Similarly, the AP and NTS were found to mainly express PDE4D and, to a lesser extent, PDE4B in mouse (Cherry and Davis, 1999), rat (Iwahashi et al., 1996; Takahashi et al., 1999; Perez-Torres et al., 2000), and human brain (Mori et al., 2010). PDE4D expression was also found in medulla oblongata neurons that are innervated by substance $P$, which has been reported to be involved in emetic responses upon PDE4 inhibition (Robichaud et al., 1999; Lamontagne et al., 
2001). At the PDE4D transcript variant level, mRNA of PDE4D1 and PDE4D4 showed high expression in the rat AP compared with lower levels of PDE4D2 and PDE4D5 and absence of PDE4D3. Furthermore, low levels of PDE4D2, PDE4D4, and PDE4D5 were detected in the NTS (Miro et al., 2002b). Strikingly, in another study by Miro et al. (2002a), no PDE4D4 mRNA was detected in the rat AP. Human data regarding PDE4D mRNA content in the AP also suggest that PDE4D4 is not abundantly present, and the highest expression was found for PDE4D3 and PDE4D9 (Vanmierlo et al., 2019).

In addition to localization studies showing high expression of PDE4D in emesis-related brainstem areas, mechanistically, PDE4D also seems to mediate emetic responses. In a study by Robichaud et al., (2002b), PDE4D, but not PDE4B, knockout mice displayed reduced sleeping time under xylazine/ketamine-induced anesthesia, a measure of emetic-like behavior. Furthermore, the PDE4 inhibitor PMNPQ did reduce anesthesia duration in wild-type and PDE4B-deficient mice but not in PDE4D-deficient mice, which again indicates an involvement of PDE4D in emetic-like behavior. Xylazine/ketamine-induced anesthesia assesses emetic-like behavior in nonvomiting species through $\alpha 2$-adrenergic receptor antagonism (Robichaud et al., 2001; Robichaud et al., 2002a; Nelissen et al., 2019). The involvement of PDE4D in this mechanism corresponds with the expression of both $\alpha 2$ adrenoceptor and PDE4D mRNA in the NTS (Scheinin et al., 1994; Lamontagne et al., 2001). However, PDE4A and PDE4B also seem to mediate $\alpha 2$-dependent signaling, at least in retinal rod bipolar cells (Dong et al., 2014). PDE4 inhibitors may enhance neuronal firing in both the AP and NTS of rats, as higher expression of the neuronal activity marker Fos was observed in these regions upon administration of rolipram or PMNPQ in rats (Bureau et al., 2006). Accordingly, AP neurons could be excited by cAMP, which would be elevated upon inhibitor administration (Carpenter et al., 1988). Notably, AP neurons exhibit a hyperpolarization-activated cation current $\left(\mathrm{I}_{\mathrm{h}}\right)$ that acts as pacemaker current and is found to be activated through stimulation of cAMP signaling (Funahashi et al., 2003). Consequently, PDE4 inhibition may increase the frequency of this pacemaker current, leading to an increased firing rate. Actually, the influence of PDE4 on pacemaker currents has already been demonstrated in the sinoatrial node of the heart (St Clair et al., 2017). The xylazine/ketamine-induced anesthesia test suggests that PDE4 inhibition alters $\mathrm{AP}$ activity through antagonizing $\alpha 2$-adenergic receptor signaling (Nelissen et al., 2019). Accordingly, $\alpha 2$ adrenergic receptor stimulation was shown to inhibit cAMP and close hyperpolarized cyclic nucleotide-gated channels (Wang et al., 2007b). Vice versa, PDE4 inhibition could enhance cAMP, open hyperpolarized cyclic nucleotide-gated channels, increase hyperpolarization-activated currents $\left(\mathrm{I}_{\mathrm{h}}\right)$, and increase the firing rate of AP neurons, leading to an emetic response. Anesthesia induced by injecting an $\alpha 2$-adrenergic agonist into the locus coeruleus, which innervates the $\mathrm{AP}$, of rats could be reversed by rolipram. However, pretreatment of a PKA inhibitor blocked the effects of rolipram, suggesting emetogenic effects by PDE4 inhibitors are mediated through actions requiring cAMP-PKA signaling (Correa-Sales et al., 1992). Moreover, phosphorylation of PKA and ERK, downstream kinases of cAMP, was found to be highest during peak emesis in AP neurons (Zhong and Darmani, 2017).

These findings support the notion that PDE4-mediated cAMP signaling and its downstream effectors contribute to emetic behavior. Still, the exact mechanism underlying these adverse side effects caused by PDE4 inhibitors remains to be resolved. Since the AP may in part be outside of the blood-brain barrier, emetic effects can be dependent on both peripheral and central actions (Miller and Leslie, 1994). Based on the gene deletion and localization studies discussed above, PDE4D seems to be involved in central and peripheral actions, leading to the induction of emesis. However, emetic(-like) effects cannot be attributed entirely to PDE4D, as the PDE4D-selective inhibitors GEBR32a, V11294A, and BPN14770 appear to be well tolerated in animals and/or healthy volunteers [NCT02648672] [NCT02840279] (Rogers and Giembycz, 1998; Gale et al., 2002, 2003; Sutcliffe et al., 2014; Ricciarelli et al., 2017). It is likely that multiple PDE4 subtypes and isoforms in different bodily tissues contribute collectively to PDE4-associated side effects, as also suggested by Richter and colleagues (McDonough et al., 2020a). Hence, subtype- or isoform-selective PDE4 inhibitor may yield less severe side effects. As PDE4 subtypes and isoforms have nonredundant roles and show specific intracellular localization, certain subtypes or isoforms may be specifically involved in mechanisms that eventually evoke unwanted effects. The potency of the inhibitor to inhibit these particular isoforms would then explain their potency to induce adverse effects. However, which exact PDE4 subtypes and isoforms mediate these processes remains to be determined. Another explanation may lie in the differential affinities of the compound to different PDE4 conformational states. Indeed, correlations have been found between the degree of binding HARBS and emetic effects (Duplantier et al., 1996; Christensen et al., 1998; Hirose et al., 2007). Inhibitors that preferentially target LARBS or show no preference would therefore be safer, which is supported by the relatively low emetogenicity of cilomilast and roflumilast (Davis et 
TABLE 5

PDE4 inhibitors tested for their potential to induce emesis-like behavior (rodents) or emesis compared with rolipram

\begin{tabular}{|c|c|c|c|c|c|c|}
\hline Compound & Emetic(-like) Dose & $\begin{array}{c}\text { Emetic(-like) } \\
\text { Dose Ratio to Rolipram }\end{array}$ & $\begin{array}{c}\text { Administration } \\
\text { Route }\end{array}$ & Species & Test & Study \\
\hline Rolipram & $\begin{array}{c}\mu g / k g \\
300\end{array}$ & - & Intraperitoneal & Mouse & $\begin{array}{l}\text { Xylazine/ketamine/ } \\
\text { anesthesia test }\end{array}$ & Vanmierlo et al., 2016 \\
\hline Roflumilast & 3000 & 10 & & & & \\
\hline R-rolipram & 100 & - & Subcutaneous & Mouse & $\begin{array}{l}\text { Xylazine/ketamine/ } \\
\text { anesthesia test }\end{array}$ & Robichaud et al., $2002 b$ \\
\hline S-rolipram & 1000 & 10 & & & & \\
\hline PMNPQ & 1 & 0.01 & & & & \\
\hline CT-2450 & $>30,000$ & $>300$ & & & & \\
\hline Rolipram & 100 & - & Intravenous & Mouse & $\begin{array}{l}\text { Xylazine/ketamine/ } \\
\text { anesthesia test }\end{array}$ & Burgin et al., 2010 \\
\hline D157140 & 10 & 0.1 & & & & \\
\hline D158681 & $>1000$ & $>10$ & & & & \\
\hline D159153 & 100 & 1 & & & & \\
\hline D159382 & 30 & 0.3 & & & & \\
\hline D159404 & $>3000$ & $>30$ & & & & \\
\hline D159687 & $>3000$ & $>30$ & & & & \\
\hline Rolipram & 30 & - & Subcutaneous & Mouse & $\begin{array}{l}\text { Xylazine/ketamine/ } \\
\text { anesthesia test }\end{array}$ & Ricciarelli et al., 2017 \\
\hline GEBR32a & $>3000$ & $>30$ & & & & \\
\hline Rolipram & 30 & - & Subcutaneous & Mouse & $\begin{array}{l}\text { Xylazine/ketamine/ } \\
\text { anesthesia test }\end{array}$ & Bruno et al., 2011 \\
\hline GEBR7b & 300 & 10 & & & & \\
\hline Rolipram & 500 & - & Intragastric & Mouse & $\begin{array}{l}\text { Xylazine/ketamine/ } \\
\text { anesthesia test }\end{array}$ & Zhou et al., 2017 \\
\hline $10 \mathrm{j}$ & $>1500$ & $>3$ & & & & \\
\hline Rolipram & 800 & - & Oral & Dog & Emesis incidence & Zhou et al., 2017 \\
\hline Rolipram & $\begin{array}{c}>800 \\
400\end{array}$ & $\begin{array}{l}>1 \\
-\end{array}$ & Oral & Rat & Pica feeding & Davis et al., 2009 \\
\hline Roflumilast & 1570 & $>\overline{3.5}$ & Ural & năt & Fica leeuing & Davis el di., zuvy \\
\hline Cilomilast & 6410 & $>16$ & & & & \\
\hline EPPA-1 & 24,260 & $>60$ & & & & \\
\hline Rolipram & 500 & - & Oral & Dog & Emesis incidence & Zhang et al., 2013 \\
\hline Chlorbipram & $>1000$ & $>2$ & & & & \\
\hline $\begin{array}{l}\text { Chlorbipram } \\
\text { hydrochloride }\end{array}$ & $>1070$ & $>2$ & & & & \\
\hline Rolipram & $<100$ & - & Oral & Dog & Emesis incidence & Nose et al., 2016 \\
\hline Roflumilast & 500 & $>5$ & & & & \\
\hline GPD-1116 & 1000 & $>10$ & & & & \\
\hline Rolipram & 3000 & - & Oral & Ferret & Emesis incidence & Aoki et al., 2001b \\
\hline YM976 & 30,000 & 10 & & & & \\
\hline RP73401 & 3000 & 1 & & & & \\
\hline CPP840 & 30,000 & 10 & & & & \\
\hline Rolipram & 10,000 & - & Oral & Ferret & Emesis incidence & Gale et al., 2003 \\
\hline $\begin{array}{l}\text { V11294 } \\
\text { Rolipram }\end{array}$ & $\begin{array}{c}>30,000 \\
40\end{array}$ & $\stackrel{>3}{-}$ & Intraperitoneal & Mouse & $\begin{array}{l}\text { Acute gastric } \\
\text { retention } \\
\text { measurement }\end{array}$ & McDonough et al., 2020a \\
\hline Piclamilast & 200 & 5 & & & & \\
\hline YM976 & 1000 & 25 & & & & \\
\hline
\end{tabular}

al., 2009). In contrast, the PDE4D-selective inhibitor BPN14770 preferentially binds HARBS but appears to be well tolerated in humans [NCT02648672] [NCT02840279] (https://tetratherapeutics.com/wp-con tent/uploads/2016/11/FINAL-Tetra-Phase-1-121616FINAL.pdf). Although BPN14770 can bind HARBS, its relatively low emetogenicity may be explained by its PDE4D-selective inhibition and/or the fact that it acts as a partial inhibitor [see section $I V$. Phosphodiesterase 4 Inhibitors (Burgin et al., 2010)]. Thus, the occurrence of adverse effects may not be fully attributed to preferential binding of HARBS or LARBS, or to PDE4Dselective inhibition, but rather is more complex, involving inhibition of specific PDE4 subtypes and/or isoforms in different central and peripheral tissues.
Thus, it has been shown that it is possible to develop PDE4 inhibitors with safer pharmacological profile compared with the prototypical rolipram. In Table 5, an overview is provided of several compounds that have been tested for their ability to elicit PDE4-associated side effects compared with rolipram. Because of discrepancies among studies regarding the type of test, species, and administration routes used, results can mainly be compared within studies using the same procedures. Table 5 indicates that multiple PDE4 inhibitors induce emetic and emetic-like effects at doses more than 30 -fold of those induced by rolipram (e.g., CT-2450 and D159687), whereas some compounds require lower doses than rolipram (e.g., PMNPQ and D157140). Since adverse side effects are 
often assessed in nonprimate species (e.g., mice, rats, dogs, and ferrets), it should be considered that these tests do not accurately reflect the potential emetic effects of PDE4 inhibitors that exploit the primate PDE4D-specific phenylalanine in the UCR2 region. In addition, rodents cannot vomit and therefore require an indirect emesis test like the xylazine/ketamine test or pica feeding test. Despite the fact that several compounds can be used safely at higher doses than rolipram, their therapeutic potential is also dependent on the doses required for the desired therapeutic effect. As such, the eventual therapeutic windows of these compounds, i.e., the range of doses that elicit therapeutic, yet no adverse, effects may still be similar to those of rolipram for a specific disease indication. Nevertheless, a wide variety of PDE4 inhibitors have been developed with improved affinities to specific subtypes and/or conformational states (Tables 2-4) and minimized emetogenicity compared with rolipram (Table 5). Thus, to establish safer and more efficacious PDE4 inhibition for a disease, it should be determined which PDE4 subtypes, isoforms, or conformations have to be targeted to determine which inhibitor displays the broadest therapeutic window.

\section{Strategies to Minimize Phosphodiesterase 4-Mediated Adverse Side Effects}

Although PDE4 inhibition can produce several adverse side effects, as described above, multiple strategies can be exploited to minimize or prevent these unwanted responses while retaining efficacy. Most notably, more selective inhibition of PDE 4 forms may be pursued to improve treatment efficacy and/or avoid inhibiting PDE4 forms mediating adverse side effects. Regardless, a mechanistic understanding of which PDE4 subtypes, isoforms, and/or conformational states mediate adverse effects will aid in the development of new-generation PDE4 inhibitors that then should actually avoid potently inhibiting these forms. Several PDE4 inhibitors already exist that preferentially bind nonconserved amino acids and different conformational states (see Table 4). Moreover, partial inhibitors may provide a safer pharmacological profile compared with full inhibitors through distinct potencies for different PDE4 conformations and/or subtypes (Gurney et al., 2011). In case PDE4 inhibition is desired in peripheral organs rather than the central nervous system, PDE4 inhibitors with limited brain penetrance may minimize the occurrence of side effects that are mediated through central actions (Aoki et al., 2001a). Likewise, depending on the target organ, a particular route of administration can be chosen to minimize systemic exposure (e.g., intranasal or topical administration, or via inhalation) (TralauStewart et al., 2011). More precise targeting of PDE4 inhibitors has also been achieved by using inhibitorantibody conjugates, which are internalized specifically by cells that express the antibody's antigen (Yu et al., 2016). Systemic exposure can also be minimized by using PDE4 inhibitors that are quickly degraded, as recently reported (Larsen et al., 2020).

Finally, combination treatments may reduce the severity of PDE4-mediated side effects. For example, it has been described that diarrhea caused by high doses of roflumilast can be attenuated when paired with a cyclooxygenase inhibitor (Peter et al., 2011). Furthermore, inhibition of different PDE families (e.g., PDE4 and PDE5 or PDE2 and PDE4) can produce synergistic effects that enable the use of lower doses, with reduced chances of adverse effects, to produce the same treatment effect (Bollen et al., 2015; Gulisano et al., 2018; Paes et al., 2021b). Lastly, the treatment of certain diseases in which cAMP elevation is desired may benefit from dual PDE4/PDE7 inhibitors, which may subsequently reduce PDE4selective inhibition and its associated side effects (Sharma et al., 2019; Ručilová et al., 2021).

\section{Outlook}

As important regulators of cAMP signaling in the entire body, the PDE4 enzyme family presents an interesting and promising pharmacological target in a

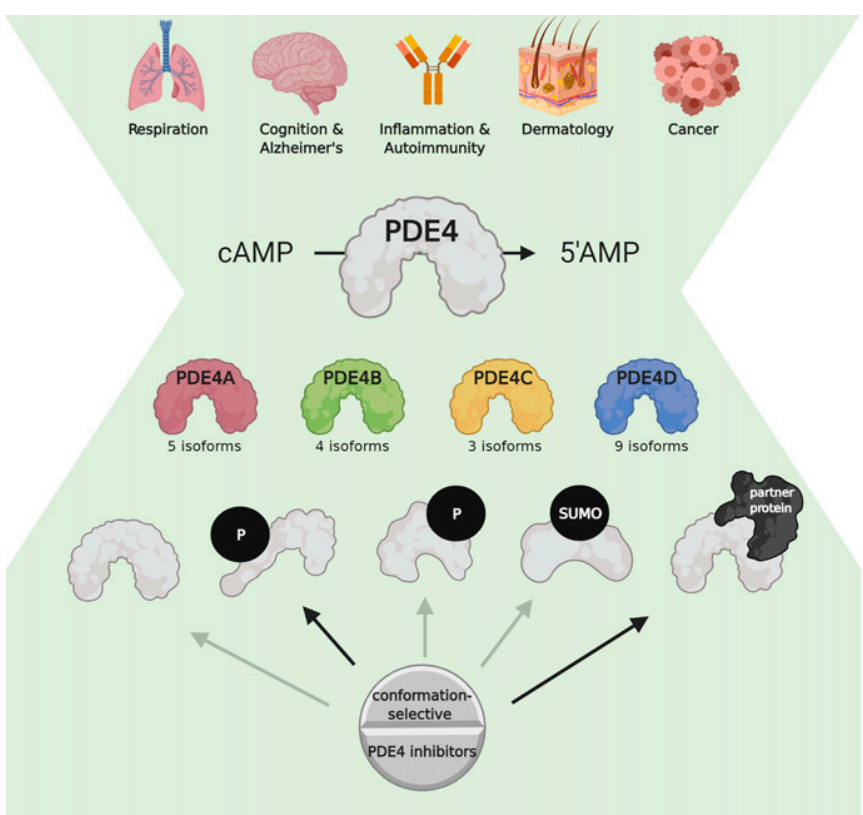

Fig 5. PDE4 as a pharmacological target in a variety of disease areas. In a broad range of diseases, PDE4 inhibition shows therapeutic potential. Nonselective PDE4 inhibition is associated with adverse effects, but the existence of PDE4 subtypes (PDE4A-D) and associated isoforms allows for more specific targeting. PDE4 subtypes and isoforms can undergo conformational changes upon post-translational modifications and interactions with partner proteins. PDE4 inhibitors can display different affinities toward PDE4 subtypes, isoforms, and conformations. Diseasespecific determination of which PDE4 isoform(s) should be inhibited will facilitate the development of safe and efficacious PDE4 inhibitors. This figure was created with BioRender.com. P, phosphorylation; SUMO, SUMOylation. 
broad range of disease areas. Accordingly, PDE4 inhibition has preclinically shown therapeutic potential for many diseases, yet its nonselective inhibition is associated with severe adverse effects, which has seriously hampered its translation to the clinic. To increase efficacy and avoid adverse effects, more selective targeting is required. This is actually possible, as PDE4 enzymes consists of multiple similar, but different, subtypes that each comprise different isoforms. In this review it is summarized how these subtypes and isoforms can, through PDE4-inherent regulation, post-translational modifications, and interactions with other proteins, adopt different conformational states to which PDE4 inhibitors can selectively bind. Since PDE4 subtypes and isoforms are expressed in specific tissue, cell type, and intracellular expression patterns, selective PDE4 subtype/ isoform inhibition will enable a more directed modulation of cAMP signaling in the target organ of interest. To further improve PDE4 inhibitor treatment efficacy and safety, it should also be investigated which PDE4 subtypes and isoforms contribute most to the organ's disease-specific aberrant cAMP signaling. Additionally, upon PDE4 specification, the conformational state of these enzymes in their disease context would have to be determined to choose or develop the most efficacious inhibitors (Fig. 5). Consequently, it is crucial to determine preferential binding of PDE4 inhibitors to specific subtypes, isoforms, and conformations rather than testing their affinity toward PDE4 catalytic domains only. Moreover, a deeper insight into the mechanisms underlying PDE4-mediated unwanted effects in organs is also warranted to facilitate the development and use of safe PDE4 inhibitors to treat diseases. In conclusion, specification and subsequent selective inhibition of PDE4 subtypes, isoforms, or conformations grants the opportunity to effectively and safely modulate aberrant cAMP signaling in myriad diseases. This will increase the chance of success of more PDE4 inhibitors reaching the patient eventually.

\section{Authorship Contributions}

Wrote or contributed to the writing of the manuscript: Paes, Schepers, Rombaut, van den Hove, Vanmierlo, Prickaerts.

\section{References}

Al-Tawashi A and Gehring C (2013) Phosphodiesterase activity is regulated by CC2D1A that is implicated in non-syndromic intellectual disability. Cell Commun Signal 11:47.

Al-Tawashi A, Jung SY, Liu D, Su B, and Qin J (2012) Protein implicated in nonsyndromic mental retardation regulates protein kinase A (PKA) activity. $J$ Biol Chem 287:14644-14658.

Alvarez R, Daniels DV, Shelton ER, Baecker PA, Annie T, Fong T, Devens B, Wilhelm R, Eglen RM, and Conti M (1996) 11 - An Isoform-selective Inhibitor of Cyclic AMP-Specific Phosphodiesterase (PDE4) with Anti-inflammatory Properties, in Phosphodiesterase Inhibitors (Schudt C, Dent G, and Rabe KF, eds) pp 161-171, Academic Press, San Diego.

Alvarez R, Sette C, Yang D, Eglen RM, Wilhelm R, Shelton ER, and Conti M (1995) Activation and selective inhibition of a cyclic AMP-specific phosphodiesterase, PDE-4D3. Mol Pharmacol 48:616-622.

Andreassi C and Riccio A (2009) To localize or not to localize: mRNA fate is in 3’UTR ends. Trends Cell Biol 19:465-474.
Aoki M, Fukunaga M, Sugimoto T, Hirano Y, Kobayashi M, Honda K, and Yamada $\mathrm{T}$ (2001a) Studies on mechanisms of low emetogenicity of YM976, a novel phosphodiesterase type 4 inhibitor. J Pharmacol Exp Ther 298:1142-1149.

Aoki M, Yamamoto S, Kobayashi M, Ohga K, Kanoh H, Miyata K, Honda K, and Yamada T (2001b) Antiasthmatic effect of YM976, a novel PDE4 inhibitor, in guinea pigs. J Pharmacol Exp Ther 297:165-173.

Asaka N, Kakuo H, Ohmori K, Sasaki E, Togawa M, Yamada S, Oka T, and Kiniwa M (2010) Effects of the new benzimidazole derivative TAS-203, an orally active phosphodiesterase 4 inhibitor, on airway inflammation in rats and emetic responses in ferrets. Arzneimittelforschung 60:564-570.

Asirvatham AL, Galligan SG, Schillace RV, Davey MP, Vasta V, Beavo JA, and Carr DW (2004) A-kinase anchoring proteins interact with phosphodiesterases in T lymphocyte cell lines. J Immunol 173:4806-4814.

Baillie GS, Adams DR, Bhari N, Houslay TM, Vadrevu S, Meng D, Li X, Dunlop A, Milligan G, Bolger GB, et al. (2007) Mapping binding sites for the PDE4D5 cAMP-specific phosphodiesterase to the $\mathrm{N}$ - and C-domains of beta-arrestin using spot-immobilized peptide arrays. Biochem J 404:71-80.

Baillie GS, Huston E, Scotland G, Hodgkin M, Gall I, Peden AH, MacKenzie C, Houslay ES, Currie R, Pettitt TR, et al. (2002) TAPAS-1, a novel microdomain within the unique N-terminal region of the PDE4A1 cAMP-specific phosphodiesterase that allows rapid, $\mathrm{Ca} 2+$-triggered membrane association with selectivity for interaction with phosphatidic acid. J Biol Chem 277:28298-28309.

Baillie GS, MacKenzie SJ, McPhee I, and Houslay MD (2000) Sub-family selective actions in the ability of Erk2 MAP kinase to phosphorylate and regulate the activity of PDE4 cyclic AMP-specific phosphodiesterases. Br J Pharmacol 131:811-819.

Baillie GS, Tejeda GS, and Kelly MP (2019) Therapeutic targeting of $3^{\prime}, 5^{\prime}$-cyclic nucleotide phosphodiesterases: inhibition and beyond. Nat Rev Drug Discov 18:770-796.

Bajpai M, Fiedler SE, Huang Z, Vijayaraghavan S, Olson GE, Livera G, Conti M, and Carr DW (2006) AKAP3 selectively binds PDE4A isoforms in bovine spermatozoa. Biol Reprod 74:109-118.

Barnette MS, Bartus JO, Burman M, Christensen SB, Cieslinski LB, Esser KM, Prabhakar US, Rush JA, and Torphy TJ (1996) Association of the anti-inflammatory activity of phosphodiesterase 4 (PDE4) inhibitors with either inhibition of PDE4 catalytic activity or competition for $[3 \mathrm{H}]$ rolipram binding. Biochem Pharmacol 51:949-956.

Barnette MS, Grous M, Cieslinski LB, Burman M, Christensen SB, and Torphy TJ (1995) Inhibitors of phosphodiesterase IV (PDE IV) increase acid secretion in rabbit isolated gastric glands: correlation between function and interaction with a high-affinity rolipram binding site. J Pharmacol Exp Ther 273:1396-1402.

Beard MB, Huston E, Campbell L, Gall I, McPhee I, Yarwood S, Scotland G, and Houslay MD (2002) In addition to the SH3 binding region, multiple regions within the N-terminal noncatalytic portion of the cAMP-specific phosphodiesterase, PDE4A5, contribute to its intracellular targeting. Cell Signal 14:453-465.

Beard MB, O'Connell JC, Bolger GB, and Houslay MD (1999) The unique Nterminal domain of the cAMP phosphodiesterase PDE4D4 allows for interaction with specific SH3 domains. FEBS Lett 460:173-177.

Beard MB, Olsen AE, Jones RE, Erdogan S, Houslay MD, and Bolger GB (2000) UCR1 and UCR2 domains unique to the cAMP-specific phosphodiesterase family form a discrete module via electrostatic interactions. $J$ Biol Chem 275:10349-10358.

Beavo JA (1995) Cyclic nucleotide phosphodiesterases: functional implications of multiple isoforms. Physiol Rev 75:725-748.

Bender AT and Beavo JA (2006) Cyclic nucleotide phosphodiesterases: molecular regulation to clinical use. Pharmacol Rev 58:488-520.

Bird RJ, Baillie GS, and Yarwood SJ (2010) Interaction with receptor for activated C-kinase 1 (RACK1) sensitizes the phosphodiesterase PDE4D5 towards hydrolysis of cAMP and activation by protein kinase C. Biochem J 432:207-216.

Blackman BE, Horner K, Heidmann J, Wang D, Richter W, Rich TC, and Conti M (2011) PDE4D and PDE4B function in distinct subcellular compartments in mouse embryonic fibroblasts. J Biol Chem 286:12590-12601.

Blanchard E, Zlock L, Lao A, Mika D, Namkung W, Xie M, Scheitrum C, Gruenert DC, Verkman AS, Finkbeiner WE, et al. (2014) Anchored PDE4 regulates chloride conductance in wild-type and $\triangle$ F508-CFTR human airway epithelia. FASEB J 28:791-801.

Blokland A, Van Duinen MA, Sambeth A, Heckman PRA, Tsai M, Lahu G, Uz T, and Prickaerts J (2019) Acute treatment with the PDE4 inhibitor roflumilast improves verbal word memory in healthy old individuals: a double-blind placebocontrolled study. Neurobiol Aging 77:37-43.

Bogoyevitch MA and Kobe B (2006) Uses for JNK: the many and varied substrates of the c-Jun N-terminal kinases. Microbiol Mol Biol Rev 70:1061-1095.

Bolger G, Michaeli T, Martins T, St John T, Steiner B, Rodgers L, Riggs M, Wigler $\mathrm{M}$, and Ferguson K (1993) A family of human phosphodiesterases homologous to the dunce learning and memory gene product of Drosophila melanogaster are potential targets for antidepressant drugs. Mol Cell Biol 13:6558-6571.

Bolger GB (1994) Molecular biology of the cyclic AMP-specific cyclic nucleotide phosphodiesterases: a diverse family of regulatory enzymes. Cell Signal 6:851-859.

Bolger GB (2016) RACK1 and $\beta$-arrestin2 attenuate dimerization of PDE4 cAMP phosphodiesterase PDE4D5. Cell Signal 28:706-712.

Bolger GB, Baillie GS, Li X, Lynch MJ, Herzyk P, Mohamed A, Mitchell LH, McCahill A, Hundsrucker C, Klussmann E, et al. (2006) Scanning peptide array analyses identify overlapping binding sites for the signalling scaffold proteins, beta-arrestin and RACK1, in cAMP-specific phosphodiesterase PDE4D5. Biochem $J$ 398:23-36.

Bolger GB, Dunlop AJ, Meng D, Day JP, Klussmann E, Baillie GS, Adams DR, and Houslay MD (2015) Dimerization of cAMP phosphodiesterase-4 (PDE4) in living cells requires interfaces located in both the UCR1 and catalytic unit domains. Cell Signal 27:756-769. 
Bolger GB, Erdogan S, Jones RE, Loughney K, Scotland G, Hoffmann R, Wilkinson I, Farrell C, and Houslay MD (1997) Characterization of five different proteins produced by alternatively spliced mRNAs from the human cAMP-specific phosphodiesterase PDE4D gene. Biochem $J$ 328:539-548.

Bolger GB, McCahill A, Yarwood SJ, Steele MR, Warwicker J, and Houslay MD (2002) Delineation of RAID1, the RACK1 interaction domain located within the unique N-terminal region of the cAMP-specific phosphodiesterase, PDE4D5. BMC Biochem 3:24.

Bolger GB, Peden AH, Steele MR, MacKenzie C, McEwan DG, Wallace DA, Huston E, Baillie GS, and Houslay MD (2003) Attenuation of the activity of the cAMPspecific phosphodiesterase PDE4A5 by interaction with the immunophilin XAP2. J Biol Chem 278:33351-33363.

Bolger GB, Smoot LHM, and van Groen T (2020) Dominant-Negative Attenuation of cAMP-Selective Phosphodiesterase PDE4D Action Affects Learning and Behavior. Int J Mol Sci 21:5704.

Bollen E, Akkerman S, Puzzo D, Gulisano W, Palmeri A, D'Hooge R, Balschun D, Steinbusch HW, Blokland A, and Prickaerts J (2015) Object memory enhancement by combining sub-efficacious doses of specific phosphodiesterase inhibitors. Neuropharmacology 95:361-366.

Boomkamp SD, McGrath MA, Houslay MD, and Barnett SC (2014) Epac and the high affinity rolipram binding conformer of PDE4 modulate neurite outgrowth and myelination using an in vitro spinal cord injury model. $\mathrm{Br} J$ Pharmacol 171:2385-2398.

Briet C, Pereda A, Le Stunff C, Motte E, de Dios Garcia-Diaz J, de Nanclares GP, Dumaz N, and Silve C (2017) Mutations causing acrodysostosis-2 facilitate activation of phosphodiesterase 4D3. Hum Mol Genet 26:3883-3894.

Brullo C, Massa M, Rapetti F, Alfei S, Bertolotto MB, Montecucco F, Signorello MG, and Bruno O (2020) New hybrid pyrazole and imidazopyrazole antinflammatory agents able to reduce ROS production in different biological targets. Molecules 25:899.

Brullo C, Massa M, Rocca M, Rotolo C, Guariento S, Rivera D, Ricciarelli R, Fedele E, Fossa P, and Bruno O (2014) Synthesis, biological evaluation, and molecular modeling of new 3-(cyclopentyloxy)-4-methoxybenzaldehyde O-(2-(2,6-dimethylmorpholino)-2oxoethyl) Oxime (GEBR-7b) related phosphodiesterase 4D (PDE4D) inhibitors. J Med Chem 57:7061-7072.

Bruno O, Fedele E, Prickaerts J, Parker LA, Canepa E, Brullo C, Cavallero A Gardella E, Balbi A, Domenicotti C, et al. (2011) GEBR-7b, a novel PDE4D selective inhibitor that improves memory in rodents at non-emetic doses. $\mathrm{Br} J$ Pharmacol 164:2054-2063.

Bruno O, Romussi A, Spallarossa A, Brullo C, Schenone S, Bondavalli F, Vanthuyne N, and Roussel C (2009) New selective phosphodiesterase 4D inhibitors differently acting on long, short, and supershort isoforms. J Med Chem 52:6546-6557

Bureau Y, Handa M, Zhu Y, Laliberte F, Moore CS, Liu S, Huang Z, MacDonald D, Xu DG, and Robertson GS (2006) Neuroanatomical and pharmacological assessment of Fos expression induced in the rat brain by the phosphodiesterase-4 inhibitor 6-(4pyridylmethyl)-8-(3-nitrophenyl) quinoline. Neuropharmacology 51:974-985.

Burgin AB, Magnusson OT, Singh J, Witte P, Staker BL, Bjornsson JM, Thorsteinsdottir M, Hrafnsdottir S, Hagen T, Kiselyov AS, et al. (2010) Design of phosphodiesterase 4D (PDE4D) allosteric modulators for enhancing cognition with improved safety. Nat Biotechnol 28:63-70.

Byrne AM, Elliott C, Hoffmann R, and Baillie GS (2015) The activity of cAMPphosphodiesterase 4D7 (PDE4D7) is regulated by protein kinase A-dependent phosphorylation within its unique N-terminus. FEBS Lett 589:750-755.

Cai Y, Huang G, Ma L, Dong L, Chen S, Shen X, Zhang S, Xue R, Sun D, and Zhang S (2018) Smurf2, an E3 ubiquitin ligase, interacts with PDE4B and attenuates liver fibrosis through miR-132 mediated CTGF inhibition. Biochim Biophys Acta Mol Cell Res 1865:297-308.

Cameron RT, Coleman RG, Day JP, Yalla KC, Houslay MD, Adams DR, Shoichet BK, and Baillie GS (2013) Chemical informatics uncovers a new role for moexipril as a novel inhibitor of cAMP phosphodiesterase-4 (PDE4). Biochem Pharmacol 85:1297-1305.

Campbell SL, van Groen T, Kadish I, Smoot LHM, and Bolger GB (2017) Altered phosphorylation, electrophysiology, and behavior on attenuation of PDE4B action in hippocampus. BMC Neurosci 18:77.

Carlisle Michel JJ, Dodge KL, Wong W, Mayer NC, Langeberg LK, and Scott JD (2004) PKA-phosphorylation of PDE4D3 facilitates recruitment of the mAKAP signalling complex. Biochem $J$ 381:587-592.

Carpenter DO, Briggs DB, Knox AP, and Strominger N (1988) Excitation of area postrema neurons by transmitters, peptides, and cyclic nucleotides. $J$ Neurophysiol 59:358-369.

Cavalloro V, Russo K, Vasile F, Pignataro L, Torretta A, Donini S, Semrau MS, Storici P, Rossi D, Rapetti F, et al. (2020) Insight into GEBR-32a: Chiral Resolution, Absolute Configuration and Enantiopreference in PDE4D Inhibition. Molecules 25:935.

Cedervall P, Aulabaugh A, Geoghegan KF, McLellan TJ, and Pandit J (2015) Engineered stabilization and structural analysis of the autoinhibited conformation of PDE4. Proc Natl Acad Sci USA 112:E1414-E1422.

Chandrasekaran A, Toh KY, Low SH, Tay SK, Brenner S, and Goh DL (2008) Identification and characterization of novel mouse PDE4D isoforms: molecular cloning, subcellular distribution and detection of isoform-specific intracellular localization signals. Cell Signal 20:139-153.

Chao AC, de Sauvage FJ, Dong YJ, Wagner JA, Goeddel DV, and Gardner P (1994) Activation of intestinal CFTR Cl- channel by heat-stable enterotoxin and guanylin via cAMP-dependent protein kinase. EMBO J 13:1065-1072.

Cherry JA and Davis RL (1999) Cyclic AMP phosphodiesterases are localized in regions of the mouse brain associated with reinforcement, movement, and affect. $J$ Comp Neurol 407:287-301.

Cheung YF, Kan Z, Garrett-Engele P, Gall I, Murdoch H, Baillie GS, Camargo LM, Johnson JM, Houslay MD, and Castle JC (2007) PDE4B5, a novel, super-short, brain-specific cAMP phosphodiesterase-4 variant whose isoform-specifying Nterminal region is identical to that of cAMP phosphodiesterase-4D6 (PDE4D6). $J$ Pharmacol Exp Ther 322:600-609.

Chin A and Lécuyer E (2017) RNA localization: making its way to the center stage. Biochim Biophys Acta, Gen Subj 1861 (11 Pt B):2956-2970.

Choi YH, Suzuki A, Hajarnis S, Ma Z, Chapin HC, Caplan MJ, Pontoglio M, Somlo $\mathrm{S}$, and Igarashi $\mathrm{P}$ (2011) Polycystin-2 and phosphodiesterase 4C are components of a ciliary A-kinase anchoring protein complex that is disrupted in cystic kidney diseases. Proc Natl Acad Sci USA 108:10679-10684.

Christensen SB, Guider A, Forster CJ, Gleason JG, Bender PE, Karpinski JM, DeWolf Jr WE, Barnette MS, Underwood DC, Griswold DE, et al. (1998) 1,4Cyclohexanecarboxylates: potent and selective inhibitors of phosophodiesterase 4 for the treatment of asthma. J Med Chem 41:821-835.

Christian F, Anthony DF, Vadrevu S, Riddell T, Day JP, McLeod R, Adams DR, Baillie GS, and Houslay MD (2010) p62 (SQSTM1) and cyclic AMP phosphodiesterase-4A4 (PDE4A4) locate to a novel, reversible protein aggregate with links to autophagy and proteasome degradation pathways. Cell Signal 22:1576-1596.

Claveau D, Chen SL, O'Keefe S, Zaller DM, Styhler A, Liu S, Huang Z, Nicholson DW, and Mancini JA (2004) Preferential inhibition of T helper 1, but not T helper 2, cytokines in vitro by L-826,141 [4-[2-(3,4-Bisdifluromethoxyphenyl)-2[4-(1,1,1,3,3,3-hexafluoro-2-hydroxypropan-2-yl)-phenyl]-ethyl]3-methylpyridine1-oxide], a potent and selective phosphodiesterase 4 inhibitor. $J$ Pharmacol Exp Ther 310:752-760.

Clister T, Greenwald EC, Baillie GS, and Zhang J (2019) AKAP95 organizes a nuclear microdomain to control local cAMP for regulating nuclear PKA. Cell Chem Biol 26:885-891.e4.

Collins DM, Murdoch H, Dunlop AJ, Charych E, Baillie GS, Wang Q, Herberg FW, Brandon N, Prinz A, and Houslay MD (2008) Ndel1 alters its conformation by sequestering cAMP-specific phosphodiesterase-4D3 (PDE4D3) in a manner that is dynamically regulated through Protein Kinase A (PKA). Cell Signal 20:2356-2369

Compton CH, Gubb J, Nieman R, Edelson J, Amit O, Bakst A, Ayres JG, Creemers JP, Schultze-Werninghaus G, Brambilla C, et al.; International Study Group (2001) Cilomilast, a selective phosphodiesterase-4 inhibitor for treatment of patients with chronic obstructive pulmonary disease: a randomised, dose-ranging study. Lancet 358:265-270.

Conn SJ, Pillman KA, Toubia J, Conn VM, Salmanidis M, Phillips CA, Roslan S, Schreiber AW, Gregory PA, and Goodall GJ (2015) The RNA binding protein quaking regulates formation of circRNAs. Cell 160:1125-1134.

Conti M, Iona S, Cuomo M, Swinnen JV, Odeh J, and Svoboda ME (1995 Characterization of a hormone-inducible, high affinity adenosine $3^{\prime}-5^{\prime}$-cyclic monophosphate phosphodiesterase from the rat Sertoli cell. Biochemistry 34:7979-7987.

Correa-Sales C, Nacif-Coelho C, Reid K, and Maze M (1992) Inhibition of adenylate cyclase in the locus coeruleus mediates the hypnotic response to an alpha 2 agonist in the rat. J Pharmacol Exp Ther 263:1046-1049.

Creighton J, Zhu B, Alexeyev M, and Stevens T (2008) Spectrin-anchored phosphodiesterase 4D4 restricts cAMP from disrupting microtubules and inducing endothelial cell gap formation. J Cell Sci 121:110-119.

D'Andrea I, Fardella V, Fardella S, Pallante F, Ghigo A, Iacobucci R, Maffei A, Hirsch E, Lembo G, and Carnevale D (2015) Lack of kinase-independent activity of PI3K $\gamma$ in locus coeruleus induces ADHD symptoms through increased CREB signaling. EMBO Mol Med 7:904-917.

D'Sa C, Tolbert LM, Conti M, and Duman RS (2002) Regulation of cAMP-specific phosphodiesterases type 4B and 4D (PDE4) splice variants by cAMP signaling in primary cortical neurons. J Neurochem 81:745-757.

Davis RL, Takayasu H, Eberwine M, and Myres J (1989) Cloning and characterization of mammalian homologs of the Drosophila dunce+ gene. Proc Natl Acad Sci USA 86:3604-3608.

Davis TG, Peterson JJ, Kou JP, Capper-Spudich EA, Ball D, Nials AT, Wiseman J, Solanke YE, Lucas FS, Williamson RA, et al. (2009) The identification of a nove phosphodiesterase 4 inhibitor, 1-ethyl-5-\{5-[(4-methyl-1-piperazinyl)methyl]-1,3,4oxadiazol-2-yl\}-N-(tetrahydro $\quad$-2H-pyran-4-yl)-1H-pyrazolo[3,4-b]pyridin-4-amine (EPPA-1), with improved therapeutic index using pica feeding in rats as a measure of emetogenicity. J Pharmacol Exp Ther 330:922-931.

Day JP, Lindsay B, Riddell T, Jiang Z, Allcock RW, Abraham A, Sookup S, Christian F, Bogum J, Martin EK, et al. (2011) Elucidation of a structural basis for the inhibitor-driven, p62 (SQSTM1)-dependent intracellular redistribution of cAMP phosphodiesterase-4A4 (PDE4A4). J Med Chem 54:3331-3347.

Degerman E, In 't Zandt R, Palbrink A, Eliasson L, Caye-Thomasen P, and Magnusson M (2017) Inhibition of phosphodiesterase 3, 4, and 5 induces endolymphatic hydrops in mouse inner ear, as evaluated with repeated $9.4 \mathrm{~T}$ MRI. Acta Otolaryngol 137:8-15.

Di Liegro CM, Schiera G, and Di Liegro I (2014) Regulation of mRNA transport, localization and translation in the nervous system of mammals (Review). Review Int J Mol Med 33:747-762.

Dodge KL, Khouangsathiene S, Kapiloff MS, Mouton R, Hill EV, Houslay MD, Langeberg LK, and Scott JD (2001) mAKAP assembles a protein kinase A/PDE4 phosphodiesterase cAMP signaling module. EMBO J 20:1921-1930.

Dong CJ, Guo Y, Ye Y, and Hare WA (2014) Presynaptic inhibition by $\alpha 2$ receptor/ adenylate cyclase/PDE4 complex at retinal rod bipolar synapse. $J$ Neurosci 34:9432-9440.

du Sert NP, Holmes AM, Wallis R, and Andrews PL (2012) Predicting the emetic liability of novel chemical entities: a comparative study. $\mathrm{Br} J$ Pharmacol 165:1848-1867.

Duplantier AJ, Biggers MS, Chambers RJ, Cheng JB, Cooper K, Damon DB, Eggler JF, Kraus KG, Marfat A, Masamune H, et al. (1996) Biarylcarboxylic acids and -amides: inhibition of phosphodiesterase type IV versus [3H]rolipram 
binding activity and their relationship to emetic behavior in the ferret. $J \mathrm{Med}$ Chem 39:120-125.

Engels P, Sullivan M, Müller T, and Lübbert H (1995) Molecular cloning and functional expression in yeast of a human cAMP-specific phosphodiesterase subtype (PDE IV-C). FEBS Lett 358:305-310.

Fang R, Cui Q, Sun J, Duan X, Ma X, Wang W, Cheng B, Liu Y, Hou Y, and Bai G (2015) PDK1/Akt/PDE4D axis identified as a target for asthma remedy synergistic with $\beta 2 \mathrm{AR}$ agonists by a natural agent arctigenin. Allergy 70:1622-1632.

Fatemi SH, King DP, Reutiman TJ, Folsom TD, Laurence JA, Lee S, Fan YT, Paciga SA, Conti M, and Menniti FS (2008) PDE4B polymorphisms and decreased PDE4B expression are associated with schizophrenia. Schizophr Res 101:36-49.

Fox 3rd D, Burgin AB, and Gurney ME (2014) Structural basis for the design of selective phosphodiesterase 4B inhibitors. Cell Signal 26:657-663.

Funahashi M, Mitoh Y, Kohjitani A, and Matsuo R (2003) Role of the hyperpolarization-activated cation current (Ih) in pacemaker activity in area postrema neurons of rat brain slices. J Physiol 552:135-148.

Gale DD, Hofer P, Spina D, Seeds EA, Banner KH, Harrison S, Douglas G, Matsumoto T, Page CP, Wong RH, et al. (2003) Pharmacology of a new cyclic nucleotide phosphodiesterase type 4 inhibitor, V11294. Pulm Pharmacol Ther 16:97-104.

Gale DD, Landells LJ, Spina D, Miller AJ, Smith K, Nichols T, Rotshteyn Y, Tonelli A, Lacouture P, Burch RM, et al. (2002) Pharmacokinetic and pharmacodynamic profile following oral administration of the phosphodiesterase (PDE)4 inhibitor V11294A in healthy volunteers. Br J Clin Pharmacol 54:478-484.

Ge X, Milenkovic L, Suyama K, Hartl T, Purzner T, Winans A, Meyer T, and Scott MP (2015) Phosphodiesterase 4D acts downstream of Neuropilin to control Hedgehog signal transduction and the growth of medulloblastoma. eLife 4:e07068.

Ghigo A, Perino A, Mehel H, Zahradníková Jr A, Morello F, Leroy J, Nikolaev VO, Damilano F, Cimino J, De Luca E, et al. (2012) Phosphoinositide 3-kinase protects against catecholamine-induced ventricular arrhythmia through protein kinase A-mediated regulation of distinct phosphodiesterases. Circulation 126:2073-2083.

Goto T, Shiina A, Murata T, Tomii M, Yamazaki T, Yoshida K, Yoshino T, Suzuki O, Sogawa Y, Mizukami K, et al. (2014) Identification of the 5,5-dioxo-7,8-dihydro$6 \mathrm{H}$-thiopyrano[3,2-d]pyrimidine derivatives as highly selective PDE4B inhibitors. Bioorg Med Chem Lett 24:893-899.

Grange M, Sette C, Cuomo M, Conti M, Lagarde M, Prigent AF, and Némoz G (2000) The cAMP-specific phosphodiesterase PDE4D3 is regulated by phosphatidic acid binding. Consequences for cAMP signaling pathway and characterization of a phosphatidic acid binding site. J Biol Chem 275:33379-33387.

Gretarsdottir S, Thorleifsson G, Reynisdottir ST, Manolescu A, Jonsdottir S, Jonsdottir T, Gudmundsdottir T, Bjarnadottir SM, Einarsson OB, Gudjonsdottir $\mathrm{HM}$, et al. (2003) The gene encoding phosphodiesterase 4D confers risk of ischemic stroke. Nat Genet 35:131-138.

Grover M, Farrugia G, and Stanghellini V (2019) Gastroparesis: a turning point in understanding and treatment. Gut 68:2238-2250.

Gulisano W, Tropea MR, Arancio O, Palmeri A, and Puzzo D (2018) Sub-efficacious doses of phosphodiesterase 4 and 5 inhibitors improve memory in a mouse model of Alzheimer's disease. Neuropharmacology 138:151-159.

Gurney ME, Burgin AB, Magnusson OT, and Stewart LJ (2011) Small molecule allosteric modulators of phosphodiesterase 4. Handb Exp Pharmacol 204:167-192.

Gurney ME, D'Amato EC, and Burgin AB (2015) Phosphodiesterase-4 (PDE4) molecular pharmacology and Alzheimer's disease. Neurotherapeutics 12:49-56.

Gurney ME, Nugent RA, Mo X, Sindac JA, Hagen TJ, Fox 3rd D, O'Donnell JM Zhang C, Xu Y, Zhang HT, et al. (2019) Design and synthesis of selective phosphodiesterase 4D (PDE4D) allosteric inhibitors for the treatment of fragile X syndrome and other brain disorders. J Med Chem 62:4884-4901.

Hagen TJ, Mo X, Burgin AB, Fox 3rd D, Zhang Z, and Gurney ME (2014) Discovery of triazines as selective PDE4B versus PDE4D inhibitors. Bioorg Med Chem Lett 24:4031-4034.

Halls ML and Cooper DM (2010) Sub-picomolar relaxin signalling by a preassembled RXFP1, AKAP79, AC2, beta-arrestin 2, PDE4D3 complex. EMBO J 29:2772-2787.

Harris AL, Connell MJ, Ferguson EW, Wallace AM, Gordon RJ, Pagani ED, and Silver PJ (1989) Role of low Km cyclic AMP phosphodiesterase inhibition in tracheal relaxation and bronchodilation in the guinea pig. J Pharmacol Exp Ther 251:199-206.

Hebenstreit GF, Fellerer K, Fichte K, Fischer G, Geyer N, Meya U, Sastre-yHernández M, Schöny W, Schratzer M, Soukop W, et al. (1989) Rolipram in major depressive disorder: results of a double-blind comparative study with imipramine. Pharmacopsychiatry 22:156-160.

Hedde JR, Hanks AN, Schmidt CJ, and Hughes ZA (2017) The isozyme selective phosphodiesterase-4 inhibitor, ABI-4, attenuates the effects of lipopolysaccharide in human cells and rodent models of peripheral and CNS inflammation. Brain Behav Immun 64:285-295.

Hill EV, Sheppard CL, Cheung YF, Gall I, Krause E, and Houslay MD (2006) Oxidative stress employs phosphatidyl inositol 3-kinase and ERK signalling pathways to activate cAMP phosphodiesterase-4D3 (PDE4D3) through multi-site phosphorylation at Ser239 and Ser579. Cell Signal 18:2056-2069.

Hirose R, Manabe H, Nonaka H, Yanagawa K, Akuta K, Sato S, Ohshima E, and Ichimura M (2007) Correlation between emetic effect of phosphodiesterase 4 inhibitors and their occupation of the high-affinity rolipram binding site in Suncus murinus brain. Eur J Pharmacol 573:93-99.

Hoffmann R, Baillie GS, MacKenzie SJ, Yarwood SJ, and Houslay MD (1999) The MAP kinase ERK2 inhibits the cyclic AMP-specific phosphodiesterase HSPDE4D3 by phosphorylating it at Ser579. EMBO J 18:893-903.
Hoffmann R, Wilkinson IR, McCallum JF, Engels P, and Houslay MD (1998) cAMPspecific phosphodiesterase HSPDE4D3 mutants which mimic activation and changes in rolipram inhibition triggered by protein kinase A phosphorylation of Ser-54: generation of a molecular model. Biochem $J$ 333:139-149.

Houslay KF, Christian F, MacLeod R, Adams DR, Houslay MD, and Baillie GS (2017) Identification of a multifunctional docking site on the catalytic unit of phosphodiesterase-4 (PDE4) that is utilised by multiple interaction partners. Biochem J 474:597-609.

Houslay KF, Fertig BA, Christian F, Tibbo AJ, Ling J, Findlay JE, Houslay MD and Baillie GS (2019) Phosphorylation of PDE4A5 by MAPKAPK2 attenuates fibrin degradation via 75 signalling. $J$ Biochem 166:97-106.

Houslay MD (2001) PDE4 cAMP-specific phosphodiesterases. Prog Nucleic Acid Res Mol Biol 69:249-315.

Houslay MD (2010) Underpinning compartmentalised cAMP signalling through targeted cAMP breakdown. Trends Biochem Sci 35:91-100.

Houslay MD and Adams DR (2003) PDE4 cAMP phosphodiesterases: modular enzymes that orchestrate signalling cross-talk, desensitization and compartmentalization. Biochem J 370:1-18.

Houslay MD and Adams DR (2010) Putting the lid on phosphodiesterase 4. Nat Biotechnol 28:38-40.

Houslay MD and Baillie GS (2003) The role of ERK2 docking and phosphorylation of PDE4 cAMP phosphodiesterase isoforms in mediating cross-talk between the cAMP and ERK signalling pathways. Biochem Soc Trans 31:1186-1190.

Houslay MD, Scotland G, Pooley L, Spence S, Wilkinson I, McCallum F, Julien P, Rena NG, Michie AM, Erdogan S, et al. (1995) Alternative splicing of the typeIVA cyclic AMP phosphodiesterase gene provides isoform variants with distinct N-terminal domains fused to a common, soluble catalytic unit: 'designer' changes in Vmax, stability and membrane association. Biochem Soc Trans 23:393-398.

Huai Q, Sun Y, Wang H, Macdonald D, Aspiotis R, Robinson H, Huang Z, and Ke H (2006) Enantiomer discrimination illustrated by the high resolution crystal structures of type 4 phosphodiesterase. J Med Chem 49:1867-1873.

Huai Q, Wang H, Sun Y, Kim HY, Liu Y, and Ke H (2003) Three-dimensional structures of PDE4D in complex with roliprams and implication on inhibitor selectivity. Structure 11:865-873.

Huang C, Zhong QP, Tang L, Wang HT, Xu JP, and Zhou ZZ (2019) Discovery of 2 (3,4-dialkoxyphenyl)-2-(substituted pyridazin-3-yl)acetonitriles as phosphodiesterase 4 inhibitors with anti-neuroinflammation potential based on three-dimensional quantitative structure-activity relationship study. Chem Biol Drug Des 93:484-502.

Huang H, Wang Y, Kandpal M, Zhao G, Cardenas H, Ji Y, Chaparala A, Tanner EJ, Chen J, Davuluri RV, et al. (2020) FTO-dependent $N^{6}$-methyladenosine modifications inhibit ovarian cancer stem cell self-renewal by blocking cAMP signaling. Cancer Res 80:3200-3214.

Huang Z, Dias R, Jones T, Liu S, Styhler A, Claveau D, Otu F, Ng K, Laliberte F, Zhang L, et al. (2007) L-454,560, a potent and selective PDE4 inhibitor with in vivo efficacy in animal models of asthma and cognition. Biochem Pharmacol 73:1971-1981

Huang Z, Liu S, Zhang L, Salem M, Greig GM, Chan CC, Natsumeda Y, and Noguchi K (2006) Preferential inhibition of human phosphodiesterase 4 by ibudilast. Life Sci 78:2663-2668.

Huo Z, Ye JC, Chen J, Lin X, Zhou ZN, Xu XR, Li CM, Qi M, Liang D, Liu Y, et al. (2012) Prolyl hydroxylase domain protein 2 regulates the intracellular cyclic AMP level in cardiomyocytes through its interaction with phosphodiesterase 4D. Biochem Biophys Res Commun 427:73-79.

Huston E, Beard M, McCallum F, Pyne NJ, Vandenabeele P, Scotland G, and Houslay MD (2000) The cAMP-specific phosphodiesterase PDE4A5 is cleaved downstream of its SH3 interaction domain by caspase-3. Consequences for altered intracellular distribution. J Biol Chem 275:28063-28074.

Huston E, Lumb S, Russell A, Catterall C, Ross AH, Steele MR, Bolger GB, Perry MJ, Owens RJ, and Houslay MD (1997) Molecular cloning and transient expression in COS7 cells of a novel human PDE4B cAMP-specific phosphodiesterase, HSPDE4B3. Biochem $J$ 328:549-558.

Huston E, Pooley L, Julien P, Scotland G, McPhee I, Sullivan M, Bolger G, and Houslay MD (1996) The human cyclic AMP-specific phosphodiesterase PDE-46 (HSPDE4A4B) expressed in transfected COS7 cells occurs as both particulate and cytosolic species that exhibit distinct kinetics of inhibition by the antidepressant rolipram. J Biol Chem 271:31334-31344.

Innamorati G, Wilkie TM, Kantheti HS, Valenti MT, Dalle Carbonare L, Giacomello L, Parenti M, Melisi D, and Bassi C (2018) The curious case of G $\alpha \mathrm{s}$ gain-of-function in neoplasia. BMC Cancer 18:293.

Iwahashi Y, Furuyama T, Tano Y, Ishimoto I, Shimomura Y, and Inagaki S (1996) Differential distribution of mRNA encoding cAMP-specific phosphodiesterase isoforms in the rat brain. Brain Res Mol Brain Res 38:14-24.

Jacobitz S, McLaughlin MM, Livi GP, Burman M, and Torphy TJ (1996) Mapping the functional domains of human recombinant phosphodiesterase 4A: structural requirements for catalytic activity and rolipram binding. Mol Pharmacol 50:891-899.

Jang DJ, Park SW, Lee JA, Lee C, Chae YS, Park H, Kim MJ, Choi SL, Lee N, Kim $\mathrm{H}$, et al. (2010) $\mathrm{N}$ termini of apPDE4 isoforms are responsible for targeting the isoforms to different cellular membranes. Learn Mem 17:469-479.

Johnson KR, Nicodemus-Johnson J, and Danziger RS (2010) An evolutionary analysis of cAMP-specific phosphodiesterase 4 alternative splicing. BMC Evol Biol 10:247.

Johnston LA, Erdogan S, Cheung YF, Sullivan M, Barber R, Lynch MJ, Baillie GS, Van Heeke G, Adams DR, Huston E, et al. (2004) Expression, intracellular distribution and basis for lack of catalytic activity of the PDE4A7 isoform encoded by the human PDE4A cAMP-specific phosphodiesterase gene. Biochem $J$ 380:371-384

Kaname T, Ki CS, Niikawa N, Baillie GS, Day JP, Yamamura K, Ohta T, Nishimura G, Mastuura N, Kim OH, et al. (2014) Heterozygous mutations in 
cyclic AMP phosphodiesterase-4D (PDE4D) and protein kinase A (PKA) provide new insights into the molecular pathology of acrodysostosis. Cell Signal 26:2446-2459

Khaled M, Levy C, and Fisher DE (2010) Control of melanocyte differentiation by a MITF-PDE4D3 homeostatic circuit. Genes Dev 24:2276-2281.

Kim HW, Ha SH, Lee MN, Huston E, Kim DH, Jang SK, Suh PG, Houslay MD, and Ryu SH (2010) Cyclic AMP controls mTOR through regulation of the dynamic interaction between Rheb and phosphodiesterase 4D. Mol Cell Biol 30:5406-5420.

Kim MJ, Park SK, Lee JH, Jung CY, Sung DJ, Park JH, Yoon YS, Park J, Park KG, Song DK, et al. (2015) Salt-inducible kinase 1 terminates cAMP signaling by an evolutionarily conserved negative-feedback loop in $\beta$-cells. Diabetes 64:3189-3202.

Klussmann E (2016) Protein-protein interactions of PDE4 family members functions, interactions and therapeutic value. Cell Signal 28:713-718.

Koçer SS, Wang HY, and Malbon CC (2012) "Shaping" of cell signaling via AKAPtethered PDE4D: probing with AKAR2-AKAP5 biosensor. J Mol Signal 7:4.

Kovala T, Sanwal BD, and Ball EH (1997) Recombinant expression of a type IV, cAMP-specific phosphodiesterase: characterization and structure-function studies of deletion mutants. Biochemistry 36:2968-2976.

Kranz M, Wall M, Evans B, Miah A, Ballantine S, Delves C, Dombroski B, Gross J Schneck J, Villa JP, et al. (2009) Identification of PDE4B Over 4D subtypeselective inhibitors revealing an unprecedented binding mode. Bioorg Med Chem 17:5336-5341.

Kristensen LS, Andersen MS, Stagsted LVW, Ebbesen KK, Hansen TB, and Kjems $\mathrm{J}$ (2019) The biogenesis, biology and characterization of circular RNAs. Nat Rev Genet 20:675-691.

Lakics V, Karran EH, and Boess FG (2010) Quantitative comparison of phosphodiesterase mRNA distribution in human brain and peripheral tissues. Neuropharmacology 59:367-374.

Laliberté F, Han Y, Govindarajan A, Giroux A, Liu S, Bobechko B, Lario P, Bartlett A, Gorseth E, Gresser M, et al. (2000) Conformational difference between PDE4 apoenzyme and holoenzyme. Biochemistry 39:6449-6458.

Lamontagne S, Meadows E, Luk P, Normandin D, Muise E, Boulet L, Pon DJ, Robichaud A, Robertson GS, Metters KM, et al. (2001) Localization of phosphodiesterase-4 isoforms in the medulla and nodose ganglion of the squirrel monkey. Brain Res 920:84-96.

Lario PI, Bobechko B, Bateman K, Kelly J, Vrielink A, and Huang Z (2001) Purification and characterization of the human PDE4A catalytic domain (PDE4A330-723) expressed in Sf9 cells. Arch Biochem Biophys 394:54-60.

Larsen J, Lambert M, Pettersson H, Vifian T, Larsen M, Ollerstam A, Hegardt P, Eskilsson C, Laursen S, Soehoel A, Skak-Nielsen T, Hansen LM, Knudsen NO, Eirefelt S, Sorensen MD, Stilou TG and Nielsen SF (2020) Discovery and early clinical development of isobutyl 1-[8-methoxy-5-(1-oxo-3H-isobenzofuran-5-yl)$[1,2,4]$ triazolo[1,5-a]pyridin-2-yl]c yclopropanecarboxylate (LEO 39652), a novel "dual-soft" PDE4 inhibitor for topical treatment of atopic dermatitis. J Med Chem 63:14502-14521.

Le Jeune IR, Shepherd M, Van Heeke G, Houslay MD, and Hall IP (2002) Cyclic AMP-dependent transcriptional up-regulation of phosphodiesterase 4D5 in human airway smooth muscle cells. Identification and characterization of a novel PDE4D5 promoter. J Biol Chem 277:35980-35989.

Lee JH, Richter W, Namkung W, Kim KH, Kim E, Conti M, and Lee MG (2007) Dynamic regulation of cystic fibrosis transmembrane conductance regulator by competitive interactions of molecular adaptors. J Biol Chem 282:10414-10422.

Lee ME, Markowitz J, Lee JO, and Lee H (2002) Crystal structure of phosphodiesterase 4D and inhibitor complex(1). FEBS Lett 530:53-58.

Lehnart SE, Wehrens XH, Reiken S, Warrier S, Belevych AE, Harvey RD, Richter W, Jin SL, Conti M, and Marks AR (2005) Phosphodiesterase 4D deficiency in the ryanodine-receptor complex promotes heart failure and arrhythmias. Cell 123:25-35.

Lenhard JM, Kassel DB, Rocque WJ, Hamacher L, Holmes WD, Patel I, Hoffman C, and Luther M (1996) Phosphorylation of a cAMP-specific phosphodiesterase (HSPDE4B2B) by mitogen-activated protein kinase. Biochem $J$ 316:751-758.

Levine MA (1999) Clinical implications of genetic defects in G proteins: oncogenic mutations in $G$ alpha $s$ as the molecular basis for the McCune-Albright syndrome. Arch Med Res 30:522-531.

Li X, Baillie GS, and Houslay MD (2009) Mdm2 directs the ubiquitination of beta-arrestin-sequestered cAMP phosphodiesterase-4D5. J Biol Chem 284: 16170-16182.

Li X, Vadrevu S, Dunlop A, Day J, Advant N, Troeger J, Klussmann E, Jaffrey E, Hay RT, Adams DR, et al. (2010) Selective SUMO modification of cAMP-specific phosphodiesterase-4D5 (PDE4D5) regulates the functional consequences of phosphorylation by PKA and ERK. Biochem $J$ 428:55-65.

Liang J, Huang YY, Zhou Q, Gao Y, Li Z, Wu D, Yu S, Guo L, Chen Z, Huang L, et al. (2020) Discovery and optimization of $\alpha$-mangostin derivatives as novel PDE4 inhibitors for the treatment of vascular dementia. J Med Chem 63:3370-3380.

Lim J, Pahlke G, and Conti M (1999) Activation of the cAMP-specific phosphodiesterase PDE4D3 by phosphorylation. Identification and function of an inhibitory domain. $J$ Biol Chem 274:19677-19685.

Lipworth BJ (2005) Phosphodiesterase-4 inhibitors for asthma and chronic obstructive pulmonary disease. Lancet 365:167-175

Liu H and Maurice DH (1999) Phosphorylation-mediated activation and translocation of the cyclic AMP-specific phosphodiesterase PDE4D3 by cyclic AMP-dependent protein kinase and mitogen-activated protein kinases. A potential mechanism allowing for the coordinated regulation of PDE4D activity and targeting. J Biol Chem 274:10557-10565.

Liu S, Huang S, Wu X, Feng Y, Shen Y, Zhao QS, and Leng Y (2020) Activation of SIK1 by phanginin A inhibits hepatic gluconeogenesis by increasing PDE4 activity and suppressing the cAMP signaling pathway. Mol Metab 41:101045.
Liu S, Laliberté F, Bobechko B, Bartlett A, Lario P, Gorseth E, Van Hamme J, Gresser MJ, and Huang Z (2001) Dissecting the cofactor-dependent and independent bindings of PDE4 inhibitors. Biochemistry 40:10179-10186.

Lobban M, Shakur Y, Beattie J, and Houslay MD (1994) Identification of two splice variant forms of type-IVB cyclic AMP phosphodiesterase, DPD (rPDE-IVB1) and PDE-4 (rPDE-IVB2) in brain: selective localization in membrane and cytosolic compartments and differential expression in various brain regions. Biochem $J$ 304:399-406

Lynex CN, Li Z, Chen ML, Toh KY, Low RW, Goh DL, and Tay SK (2008) Identification and molecular characterization of a novel PDE4D11 cAMP-specific phosphodiesterase isoform. Cell Signal 20:2247-2255.

Mackenzie KF, Topping EC, Bugaj-Gaweda B, Deng C, Cheung YF, Olsen AE, Stockard CR, High Mitchell L, Baillie GS, Grizzle WE, et al. (2008) Human PDE4A8, a novel brain-expressed PDE4 cAMP-specific phosphodiesterase that has undergone rapid evolutionary change. Biochem $J$ 411:361-369.

MacKenzie KF, Wallace DA, Hill EV, Anthony DF, Henderson DJ, Houslay DM, Arthur JS, Baillie GS, and Houslay MD (2011) Phosphorylation of cAMP-specific PDE4A5 (phosphodiesterase-4A5) by MK2 (MAPKAPK2) attenuates its activation through protein kinase A phosphorylation. Biochem $J$ 435:755-769.

MacKenzie SJ, Baillie GS, McPhee I, Bolger GB, and Houslay MD (2000) ERK2 mitogen-activated protein kinase binding, phosphorylation, and regulation of the PDE4D cAMP-specific phosphodiesterases. The involvement of COOH-terminal docking sites and NH2-terminal UCR regions. J Biol Chem 275:16609-16617.

MacKenzie SJ, Baillie GS, McPhee I, MacKenzie C, Seamons R, McSorley T, Millen J, Beard MB, van Heeke G, and Houslay MD (2002) Long PDE4 cAMP specific phosphodiesterases are activated by protein kinase A-mediated phosphorylation of a single serine residue in Upstream Conserved Region 1 (UCR1). $B r J$ Pharmacol 136:421-433.

Manning CD, Burman M, Christensen SB, Cieslinski LB, Essayan DM, Grous M, Torphy TJ, and Barnette MS (1999) Suppression of human inflammatory cell function by subtype-selective PDE4 inhibitors correlates with inhibition of PDE4A and PDE4B. Br J Pharmacol 128:1393-1398.

Márquez-Ruiz AB, González-Herrera L, Luna JD, and Valenzuela A (2020) DNA methylation levels and telomere length in human teeth: usefulness for age estimation. Int J Legal Med 134:451-459.

McCahill A, McSorley T, Huston E, Hill EV, Lynch MJ, Gall I, Keryer G, Lygren B, Tasken K, van Heeke G, et al. (2005) In resting COS1 cells a dominant negative approach shows that specific, anchored PDE4 cAMP phosphodiesterase isoforms gate the activation, by basal cyclic AMP production, of AKAP-tethered protein kinase A type II located in the centrosomal region. Cell Signal 17:1158-1173.

McConnachie G, Langeberg LK, and Scott JD (2006) AKAP signaling complexes: getting to the heart of the matter. Trends Mol Med 12:317-323.

McDonough W, Aragon IV, Rich J, Murphy JM, Abou Saleh L, Boyd A, Koloteva A and Richter W (2020a) PAN-selective inhibition of cAMP-phosphodiesterase 4 (PDE4) induces gastroparesis in mice. FASEB J 34:12533-12548.

McDonough W, Rich J, Aragon IV, Abou Saleh L, Boyd A, Richter A, Koloteva A, and Richter W (2020b) Inhibition of type 4 cAMP-phosphodiesterases (PDE4s) in mice induces hypothermia via effects on behavioral and central autonomous thermoregulation. Biochem Pharmacol 180:114158.

McLaughlin MM, Cieslinski LB, Burman M, Torphy TJ, and Livi GP (1993) A low$\mathrm{Km}$, rolipram-sensitive, cAMP-specific phosphodiesterase from human brain. Cloning and expression of cDNA, biochemical characterization of recombinant protein, and tissue distribution of mRNA. J Biol Chem 268:6470-6476.

McPhee I, Yarwood SJ, Scotland G, Huston E, Beard MB, Ross AH, Houslay ES, and Houslay MD (1999) Association with the SRC family tyrosyl kinase LYN triggers a conformational change in the catalytic region of human cAMP-specific phosphodiesterase HSPDE4A4B. Consequences for rolipram inhibition. J Biol Chem 274:11796-11810.

Meng W, Liang X, Chen H, Luo H, Bai J, Li G, Zhang Q, Xiao T, He S, Zhang Y, et al. (2017) Rheb inhibits beiging of white adipose tissue via PDE4D5-dependent downregulation of the cAMP-PKA signaling pathway. Diabetes 66:1198-1213.

Mika D, Richter W, and Conti M (2015) A CaMKII/PDE4D negative feedback regulates cAMP signaling. Proc Natl Acad Sci USA 112:2023-2028.

Milatovich A, Bolger G, Michaeli T, and Francke U (1994) Chromosome localizations of genes for five cAMP-specific phosphodiesterases in man and mouse. Somat Cell Mol Genet 20:75-86.

Millar JK, Pickard BS, Mackie S, James R, Christie S, Buchanan SR, Malloy MP, Chubb JE, Huston E, Baillie GS, et al. (2005) DISC1 and PDE4B are interacting genetic factors in schizophrenia that regulate cAMP signaling. Science 310:1187-1191.

Miller AD and Leslie RA (1994) The area postrema and vomiting. Front Neuroendocrinol 15:301-320.

Miró X, Casacuberta JM, Gutiérrez-López MD, de Landázuri MO, and Puigdomènech $\mathrm{P}$ (2000) Phosphodiesterases 4D and 7A splice variants in the response of HUVEC cells to TNF-alpha(1). Biochem Biophys Res Commun 274:415-421.

Miró X, Pérez-Torres S, Artigas F, Puigdomènech P, Palacios JM, and Mengod G (2002a) Regulation of cAMP phosphodiesterase mRNAs expression in rat brain by acute and chronic fluoxetine treatment. An in situ hybridization study. Neuropharmacology 43:1148-1157.

Miró X, Pérez-Torres S, Puigdomènech P, Palacios JM, and Mengod G (2002b) Differential distribution of PDE4D splice variant mRNAs in rat brain suggests association with specific pathways and presynaptical localization. Synapse 45:259-269.

Mori F, Pérez-Torres S, De Caro R, Porzionato A, Macchi V, Beleta J, Gavaldà A, Palacios JM, and Mengod G (2010) The human area postrema and other nuclei related to the emetic reflex express cAMP phosphodiesterases $4 \mathrm{~B}$ and $4 \mathrm{D}$. $J$ Chem Neuroanat 40:36-42.

Murdoch H, Mackie S, Collins DM, Hill EV, Bolger GB, Klussmann E, Porteous DJ, Millar JK, and Houslay MD (2007) Isoform-selective susceptibility of DISC1/ 
phosphodiesterase- 4 complexes to dissociation by elevated intracellular cAMP levels. J Neurosci 27:9513-9524.

Murdoch H, Vadrevu S, Prinz A, Dunlop AJ, Klussmann E, Bolger GB, Norman JC, and Houslay MD (2011) Interaction between LIS1 and PDE4, and its role in cytoplasmic dynein function. J Cell Sci 124:2253-2266.

Naganuma K, Omura A, Maekawara N, Saitoh M, Ohkawa N, Kubota T, Nagumo H, Kodama T, Takemura M, Ohtsuka Y, et al. (2009) Discovery of selective PDE4B inhibitors. Bioorg Med Chem Lett 19:3174-3176.

Nakashima T, Pyykkö I, Arroll MA, Casselbrant ML, Foster CA, Manzoor NF, Megerian CA, Naganawa S, and Young YH (2016) Meniere's disease. Nat Rev Dis Primers 2:16028.

Naro F, Zhang R, and Conti M (1996) Developmental regulation of unique adenosine $3^{\prime}, 5^{\prime}$-monophosphate-specific phosphodiesterase variants during rat spermatogenesis. Endocrinology 137:2464-2472.

Nelissen E, van Goethem NP, Bonassoli VT, Heckman PRA, van Hagen BTJ, Suay D, Wouters C, and Prickaerts J (2019) Validation of the xylazine/ketamine anesthesia test as a predictor of the emetic potential of pharmacological compounds in rats. Neurosci Lett 699:41-46.

Némoz G, Sette C, and Conti M (1997) Selective activation of rolipram-sensitive, cAMP-specific phosphodiesterase isoforms by phosphatidic acid. Mol Pharmacol 51:242-249.

Némoz G, Zhang R, Sette C, and Conti M (1996) Identification of cyclic AMPphosphodiesterase variants from the PDE4D gene expressed in human peripheral mononuclear cells. FEBS Lett 384:97-102.

Nose T, Kondo M, Shimizu M, Hamura H, Yamaguchi Y, Sekine T, and Ishitani K (2016) Pharmacological Profile of GPD-1116, an Inhibitor of Phosphodiesterase 4 Biol Pharm Bull 39:689-698.

O'Connell JC, McCallum JF, McPhee I, Wakefield J, Houslay ES, Wishart W, Bolger G, Frame M, and Houslay MD (1996) The SH3 domain of Src tyrosyl protein kinase interacts with the $\mathrm{N}$-terminal splice region of the PDE4A cAMP-specific phosphodiesterase RPDE-6 (RNPDE4A5). Biochem $J$ 318:255-261.

Obernolte R, Ratzliff J, Baecker PA, Daniels DV, Zuppan P, Jarnagin K, and Shelton ER (1997) Multiple splice variants of phosphodiesterase PDE4C cloned from human lung and testis. Biochim Biophys Acta 1353:287-297.

Omar F, Findlay JE, Carfray G, Allcock RW, Jiang Z, Moore C, Muir AL, Lannoy M, Fertig BA, Mai D, et al. (2019) Small-molecule allosteric activators of PDE4 long form cyclic AMP phosphodiesterases. Proc Natl Acad Sci USA 116:13320-13329.

Omar MH and Scott JD (2020) AKAP signaling islands: venues for precision pharmacology. Trends Pharmacol Sci 41:933-946.

Owens RJ, Catterall C, Batty D, Jappy J, Russell A, Smith B, O'Connell J, and Perry MJ (1997a) Human phosphodiesterase 4A: characterization of full-length and truncated enzymes expressed in COS cells. Biochem $J$ 326:53-60.

Owens RJ, Lumb S, Rees-Milton K, Russell A, Baldock D, Lang V, Crabbe T, Ballesteros M, and Perry MJ (1997b) Molecular cloning and expression of a human phosphodiesterase 4C. Cell Signal 9:575-585.

Paes D, Lardenoije R, Carollo RM, Roubroeks JAY, Schepers M, Coleman P, Mastroeni D, Delvaux E, Pishva E, Lunnon K, et al. (2021a) Increased isoformspecific phosphodiesterase 4D expression is associated with pathology and cognitive impairment in Alzheimer's disease. Neurobiol Aging 97:56-64.

Paes D, Xie K, Wheeler DG, Zook D, Prickaerts J, and Peters M (2021b) Inhibition of PDE2 and PDE4 synergistically improves memory consolidation processes. Neuropharmacology 184:108414.

Papier A and Strowd LC (2018) Atopic dermatitis: a review of topical nonsteroid therapy. Drugs Context 7:212521.

Pauwelyn V, Ceelen W, and Lefebvre RA (2018) Synergy between 5 - $\mathrm{HT}_{4}$ receptor stimulation and phosphodiesterase 4 inhibition in facilitating acetylcholine release in human large intestinal circular muscle. Neurogastroenterol Motil $\mathbf{3 0}$.

Peng T, Qi B, He J, Ke H, and Shi J (2020) Advances in the development of phosphodiesterase-4 inhibitors. J Med Chem 63:10594-10617.

Perera RK, Fischer TH, Wagner M, Dewenter M, Vettel C, Bork NI, Maier LS, Conti M, Wess J, El-Armouche A, et al. (2017) Atropine augments cardiac contractility by inhibiting cAMP-specific phosphodiesterase type 4. Sci Rep $7: 15222$.

Pérez-Torres S, Miró X, Palacios JM, Cortés R, Puigdoménech P, and Mengod G (2000) Phosphodiesterase type 4 isozymes expression in human brain examined by in situ hybridization histochemistry and[3H]rolipram binding autoradiography. Comparison with monkey and rat brain. $J$ Chem Neuroanat 20:349-374.

Perry MJ, O'Connell J, Walker C, Crabbe T, Baldock D, Russell A, Lumb S, Huang Z, Howat D, Allen R, et al. (1998) CDP840: a novel inhibitor of PDE-4. Cell Biochem Biophys 29:113-132.

Perry SJ, Baillie GS, Kohout TA, McPhee I, Magiera MM, Ang KL, Miller WE, McLean AJ, Conti M, Houslay MD, et al. (2002) Targeting of cyclic AMP degradation to beta 2-adrenergic receptors by beta-arrestins. Science 298:834-836

Peter D, Göggel R, Colbatzky F, and Nickolaus P (2011) Inhibition of cyclooxygenase-2 prevents adverse effects induced by phosphodiesterase type 4 inhibitors in rats Br.J Pharmacol 162:415-427.

Plattner F, Hayashi K, Hernández A, Benavides DR, Tassin TC, Tan C, Day J, Fina MW, Yuen EY, Yan Z, et al. (2015) The role of ventral striatal cAMP signaling in stress-induced behaviors. Nat Neurosci 18:1094-1100.

Prosdocimi T, Mollica L, Donini S, Semrau MS, Lucarelli AP, Aiolfi E, Cavalli A, Storici P, Alfei S, Brullo C, et al. (2018) Molecular bases of PDE4D inhibition by memory-enhancing GEBR library compounds. Biochemistry 57:2876-2888.

Pruniaux MP, Lagente V, Ouaged M, Bertin B, Moreau F, Julien-Larose C, Rocher MN, Leportier C, Martin B, Bouget A, et al. (2010) Relationship between phosphodiesterase type 4 inhibition and anti-inflammatory activity of CI-1044 in rat airways. Fundam Clin Pharmacol 24:73-82.
Purushothaman B, Arumugam P, and Song JM (2018) A novel catecholopyrimidine based small molecule PDE4B inhibitor suppresses inflammatory cytokines in atopic mice. Front Pharmacol 9:485.

Purvis JE and Lahav G (2013) Encoding and decoding cellular information through signaling dynamics. Cell 152:945-956.

Puurunen J, Lücke C, and Schwabe U (1978) Effect of the phosphodiesterase inhibitor 4-(3-cyclopentyloxy-4-methoxyphenyl)-2-pyrrolidone (ZK 62711) on gastric secretion and gastric mucosal cyclic AMP. Naunyn Schmiedebergs Arch Pharmacol 304:69-75.

Rall TW and Sutherland EW (1958) Formation of a cyclic adenine ribonucleotide by tissue particles. J Biol Chem 232:1065-1076.

Reeves ML, Leigh BK, and England PJ (1987) The identification of a new cyclic nucleotide phosphodiesterase activity in human and guinea-pig cardiac ventricle. Implications for the mechanism of action of selective phosphodiesterase inhibitors. Biochem J 241:535-541.

Rehman NU, Ansari MN, and Samad A (2020) In silico, ex vivo and in vivo studies of roflumilast as a potential antidiarrheal and antispasmodic agent: inhibition of the PDE-4 enzyme and voltage-gated $\mathrm{Ca}++$ ion channels. Molecules 25:1008.

Rena G, Begg F, Ross A, MacKenzie C, McPhee I, Campbell L, Huston E, Sullivan $\mathrm{M}$, and Houslay MD (2001) Molecular cloning, genomic positioning, promoter identification, and characterization of the novel cyclic amp-specific phosphodiesterase PDE4A10. Mol Pharmacol 59:996-1011.

Ricciarelli R, Brullo C, Prickaerts J, Arancio O, Villa C, Rebosio C, Calcagno E, Balbi M, van Hagen BT, Argyrousi EK, et al. (2017) Memory-enhancing effects of GEBR-32a, a new PDE4D inhibitor holding promise for the treatment of Alzheimer's disease. Sci Rep 7:46320.

Richter W and Conti M (2002) Dimerization of the type 4 cAMP-specific phosphodiesterases is mediated by the upstream conserved regions (UCRs). $J$ Biol Chem 277:40212-40221.

Richter W and Conti M (2004) The oligomerization state determines regulatory properties and inhibitor sensitivity of type 4 cAMP-specific phosphodiesterases. $J$ Biol Chem 279:30338-30348.

Richter W, Jin SL, and Conti M (2005) Splice variants of the cyclic nucleotide phosphodiesterase PDE4D are differentially expressed and regulated in rat tissue. Biochem J 388:803-811.

Robichaud A, Savoie C, Stamatiou PB, Lachance N, Jolicoeur P, Rasori R, and Chan CC (2002a) Assessing the emetic potential of PDE4 inhibitors in rats. $\mathrm{Br} J$ Pharmacol 135:113-118.

Robichaud A, Savoie C, Stamatiou PB, Tattersall FD, and Chan CC (2001) PDE4 inhibitors induce emesis in ferrets via a noradrenergic pathway. Neuropharmacology 40:262-269.

Robichaud A, Stamatiou PB, Jin SL, Lachance N, MacDonald D, Laliberté F, Liu S, Huang Z, Conti M, and Chan CC (2002b) Deletion of phosphodiesterase 4D in mice shortens alpha(2)-adrenoceptor-mediated anesthesia, a behavioral correlate of emesis. J Clin Invest 110:1045-1052.

Robichaud A, Tattersall FD, Choudhury I, and Rodger IW (1999) Emesis induced by inhibitors of type IV cyclic nucleotide phosphodiesterase (PDE IV) in the ferret. Neuropharmacology 38:289-297.

Rocque WJ, Holmes WD, Patel IR, Dougherty RW, Ittoop O, Overton L, Hoffman CR, Wisely GB, Willard DH, and Luther MA (1997a) Detailed characterization of a purified type 4 phosphodiesterase, HSPDE4B2B: differentiation of high- and low-affinity (R)-rolipram binding. Protein Expr Purif 9:191-202.

Rocque WJ, Tian G, Wiseman JS, Holmes WD, Zajac-Thompson I, Willard DH Patel IR, Wisely GB, Clay WC, Kadwell SH, et al. (1997b) Human recombinant phosphodiesterase 4B2B binds (R)-rolipram at a single site with two affinities. Biochemistry 36:14250-14261.

Rogers DF and Giembycz MA (1998) Asthma therapy for the 21st century. Trends Pharmacol Sci 19:160-164.

Ručilová V, Świerczek A, Vanda D, Funk P, Lemrová B, Gawalska A, Bucki A Nowak B, Zadrożna M, Pociecha K, et al. (2021) New imidazopyridines with phosphodiesterase 4 and 7 inhibitory activity and their efficacy in animal models of inflammatory and autoimmune diseases. Eur J Med Chem 209:112854.

Sachs BD, Baillie GS, McCall JR, Passino MA, Schachtrup C, Wallace DA, Dunlop AJ, MacKenzie KF, Klussmann E, Lynch MJ, et al. (2007) p75 neurotrophin receptor regulates tissue fibrosis through inhibition of plasminogen activation via a PDE4/cAMP/PKA pathway. J Cell Biol 177:1119-1132.

Saldou N, Obernolte R, Huber A, Baecker PA, Wilhelm R, Alvarez R, Li B, Xia L, Callan O, Su C, et al. (1998) Comparison of recombinant human PDE4 isoforms: interaction with substrate and inhibitors. Cell Signal 10:427-440.

Scheinin M, Lomasney JW, Hayden-Hixson DM, Schambra UB, Caron MG, Lefkowitz RJ, and Fremeau Jr RT (1994) Distribution of alpha 2-adrenergic receptor subtype gene expression in rat brain. Brain Res Mol Brain Res 21:133-149.

Schepers M, Tiane A, Paes D, Sanchez S, Rombaut B, Piccart E, Rutten BPF, Brône B, Hellings N, Prickaerts J, et al. (2019) Targeting phosphodiesterasestowards a tailor-made approach in multiple sclerosis treatment. Front Immunol 10:1727.

Schneider HH (1984) Brain cAMP response to phosphodiesterase inhibitors in rats killed by microwave irradiation or decapitation. Biochem Pharmacol 33:1690-1693.

Schwabe U, Miyake M, Ohga Y, and Daly JW (1976) 4-(3-Cyclopentyloxy-4methoxyphenyl)-2-pyrrolidone (ZK 62711): a potent inhibitor of adenosine cyclic $3^{\prime}, 5^{\prime}$-monophosphate phosphodiesterases in homogenates and tissue slices from rat brain. Mol Pharmacol 12:900-910.

Sette C and Conti M (1996) Phosphorylation and activation of a cAMP-specific phosphodiesterase by the cAMP-dependent protein kinase. Involvement of serine 54 in the enzyme activation. $J$ Biol Chem 271:16526-16534.

Shakur Y, Pryde JG, and Houslay MD (1993) Engineered deletion of the unique $\mathrm{N}$-terminal domain of the cyclic AMP-specific phosphodiesterase RD1 prevents plasma membrane association and the attainment of enhanced thermostability 
without altering its sensitivity to inhibition by rolipram. Biochem $J$ 292:677-686.

Sharma H, Lather V, Grewal AS, and Pandita D (2019) Synthesis, antiinflammatory activity and docking studies of some newer 1,3-thiazolidine-2,4dione derivatives as dual inhibitors of PDE4 and PDE7. Curr Comput Aided Drug Des 15:225-234.

Sharrocks AD, Yang SH, and Galanis A (2000) Docking domains and substratespecificity determination for MAP kinases. Trends Biochem Sci 25:448-453.

Shepherd M, McSorley T, Olsen AE, Johnston LA, Thomson NC, Baillie GS, Houslay MD, and Bolger GB (2003) Molecular cloning and subcellular distribution of the novel PDE4B4 cAMP-specific phosphodiesterase isoform. Biochem J 370:429-438.

Sheppard CL, Lee LC, Hill EV, Henderson DJ, Anthony DF, Houslay DM, Yalla KC, Cairns LS, Dunlop AJ, Baillie GS, et al. (2014) Mitotic activation of the DISC1-inducible cyclic AMP phosphodiesterase-4D9 (PDE4D9), through multisite phosphorylation, influences cell cycle progression. Cell Signal 26:1958-1974.

Sibley CR, Emmett W, Blazquez L, Faro A, Haberman N, Briese M, Trabzuni D, Ryten M, Weale ME, Hardy J, et al. (2015) Recursive splicing in long vertebrate genes. Nature 521:371-375.

Sin YY, Edwards HV, Li X, Day JP, Christian F, Dunlop AJ, Adams DR, Zaccolo M Houslay MD, and Baillie GS (2011) Disruption of the cyclic AMP phosphodiesterase-4 (PDE4)-HSP20 complex attenuates the $\beta$-agonist induced hypertrophic response in cardiac myocytes. J Mol Cell Cardiol 50:872-883.

Skoumbourdis AP, Leclair CA, Stefan E, Turjanski AG, Maguire W, Titus SA Huang R, Auld DS, Inglese J, Austin CP, et al. (2009) Exploration and optimization of substituted triazolothiadiazines and triazolopyridazines as PDE4 inhibitors. Bioorg Med Chem Lett 19:3686-3692.

Smith KJ, Baillie GS, Hyde EI, Li X, Houslay TM, McCahill A, Dunlop AJ, Bolger GB, Klussmann E, Adams DR, et al. (2007) $1 \mathrm{H}$ NMR structural and functional characterisation of a cAMP-specific phosphodiesterase-4D5 (PDE4D5) N-terminal region peptide that disrupts PDE4D5 interaction with the signalling scaffold proteins, beta-arrestin and RACK1. Cell Signal 19:2612-2624.

Soda T, Frank C, Ishizuka K, Baccarella A, Park YU, Flood Z, Park SK, Sawa A, and Tsai LH (2013) DISC1-ATF4 transcriptional repression complex: dual regulation of the cAMP-PDE4 cascade by DISC1. Mol Psychiatry 18:898-908.

Souness JE and Rao S (1997) Proposal for pharmacologically distinct conformers of PDE4 cyclic AMP phosphodiesterases. Cell Signal 9:227-236.

Spina D (2008) PDE4 inhibitors: current status. Br J Pharmacol 155:308-315.

St Clair JR, Larson ED, Sharpe EJ, Liao Z, and Proenza C (2017) Phosphodiesterases 3 and 4 differentially regulate the funny current, $I_{f}$, in mouse sinoatrial node myocytes. $J$ Cardiovasc Dev Dis 4:10.

Stefan E, Wiesner B, Baillie GS, Mollajew R, Henn V, Lorenz D, Furkert J, Santamaria K, Nedvetsky P, Hundsrucker C, et al. (2007) Compartmentalization of cAMP-dependent signaling by phosphodiesterase-4D is involved in the regulation of vasopressin-mediated water reabsorption in renal principal cells. $J$ Am Soc Nephrol 18:199-212.

Sullivan M, Rena G, Begg F, Gordon L, Olsen AS, and Houslay MD (1998) Identification and characterization of the human homologue of the short PDE4A cAMP-specific phosphodiesterase RD1 (PDE4A1) by analysis of the human HSPDE4A gene locus located at chromosome 19p13.2. Biochem $J$ 333:693-703.

Sutcliffe JS, Beaumont V, Watson JM, Chew CS, Beconi M, Hutcheson DM, Dominguez C, and Munoz-Sanjuan I (2014) Efficacy of selective PDE4D negative allosteric modulators in the object retrieval task in female cynomolgus monkeys (Macaca fascicularis). PLoS One 9:e102449.

Sutherland EW and Rall TW (1958) Fractionation and characterization of a cyclic adenine ribonucleotide formed by tissue particles. J Biol Chem 232:1077-1091

Suzuki O, Mizukami K, Etori M, Sogawa Y, Takagi N, Tsuchida H, Morimoto K, Goto T, Yoshino T, Mikkaichi T, et al. (2013) Evaluation of the therapeutic index of a novel phosphodiesterase 4B-selective inhibitor over phosphodiesterase 4D in mice. J Pharmacol Sci 123:219-226.

Swinnen JV, Joseph DR, and Conti M (1989a) Molecular cloning of rat homologues of the Drosophila melanogaster dunce cAMP phosphodiesterase: evidence for a family of genes. Proc Natl Acad Sci USA 86:5325-5329.

Swinnen JV, Joseph DR, and Conti M (1989b) The mRNA encoding a high-affinity cAMP phosphodiesterase is regulated by hormones and cAMP. Proc Natl Acad Sci USA 86:8197-8201.

Takahashi M, Terwilliger R, Lane C, Mezes PS, Conti M, and Duman RS (1999) Chronic antidepressant administration increases the expression of cAMP-specific phosphodiesterase 4A and 4B isoforms. J Neurosci 19:610-618.

Tang L, Huang C, Zhong J, He J, Guo J, Liu M, Xu JP, Wang HT, and Zhou ZZ (2019) Discovery of arylbenzylamines as PDE4 inhibitors with potential neuroprotective effect. Eur J Med Chem 168:221-231.

Taskén KA, Collas P, Kemmner WA, Witczak O, Conti M, and Taskén K (2001) Phosphodiesterase 4D and protein kinase a type II constitute a signaling unit in the centrosomal area. $J$ Biol Chem 276:21999-22002.

Terrenoire C, Houslay MD, Baillie GS, and Kass RS (2009) The cardiac IKs potassium channel macromolecular complex includes the phosphodiesterase PDE4D3. J Biol Chem 284:9140-9146.

Terrin A, Monterisi S, Stangherlin A, Zoccarato A, Koschinski A, Surdo NC, Mongillo M, Sawa A, Jordanides NE, Mountford JC, et al. (2012) PKA and PDE4D3 anchoring to AKAP9 provides distinct regulation of cAMP signals at the centrosome. J Cell Biol 198:607-621.

Terry R, Cheung YF, Praestegaard M, Baillie GS, Huston E, Gall I, Adams DR, and Houslay MD (2003) Occupancy of the catalytic site of the PDE4A4 cyclic AMP phosphodiesterase by rolipram triggers the dynamic redistribution of this specific isoform in living cells through a cyclic AMP independent process. Cell Signa 15:955-971.

Tilley DG and Maurice DH (2005) Vascular smooth muscle cell phenotypedependent phosphodiesterase 4D short form expression: role of differential histone acetylation on cAMP-regulated function. Mol Pharmacol 68:596-605.
Torphy TJ, Stadel JM, Burman M, Cieslinski LB, McLaughlin MM, White JR, and Livi GP (1992) Coexpression of human cAMP-specific phosphodiesterase activity and high affinity rolipram binding in yeast. $J$ Biol Chem 267:1798-1804.

Tralau-Stewart CJ, Williamson RA, Nials AT, Gascoigne M, Dawson J, Hart GJ, Angell AD, Solanke YE, Lucas FS, Wiseman J, et al. (2011) GSK256066, an exceptionally high-affinity and selective inhibitor of phosphodiesterase 4 suitable for administration by inhalation: in vitro, kinetic, and in vivo characterization. $J$ Pharmacol Exp Ther 337:145-154.

Tsai Y-F, Chu T-C, Chang W-Y, Wu Y-C, Chang F-R, Yang S-C, Wu T-Y, Hsu Y-M, Chen C-Y, Chang S-H, et al. (2017) 6-Hydroxy-5,7-dimethoxy-flavone suppresses the neutrophil respiratory burst via selective PDE4 inhibition to ameliorate acute lung injury. Free Radic Biol Med 106:379-392.

Uys GM, Ramburan A, Loos B, Kinnear CJ, Korkie LJ, Mouton J, Riedemann J, and Moolman-Smook JC (2011) Myomegalin is a novel A-kinase anchoring protein involved in the phosphorylation of cardiac myosin binding protein $\mathrm{C}$. BMC Cell Biol 12:18.

Vanmierlo T, Creemers P, Akkerman S, van Duinen M, Sambeth A, De Vry J, Uz T, Blokland A, and Prickaerts J (2016) The PDE4 inhibitor roflumilast improves memory in rodents at non-emetic doses. Behav Brain Res 303:26-33.

Vanmierlo T, Prickaerts J, Wieringa P (2019) inventors, Universiteit Hasselt, Universiteit Maastricht, Academisch Ziekenhuis Maastricht, assignee. Selective pde4d inhibitors against demyelinating diseases. European Patent Office. EP3773562A1. 2019 Apr 4

Verde I, Pahlke G, Salanova M, Zhang G, Wang S, Coletti D, Onuffer J, Jin SL, and Conti M (2001) Myomegalin is a novel protein of the golgi/centrosome that interacts with a cyclic nucleotide phosphodiesterase. $J$ Biol Chem 276:11189-11198.

Vicini E and Conti M (1997) Characterization of an intronic promoter of a cyclic adenosine $3^{\prime}, 5^{\prime}$-monophosphate (cAMP)-specific phosphodiesterase gene that confers hormone and cAMP inducibility. Mol Endocrinol 11:839-850.

Wachtel $H$ (1983a) Neurotropic effects of the optical isomers of the selective adenosine cyclic $3^{\prime}, 5^{\prime}$-monophosphate phosphodiesterase inhibitor rolipram in rats in-vivo. J Pharm Pharmacol 35:440-444.

Wachtel H (1983b) Potential antidepressant activity of rolipram and other selective cyclic adenosine $3^{\prime}, 5^{\prime}$-monophosphate phosphodiesterase inhibitors. Neuropharmacology 22:267-272.

Wachtel H (1983c) Species differences in behavioural effects of rolipram and other adenosine cyclic $3 \mathrm{H}, 5 \mathrm{H}$-monophosphate phosphodiesterase inhibitors. J Neural Transm (Vienna) 56:139-152.

Wallace DA, Johnston LA, Huston E, MacMaster D, Houslay TM, Cheung YF Campbell L, Millen JE, Smith RA, Gall I, et al. (2005) Identification and characterization of PDE4A11, a novel, widely expressed long isoform encoded by the human PDE4A cAMP phosphodiesterase gene. Mol Pharmacol 67:1920-1934.

Wang D, Deng C, Bugaj-Gaweda B, Kwan M, Gunwaldsen C, Leonard C, Xin X, Hu Y, Unterbeck A, and De Vivo M (2003) Cloning and characterization of novel PDE4D isoforms PDE4D6 and PDE4D7. Cell Signal 15:883-891.

Wang H, Peng MS, Chen Y, Geng J, Robinson H, Houslay MD, Cai J, and Ke H (2007a) Structures of the four subfamilies of phosphodiesterase-4 provide insight into the selectivity of their inhibitors. Biochem $J$ 408:193-201.

Wang L, Burmeister BT, Johnson KR, Baillie GS, Karginov AV, Skidgel RA, O'Bryan JP, and Carnegie GK (2015) UCR1C is a novel activator of phosphodiesterase 4 (PDE4) long isoforms and attenuates cardiomyocyte hypertrophy. Cell Signal 27:908-922.

Wang M, Ramos BP, Paspalas CD, Shu Y, Simen A, Duque A, Vijayraghavan S, Brennan A, Dudley A, Nou E, et al. (2007b) Alpha2A-adrenoceptors strengthen working memory networks by inhibiting cAMP-HCN channel signaling in prefrontal cortex. Cell 129:397-410.

Weninger S, Van Craenenbroeck K, Cameron RT, Vandeput F, Movsesian MA, Baillie GS, and Lefebvre RA (2014) Phosphodiesterase 4 interacts with the 5HT4(b) receptor to regulate cAMP signaling Cell Signal 26:2573-2582.

Wild AR and Dell'Acqua ML (2018) Potential for therapeutic targeting of AKAP signaling complexes in nervous system disorders. Pharmacol Ther 185:99-121.

Willoughby D, Wong W, Schaack J, Scott JD, and Cooper DM (2006) An anchored PKA and PDE4 complex regulates subplasmalemmal cAMP dynamics. EMBO $J$ 25:2051-2061.

Wilson M, Sullivan M, Brown N, and Houslay MD (1994) Purification, characterization and analysis of rolipram inhibition of a human type-IVA cyclic AMP-specific phosphodiesterase expressed in yeast. Biochem $J$ 304:407-415.

Wu Y, Hong Z, Xu W, Chen J, Wang Q, Chen J, Ni W, Mei Z, Xie Z, Ma Y, et al. (2021) Circular RNA circPDE4D protects against osteoarthritis by binding to miR-103a-3p and regulating FGF18. Mol Ther 29:308-323.

Wunder F, Quednau R, Geerts A, Barg M, and Tersteegen A (2013) Characterization of the cellular activity of PDE 4 inhibitors using two novel PDE 4 reporter cell lines. Mol Pharm 10:3697-3705.

Xie D, Geng L, Xiong K, Zhao T, Wang S, Xue J, Wang C, Wang G, Feng Z, Zhou H, et al. (2020) Cold-inducible RNA-binding protein prevents an excessive heart rate response to stress by targeting phosphodiesterase. Circ Res 126:1706-1720.

Xie M, Blackman B, Scheitrum C, Mika D, Blanchard E, Lei T, Conti M, and Richter W (2014) The upstream conserved regions (UCRs) mediate homo- and hetero-oligomerization of type 4 cyclic nucleotide phosphodiesterases (PDE4s). Biochem J 459:539-550.

Yarwood SJ, Steele MR, Scotland G, Houslay MD, and Bolger GB (1999) The RACK1 signaling scaffold protein selectively interacts with the cAMP-specific phosphodiesterase PDE4D5 isoform. J Biol Chem 274:14909-14917.

Yu S, Pearson AD, Lim RK, Rodgers DT, Li S, Parker HB, Weglarz M, Hampton EN, Bollong MJ, Shen J, et al. (2016) Targeted delivery of an anti-inflammatory PDE4 inhibitor to immune cells via an antibody-drug conjugate. Mol Ther 24:2078-2089. 
Yun S, Budatha M, Dahlman JE, Coon BG, Cameron RT, Langer R, Anderson DG, Baillie G, and Schwartz MA (2016) Interaction between integrin $\alpha 5$ and PDE4D regulates endothelial inflammatory signalling. Nat Cell Biol 18:1043-1053.

Yun S, Hu R, Schwaemmle ME, Scherer AN, Zhuang Z, Koleske AJ, Pallas DC, and Schwartz MA (2019) Integrin $\alpha 5 \beta 1$ regulates PP2A complex assembly through PDE4D in atherosclerosis. $J$ Clin Invest 129:4863-4874.

Zaccolo M, Zerio A, and Lobo MJ (2021) Subcellular organization of the cAMP signaling pathway. Pharmacol Rev 73:278-309.

Zeke A, Bastys T, Alexa A, Garai Á, Mészáros B, Kirsch K, Dosztányi Z, Kalinina OV, and Reményi A (2015) Systematic discovery of linear binding motifs targeting an ancient protein interaction surface on MAP kinases. Mol Syst Biol 11:837.

Zhang C, Xu Y, Chowdhary A, Fox 3rd D, Gurney ME, Zhang HT, Auerbach BD, Salvi RJ, Yang M, Li G, et al. (2018) Memory enhancing effects of BPN14770, an allosteric inhibitor of phosphodiesterase-4D, in wild-type and humanized mice. Neuropsychopharmacology 43:2299-2309.

Zhang C, Xu Y, Zhang HT, Gurney ME, and O'Donnell JM (2017) Comparison of the pharmacological profiles of selective PDE4B and PDE4D inhibitors in the central nervous system. Sci Rep 7:40115.
Zhang HT, Zhao Y, Huang Y, Deng C, Hopper AT, De Vivo M, Rose GM, and O'Donnell JM (2006) Antidepressant-like effects of PDE4 inhibitors mediated by the high-affinity rolipram binding state (HARBS) of the phosphodiesterase-4 enzyme (PDE4) in rats. Psychopharmacology (Berl) 186:209-217.

Zhang MZ, Zhou ZZ, Yuan X, Cheng YF, Bi BT, Gong MF, Chen YP, and Xu JP (2013) Chlorbipram: a novel PDE4 inhibitor with improved safety as a potential antidepressant and cognitive enhancer. Eur J Pharmacol 721:56-63.

Zhong W and Darmani NA (2017) Intracellular vomit signals and cascades downstream of emetic receptors: Evidence from the least shrew (Cryptotis parva) model of vomiting. Rem Open Access 2:1083.

Zhou ZZ, Cheng YF, Zou ZQ, Ge BC, Yu H, Huang C, Wang HT, Yang XM, and Xu JP (2017) Discovery of N-alkyl catecholamides as selective phosphodiesterase-4 inhibitors with anti-neuroinflammation potential exhibiting antidepressant-like Effects at non-emetic doses. ACS Chem Neurosci 8:135-146.

Zhu H, Suk HY, Yu RY, Brancho D, Olabisi O, Yang TT, Yang X, Zhang J, Moussaif M, Durand JL, et al. (2010) Evolutionarily conserved role of calcineurin in phosphodegron-dependent degradation of phosphodiesterase 4D. Mol Cell Biol 30:4379-4390. 